\title{
SENSING MECHANISMS AND INDIVIDUALITY OF HEAT STRESS IN MAMMALIAN CELLS
}

Ph.D. Thesis

\section{Begüm PEKSEL ŞAHİN}

Supervisor: Dr. Zsolt TÖRÖK

\author{
Institute of Biochemistry \\ Biological Research Center of the Hungarian Academy of \\ Sciences \\ Doctoral School of Environmental Sciences \\ Faculty of Natural Sciences and Informatics \\ University of Szeged
}

Szeged 2017 


\section{TABLE OF CONTENTS}

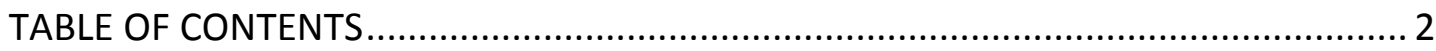

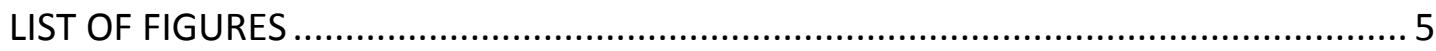

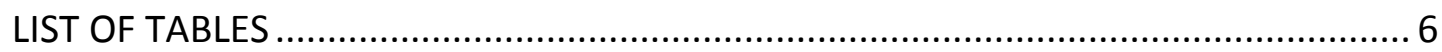

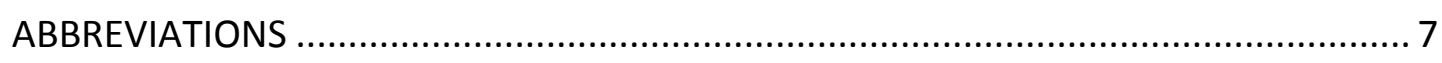

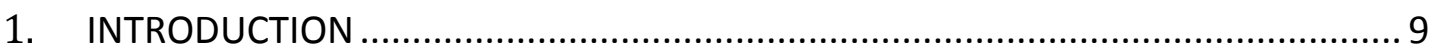

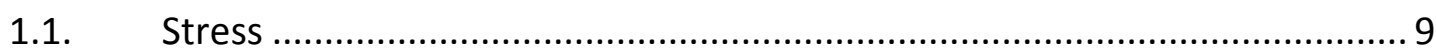

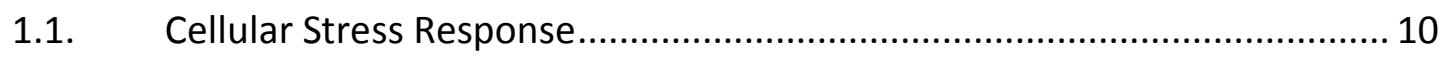

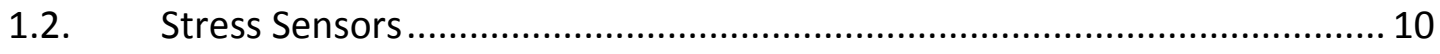

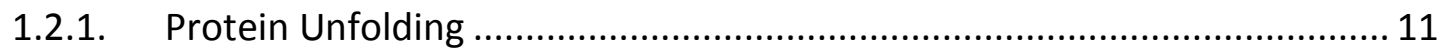

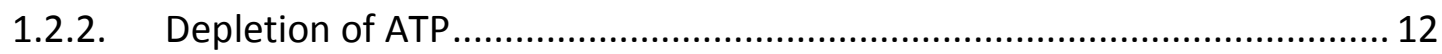

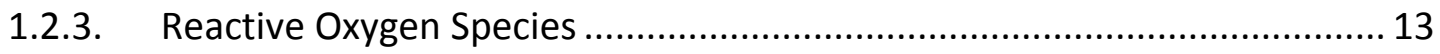

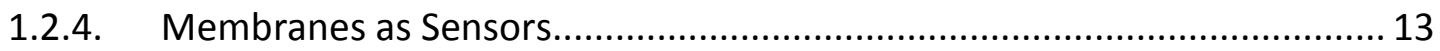

1.3. Stress Activated Signalling Pathways ................................................. 15

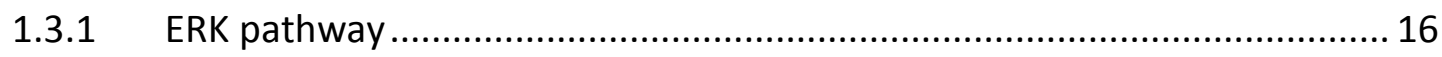

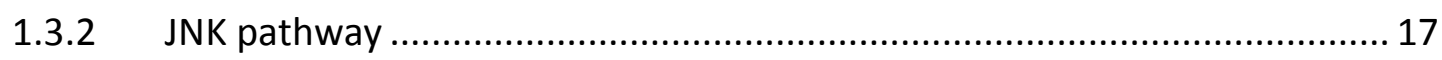

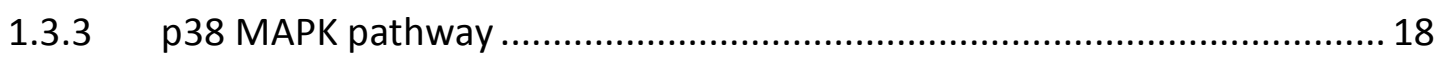

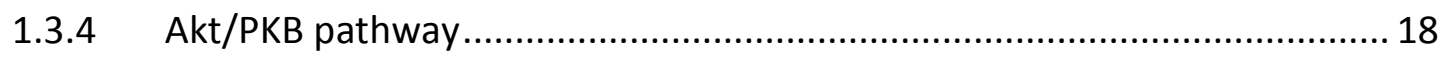

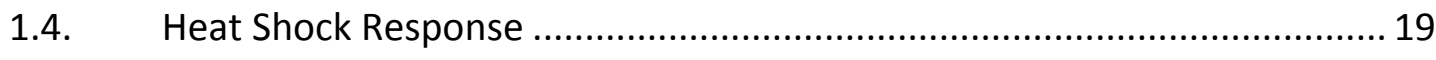

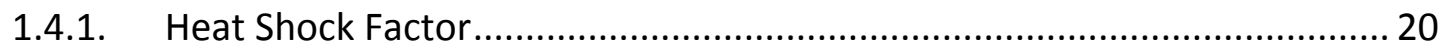

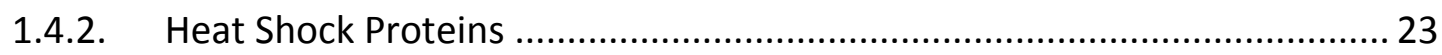

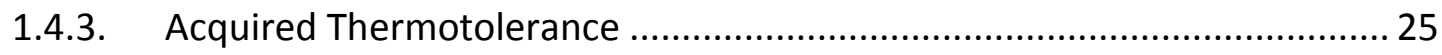

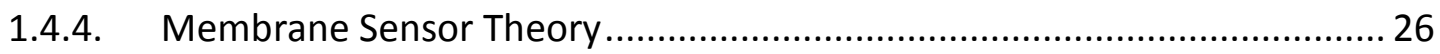

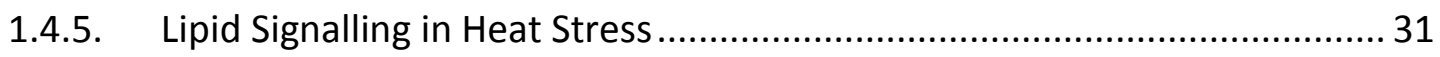

1.4.6. Dependence of HSR on the severity of stress ........................................ 34

1.5. Cell to Cell Variation in Stress Response ................................................ 36 


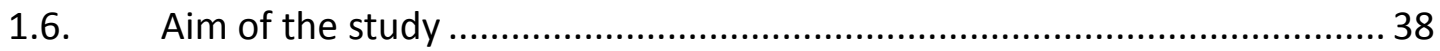

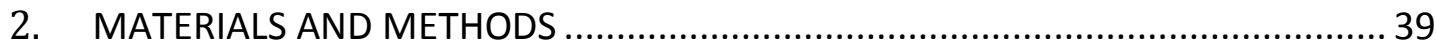

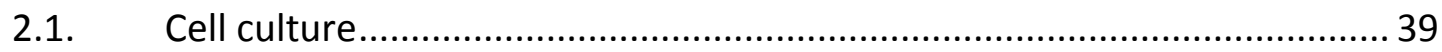

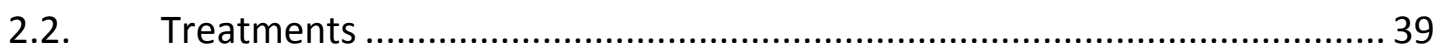

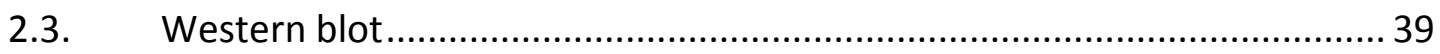

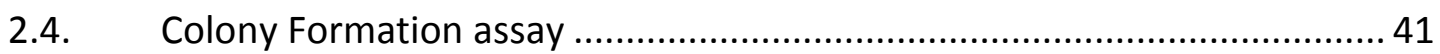

2.5. Immunoflourescence Labelling and Microscopy Experiments .................. 41

2.6. High Content Microscopy Experiments .................................................. 42

2.7. Image based Fluorescent Correlation Spectroscopy (ImFCS) .................... 43

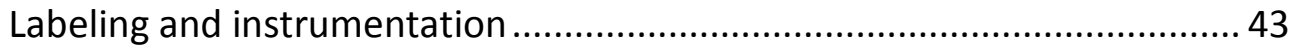

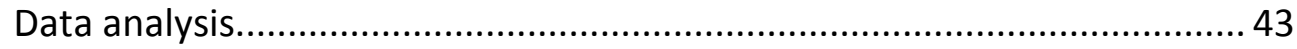

2.8. Thinning out clusters while conserving stoichiometry of labeling (TOCCSL)

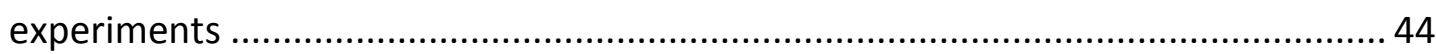

2.9. Measurement of Intracellular Calcium Levels......................................... 45

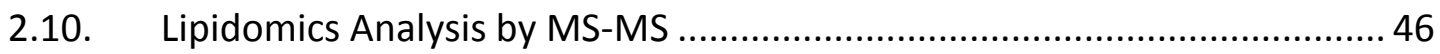

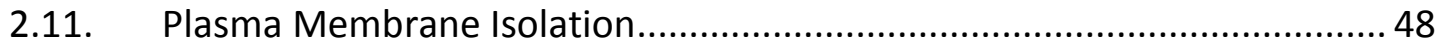

2.12. Plasma membrane sheet preparetion ................................................... 49

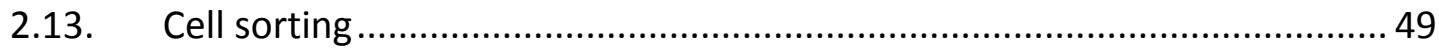

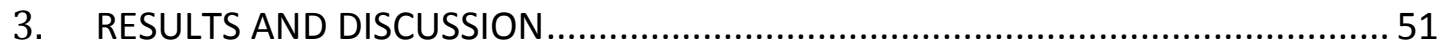

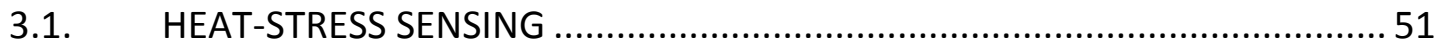

3.1.1. Heat shock proteins are induced differentially during heat stress ............. 51

3.1.2. Heat shock protein redistribution is dependent on the level of heat stress.54

3.1.3. Acquired thermotolerance is highly dependent on stress dose ..................56

3.1.4. Cells promptly respond to heat by remodelling plasma membrane .......... 58

3.1.5. Lipidomics reveals distincts stress lipidomes ...........................................6 60

3.1.6. Stress signalling is linked to plasma membrane remodelling .....................68 
Calcium signalling .

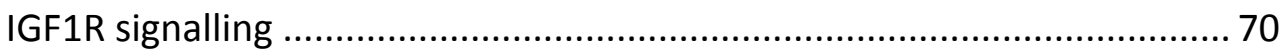

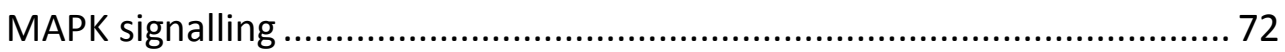

3.2. CELL TO CELL VARIATION OF HEAT SHOCK RESPONSE............................. 74

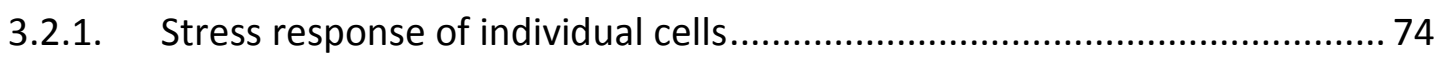

3.2.2. HSP25 translocation reveals the heterogeneity within the population ...... 76

3.2.3. Lipidomics reveals cell cycle dependent lipidomes ................................ 77

3.2.4. A microscopy-based method to analyze cell cycle phases in nonsynchronized mammalian cells to dissect the effect of cell cycle on heterogenous HSR

3.2.5. Single-cell analysis of the calcium peaks of heat shocked $\mathrm{CHO}$ cells reveals the heterogeneity of heat shock sensing/response 82

3.2.6. Heat shock response is dependent on cell density .................................. 84

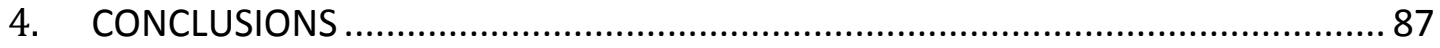

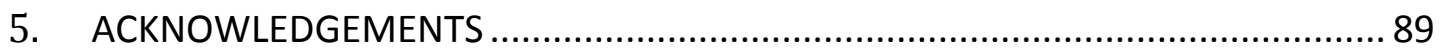

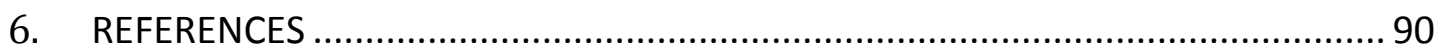

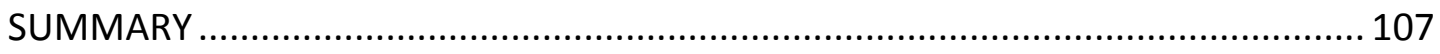

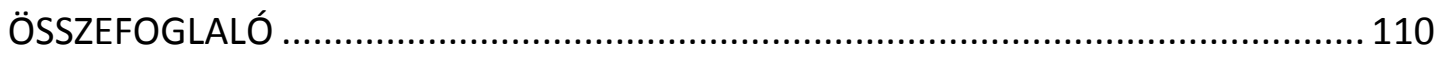

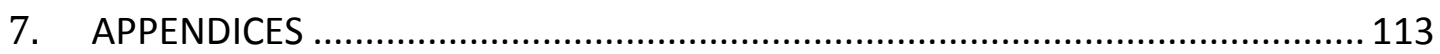

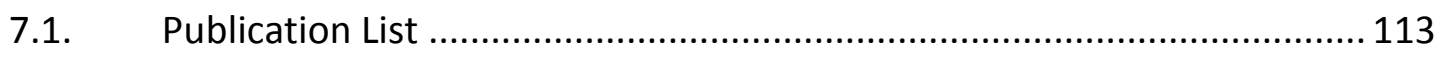




\section{LIST OF FIGURES}

Figure 1.1 Representative model for plasma membrane architecture .................... 14

Figure 1.2. Mechanisms of receptor activated MAPK pathway............................... 16

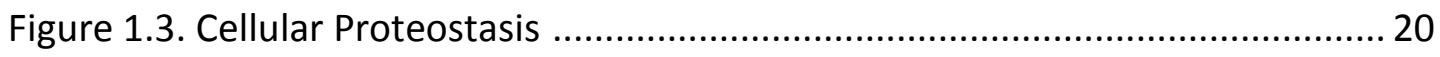

Figure 1.4. HSP interaction with HSF1 upon stress ............................................. 21

Figure 1.5. Schematic diagram of the structure and post-translational modifications of HSF1 22

Figure 1.6. Overview of sphingolipid synthesis and sphingolipid dependent signalling

Figure 1.7 Regulation of $\mathrm{PIP}_{2}$ and $\mathrm{PIP}_{3}$ Synthesis 34

Figure 2.1 Representative images for object analysis in High-throughput assays. ... 42

Figure 2.2 Representative data for Fluorescence activated cell sorting. .................. 50

Figure 3.1 The effect of heat shock duration on HSP induction............................. 52

Figure 3.2 The effect of temperature on HSP induction and HSF1 activation........... 53

Figure 3.3 Redistibution of HSPs is dose dependent.............................................. 55

Figure 3.4 The effect of heat treatment on the phosphorylation status of HSP25... 56

Figure 3.5 Different heat treatments affect ATT in a distinct manner.. 57

Figure 3.6 Lateral diffusion of GPI-mGFP behaves differently upon mild and moderate heat in live cells. 59

Figure 3.7 Characterization of lipidomes of GPI-mGFP-expressing $\mathrm{CHO}$ cells exposed to different levels of HS 61

Figure 3.8 Key features of HS-associated lipid remodeling of $\mathrm{CHO}$ lipidomes...... 62

Figure 3.9 Heat induced changes in the ceramide metabolism.. .64

Figure 3.10 Time dependent key lipid changes in CHO cells with GPI-mGFP construct.. 66

Figure 3.11 Effect of Lyso-PC addition on plasma membrane of $\mathrm{CHO}$ cells with GPImGFP construct. 68

Figure 3.12 Heat dose dependent $\mathrm{Ca}^{2+}$ increase in MCF-7 cells. 69

Figure 3.13 Mild stress activates the IGF1R. .72

Figure 3.14 Dose dependent activation of stress signaling pathways...................... 74

Figure 3.15 Cell to cell variation is observed in cellular heat shock response. .75 
Figure 3.16 Stress dose controls the individual variation................................... 77

Figure 3.17 Lipidome of $\mathrm{CHO}$ cells are shaped by the cell cycle............................... 78

Figure 3.18 Analysis of DNA content reveals the cell cycle phases. ........................ 80

Figure 3.19 Variability of stress response is dependent on the time but not cell cycle phase.

Figure 3.20 Heat induced calcium peaks shows individuality. 83

Figure 3.21 Cell density regulates the HSR. .85

\section{LIST OF TABLES}

Table 1. Cellular localizations and proposed functions of HSPS 24

Table 2. Comparison of mild and severe stress 36

Table 3. Details of the antibodies used in Western Blot experiments 40 


\section{ABBREVIATIONS}

ASK1 Apoptosis signal regulating kinase 1

ATT Acquired thermo tolerance

ATF6 Activating transcription factor 6

ATP Adenosine triphosphate

AMP Adenosine monophosphate

AMPK AMP activated kinase

Cer Ceramide

$\mathrm{CL} \quad$ Cardiolipin

CSR Cellular stress response

DAG Diacylglycerol

DDL1/2 DAF-16(Forkhead box-O transcription factor homologue in C.elegans) dependent longevity $1 / 2$

DNA Deoxyribonucleic acid

ER Endoplasmic reticulum

ERK 1/2 Extracellular signal regulated kinase 1/2

FAK1 Focal adhesion kinase 1

GFP Green fluorescent protein

GICer Glucosyl ceramide

GM3 Monosialodihexosylganglioside

GPI Glycosylphosphatidylinositol

GRP78 Glucose-regulated protein 78

GSK3 $\beta \quad$ Glycogen synthase kinase 3- $\beta$

GSTM1 Glutathione S-transferase Mu1

GTP Guanosine triphosphate

HBSS Hank's buffered salt solution

HSP Heat shock proteins

HSR Heat shock response

HSF1 Heat shock factor 1

IGF-1 Insulin-like growth factor 1

IGF1R Insulin-like growth factor receptor 1

IR Insulin receptor

IRE1 inositol-requiring transmembrane kinase/endonuclease

IRS Insulin receptor substrate

JNK c-Jun $\mathrm{N}$ terminal kinase

LPA Lysophosphatidic acid

LPC Lysophosphatidylcholine

LPI Lysophosphatidylinositol

MAPK Mitogen activated protein kinase 


\begin{tabular}{ll} 
MEK & MAPK/ERK kinase \\
mTOR & Mechanistic target of rapamycin \\
PA & Phosphatidic acid \\
PBS & Phosphate buffer saline \\
PDK 1/2 & Phosphoinositide dependent kinase 1/2 \\
PC & Phosphatidylcholine \\
PE & Phosphatidylethanolamine \\
PG & Phosphatidylglycerol \\
PI & Phosphoinositol \\
PS & Phosphatidylserine \\
PI3K & Phosphoinositide 3-kinase \\
PIP2 & Phosphoinositide 4,5-bisphosphate \\
PIP3 & Phosphoinositide 3,4,5-triphosphate \\
PKB & Protein kinase B \\
PKC & Protein kinase C \\
PLC & Phospholipase C \\
PLD & Phospholipase D \\
PN & Proteostasis network \\
RNA & Ribonucleic acid \\
ROS & Reactive oxygen species \\
SAPK & Stress activated kinase \\
SH2 & Src homology 2 \\
TRPV1 & Transient receptor potential vanilloid 1 ion channel \\
UPR & Unfolded protein response \\
& \\
\hline
\end{tabular}




\section{INTRODUCTION}

"Anything that causes stress endangers life, unless it is met by adequate adaptive responses; conversely, anything that endangers life causes stress and adaptive responses. Adaptability and resistance to stress are fundamental prerequisites for life, and every vital organ and function participates in them."

(Selye, 1950)

\subsection{Stress}

In 1936 a single author letter written by Hans Selye was describing the first observations on stress which initiated a still growing wave of research. He defined stress as a non-specific response of the body to any demand made upon it and according to his notion stress is a part of life that cannot be avoided and would be undesirable to avoid since it is an inducement, however the organism experiencing a stressful episode will pay for its survival by aging or by becoming susceptible to diseases (Selye, 1950).

According to general adaptation syndrome he defined, as organisms are stressed an alarm stage begins which pursues the organism to the fight-or-flight response. For instance, an animal facing a predator will start secreting stress hormones and mobilize energy resources towards muscles so that it can run faster. However organisms that are sessile will activate cellular machineries to minimize the damage caused by the stressors. In the second stage, resistance; the organism is still on an alerted state and continues to reduce the effects of stressors, but energy is consumed to repair the damages originated. Third stage exhaustion is when the stressor persists, so that the organism exhausts resources and becomes susceptible to disease and death (Szabo, Tache, \& Somogyi, 2012).

Nevertheless, it is beneficial for the organism to be exposed to a certain level of stress (positive stress/eustress) as it results in increased survival in a subsequent more severe stress. It is important to note another observation Selye made is that the perception of stress and response given to it is highly individualized. A stressor that is mild to an organism can be severe for another one or the extent of defense 
may not be the same. Thus both in the multicellular organism and cellular level, the stressor and response must be studied for the better understanding of stress.

\subsection{Cellular Stress Response}

All organisms are challenged by environmental changes such as fluctuations in the temperature, salinity (Krasensky \& Jonak, 2012), osmotic pressure (Ho, 2006), high cell density, exposure to heavy metals (Flora, Mittal, \& Mehta, 2008), hypoxia/ischemia (Majmundar, Wong, \& Simon, 2010) as well as pathological conditions such as infection or inflammation (Muralidharan \& Mandrekar, 2013). Cells monitor changes on the macromolecules and cellular stress response (CSR) can be defined as the cells' response towards the damage. Protein aggregation, DNA damage or lipid related changes such as raft disruption or lipid oxidation can trigger cellular stress response (CSR) (Kültz 2005). Depending on the type of the stressor cells can activate different responses which are grouped as heat shock response (HSR), unfolded protein response and DNA damage response. However these responses are interconnected and share common elements (Fulda et al. 2010).

Contingent upon the level of stress and organisms capacity of resources, cells activates mechanisms to minimize the damage and re-establish homeostasis unless damage is severe and cannot be reverted thereby pathways leading to cell death are turned on (Sørensen, Kristensen, \& Loeschcke, 2003). The persistence of cells will result in the production of heat shock proteins (HSP), which leads to improved survival for a secondary more severe stressful condition. Interestingly cross-tolerance is possible, the secondary stressor does not essentially be of the same type of stressor (Ely, Lovering, Horowitz, \& Minson, 2014; Lindquist, 1986).

\subsection{Stress Sensors}

Cells have several sensors to detect the damages occurred on the macromolecules and these machineries can activate stress signaling to produce stress response. 


\subsubsection{Protein Unfolding}

Proteins as important macromolecules of the cells are involved in vast array of functions that are highly dependent on the configuration and 3-D structure. Therefore it is not a surprise that cells have quality control mechanisms to ensure the presence of functioning proteins and to degrade the misfolded, non-functional proteins. Indeed, there is a constant flux of synthesis and degradation in the cells. Maintenance of the balance between these two states is called proteostasis and it is preserved by proteostasis network (Figure 1.3) (Balch et al. 2008). Translational and transcriptional errors, incorporation of amino acid analogs, mutations and post translational defects are factors affecting the folding of proteins. Other factors such as change in the redox balance, temperature and local variations in ionic strength can directly or indirectly cause a flux of unfolded/aggregated proteins (Gidalevitz, Prahlad, and Morimoto 2011). Unfolded protein response and heat shock response mechanisms can be activated by the increased unfolding/aggregation.

Endoplasmic reticulum (ER) is the major organelle where secretory and endomembrane proteins are targeted to meet their final tertiary and quaternary structure (e.g. with the addition of disulphide bonds) and posttranslational modifications (e.g. glycosylation) (Vitale, Ceriotti, and Denecke 1993). Perturbation of ER function can be monitored in several ways;

In $\mathrm{ER}, \mathrm{Ca}^{2+}$ is found mainly bound to high $\mathrm{Ca}^{2+}$ affinity proteins. Disruption of these molecules result in perturbation of ER-luminal $\mathrm{Ca}^{2+}$ which causes the calnexin oligomerization and its interaction with protein disulphide isomerase and calreticulin to initiate UPR signaling (Schröder and Kaufman 2005).

Formation of disulphide bonds requires oxidation and reduction reactions, the disruption of the protein folding machinery, therefore will impair the redox balance (Bulleid 2012).

Disruption in the glycosylation of proteins in one hand causes protein flux towards cytosol for degradation but also results in a transmembrane ER protein activating transcription factor 6 (ATF6) to be underglycosylated which itself serves as a sensor to activate UPR (Carrara, Prischi, and Ali 2013). 
Interaction of unfolded proteins with ER resident chaperones themselves also results in dissociation of the chaperones from sensors like IRE1 (inositol-requiring transmembrane kinase/endonuclease) and results in spontaneous dimer formation, phosphorylation and activation of signalling pathways (Hetz et al. 2011).

Due to basic thermodynamic principles the elevation of temperature may also causes denaturation of proteins. In the cytoplasm, misfolded/denatured proteins are refolded by chaperones or eliminated by ubiquitin-proteasome machineries. However, accumulation of denatured proteins activates HSF1 (heat shock factor -1) through a mechanism currently still in debate. Under normal conditions, HSF1 primarily found as monomers bound to HSP70 or HSP90. Protein denaturation causes the dissociation of HSF1 from HSPs and result in formation of active trimers to be translocated to the nucleus to induce heat shock protein genes (Morimoto 1998).

Nucleus is the largest organelle of the cell and is crucial for many activities to occur e.g. transcription, processing of RNA (Bański, Kodiha, and Stochaj 2011). During stress chaperones are transported to the nucleus promptly after temperature elevation. Even though the exact mechanism of the transport and the trigger is unknown, nucleolus is suggested to be an important place where prevention of aggregation of proteins is crucial therefore a possible place for a stress sensor (Shibata and Morimoto 2014).

\subsubsection{Depletion of ATP}

Proteins that are involved in the stress management use energy to repair the damage. Depending on the level and duration of the stress, adenosine triphosphate (ATP) production by mitochondria may not be sufficient or it may be unfunctional.

Cells have active mechanisms to sense the level of adenosine monophosphate (AMP)/ATP ratio. AMPK (AMP activated kinase) orchestrates cells' energy sources and also the stress response based on the AMP/ATP ratio. AMPK is allosterically regulated; binding of AMP activates the complex making it more susceptible for phosphorylation. Phosphorylated AMPK can activate signalling pathways to restore 
ATP supplies and limit the ATP consuming biosynthetic processes (Hardie 2011; Hardie, Ross, and Hawley 2012; Chou et al. 2012).

Heat stress, hypoxia and glucose deprivation are stressors that cause ATP depletion. Moreover chaperones that have ATPase activity for the folding proteins are interconnected to ATP depletion mechanisms (Peng et al. 2005).

\subsubsection{Reactive Oxygen Species}

There is a balance of ROS production and antioxidant capacity of the cells. However stresses such as heat, UV radiation and hypoxia are known to impair this balance and reactive oxygen species damage macromolecules such as proteins, lipids and nucleic acids (Belhadj Slimen et al. 2014; Akbarian et al. 2016; Yang et al. 2010). Hydrogen peroxide $\left(\mathrm{H}_{2} \mathrm{O}_{2}\right)$, hydroxyl radical $\left(\mathrm{OH}^{-}\right)$and superoxide $\left(\mathrm{O}_{2}^{-}\right)$are among the molecules which are produced when cells are stressed. Oxygen radicals can be formed with the radiolysis of water with ionizing radiation whereas ROS can be formed endogenously within cellular compartments such as mitochondria and endoplasmic reticulum. ROS induced damage in DNA such as formation of doublestrand breaks can result in apoptosis (Takahashi et al. 2008). Lipid autoxidation is initiated by free radicals such as hydroxyl radical and polyunsaturated fatty acid residues mostly in their cis configuration are either converted to trans configuration or electrophilic aldehydes are formed (Krumova and Cosa 2016).

Like any other stress signals, ROS can transduce signals through protein tyrosine kinases, serine/threonine kinases, phosphatases and calcium (Ben Mahdi, Andrieu, and Pasquier 2000).

\subsubsection{Membranes as Sensors}

Cell membranes are highly dynamic and complex structures formed mainly by lipids and proteins. Being more than a barrier to the external polar environment, they perform wide variety of important cellular functions. The most abundant lipids 


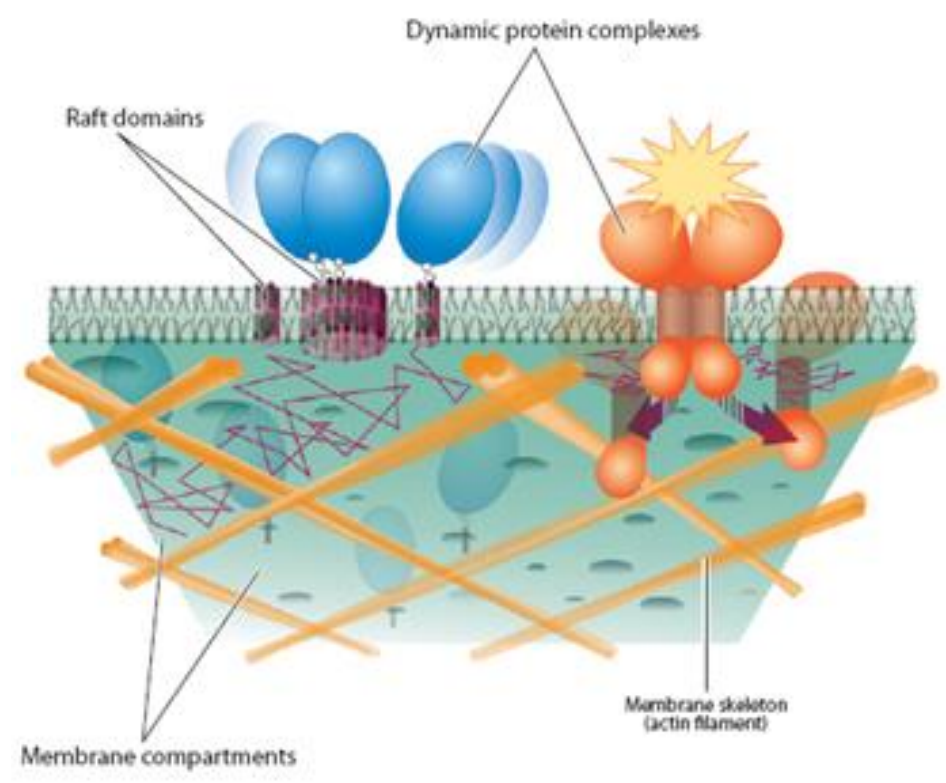

Figure 1.1 Representative model for plasma membrane architecture ladopted from (Kusumi et al. 2012)).

in the membranes are glycerophospholipids, of which more than thousand different species are involved to create the necessary environment to host membrane proteins (Hung and Link 2011). Sphingolipids and cholesterol are tightly packed lipid classes with high melting temperatures and capability of resisting mechanical stress. Their mixtures with glycerophospholipids form membrane rafts/domains that are 10$200 \mathrm{~nm}$ size, highly dynamic and heterogenous which can be stabilized to form larger platforms through protein-protein interactions. Membranes are therefore highly structured for the necessary functions and their composition is unique to each compartment/organelle. Plasma membrane is highly heterogenous by means of nanoscale organization of lipids, membrane proteins and cortical actin network (Levental, Grzybek, and Simons 2011; Sezgin et al. 2012; Sezgin, Gutmann, et al. 2015)

Another very critical membrane feature is its fluid structure that also contributes to its complexity and dynamic attribute. Fluidity allows molecules to diffuse and rotate freely within the membrane meanwhile the variation of lipid composition in nanoscale compartments permits molecules to interact and influence each other (Bernardino de la Serna et al. 2016; Klotzsch and Schütz 2013; Simons and Sampaio 2011). 
Membrane sensor theory is based on these important features. Lipid-phase behaviour is dependent on the temperature hence the fluidity of the membranes and redistribution of the rafts. Since the aforementioned nano-scale domains are influenced by lipid alterations, signalling pathways are either activated or inhibited, new interactions between proteins are formed and cells activate mechanisms to stabilize the highly dynamic organization of their membranes by remodelling lipid composition under stress. (Török et al. 2014; Sezgin, Waithe, et al. 2015). Recently, considerable evidence has been accumulated to the favor of the "Membrane sensor hypothesis" which predicts that, the level of HSPs changes as a result of alterations to the plasma membrane. This is especially pertinent to mild heat shock, a condition present during fever (Török et al. 2014; Nagy et al. 2007). It is conceivable that sensor(s) evolved in parallel to the fever response in vertebrates by detecting the elevation of temperature via membrane thermometers without any recognizable damage to the main cellular functions, thereby supplying the evolutionary basis for the membrane sensor theory.

\subsection{Stress Activated Signalling Pathways}

The orchestration of heat shock protein response is a rapid, highly regulated cellular function, which involves coordinated control of multiple signal transduction pathways. The mitogen activated protein kinases (MAPK) and protein kinase B (Akt/PKB) pathways are the most notable heat activated signalling pathways. Extracellular-signal regulated kinase 1/2 (ERK 1/2), c-Jun N-terminal kinases (JNK) and p38MAPK are Serine/Threonine kinases that are activated upstream of HSF1 phosphorylation and HSP gene transcription. However the direct link with a trigger that activates these pathways is not known. 


\subsubsection{ERK pathway}

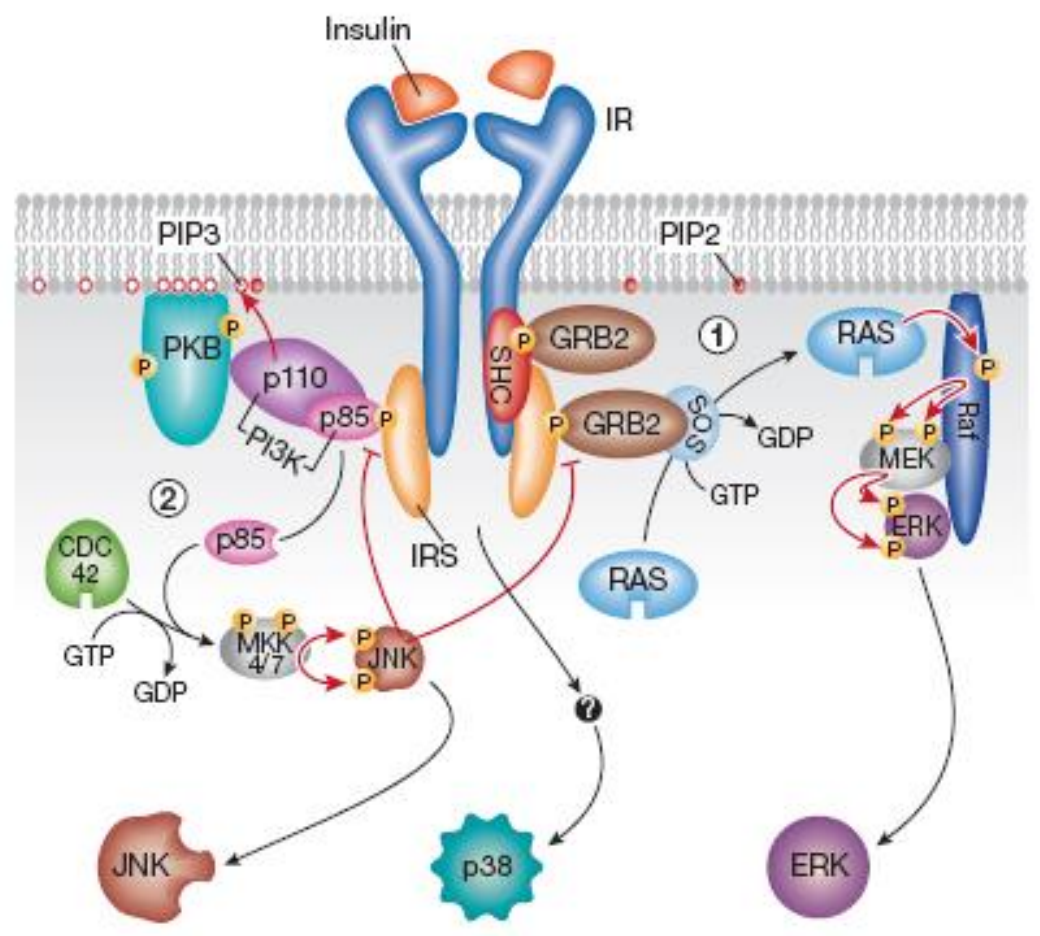

Figure 1.2. Mechanisms of receptor activated MAPK pathway (adopted from Gehart, Kumpf, Ittner, \& Ricci, 2010.) CDC42, cell division cycle 42; ERK, extracellular-signal regulated kinase; GRB2, growth factor receptor-bound protein 2; GTP/GDP, guanosine-tri-(di)phosphate; IRS, insulin receptor substrate; JNK, Jun N-terminal kinase; MEK, MAPK/ERK kinase; MAPK, mitogen-activated protein kinase; MKK4/7, MAPK kinase 4/7; PI3K, phosphatidylinositol 3 kinase; PIP3/PIP2, phosphatidylinositoltri-(di)phosphate; PKB, protein kinase B; SHC, Src homology 2 domain containing; SOS, son of sevenless.

The primary activation of ERK $1 / 2$ ( $p 44$ and $p 42$ respectively) are by cell surface receptors such as epidermal growth factor receptors, receptor tyrosine kinases and may result in differentiation or proliferation depending on the duration of the signals (Marshall 1995). Cell surface receptors are dimerized due to external stimuli e.g. ligand binding that results in autophosphorylation of the tyrosine kinase domains and recruitment of small GTPases to plasma membrane. Small GTPases are 21-30kDa monomeric guanine nucleotide binding proteins belonging to Ras superfamily with remarkable diversity of structure and functions, thus diverse effectors (Yang et al. 
2010). ERK $1 / 2$ is activated by the Ras-Raf-MEK pathway (Cargnello and Roux 2011). Mechanical stretch, hyperosmolarity, heat and hydrogen peroxide can activate receptor activated Ras-Raf-MEK-ERK 1/2 pathway. In the mechanical stress studies the inhibition of growth factor receptors by suramin blocked the activation of ERK. The dominant mutant Raf-1 has also shown to have inhibitory effects on the same pathway (Richard Z. Lin et al. 1997; Hong et al. 2006).

An alternative pathway for the activation of ERK is receptor independent. If the cells were exposed to a severe stress in which either the duration is longer or the temperature is higher, the activation of MEK decreases. However, the dual phosphatases which controls the level of phosphorylated ERK becomes inactive due to heat induced aggregation/insolubilization causing an increased levels of phosphorylated ERK (Yaglom et al. 2003). It is also interesting that overexpression of HSP70 can stabilize these phosphatases and also by competing with an Raf activating protein all of which abolishes ERK activation by heat (Song, Takeda, and Morimoto 2001; Yaglom et al. 2003).

Nevertheless, ERK activation is generally accepted as a pro-survival signal for the cells. The inhibition of MEK activation or expression of dominant negative mutant decreases the cell survival (Nadeau and Landry 2007).

\subsubsection{JNK pathway}

JNK pathway can partially be activated by receptor tyrosine kinases through phosphoinositide 3-kinase (PI3K). It converts phosphoinositide (PI) 4,5-bisphosphate (PIP2) to PI 3,4,5-triphosphate (PIP3). PI3K regulatory unit is recruited to the plasma membrane by the adapter protein IRS and phosphorylated receptor tyrosine kinase (Gehart et al. 2010). Suramin which is an inhibitor for growth factor receptors can completely block the activation of JNK by UV and hyperosmotic stress (Dorion and Landry 2002). Other pathway involves a small GTPase Rac1 activation and recruitment to the membrane. Mild stress is shown to recruit Rac1 to the plasma membrane and causes the phosphorylation of JNK. The dominant negative mutant of 
Rac1 inhibits JNK activation significantly, however this effect is abolished as the temperature increases (Han et al. 2001).

Main trigger for JNK is thought to be due to inactivation of phosphatases under stressful conditions and it is usually considered as apoptotic signal (Nadeau and Landry 2007). Interestingly HSP70 when overexpressed or induced after stress is shown to protect heat denatured phosphatase, therefore can be responsible for the increased survival and thermotolerance (K. H. Lee et al. 2005; Gabai et al. 1997).

\subsection{3 p38 MAPK pathway}

p38 MAPK pathway can be activated through variety of stresses including heat stress, UV radiation, hypoxia, ischemia and oxidative stress. In contrast to ERK and JNK pathways, it is not activated through membrane receptors. Activation of p38 is not abolished by suramin or a dominant negative EGFR mutant nor requires the phosphatase inhibition (Nadeau and Landry 2007; Dorion and Landry 2002). In fact, it requires specific canonical MAPK kinases and share common elements with JNK activation. Apoptosis signal regulating kinase 1 (ASK1), a MAPK kinase kinase is shown to activate p38 and JNK when cells are exposed to heat through the titration of thioredoxin and GSTM1 (Dorion, Lambert, and Landry 2002). Oxidative stress causes the thioredoxin dissociation from Ask1 and heat stress causes GSTM1 which creates a distinction on stress sensing pathways and p38 activation. Finally HSP70 has regulatory effects on p38 activation which can be linked to the increased survival of second heat shock or thermotolerance (Gabai et al. 1997).

\subsubsection{Akt/PKB pathway}

Akt activity can be modulated by several players. Two phosphorylation sites found on Akt are subjected to phosphorylation and dephosphorylation by two different kinases and phosphatases. Thr308 is found on the catalytic domain and Ser473 is found on the hydrophobic domain which is a non-catalytic part (Bayascas and Alessi 2005). Even though it is suggested that maximal Akt activity is obtained when both 
residues are phosphorylated, depending on the severity of the signal and interaction of chaperones it can be modulated differently

Activation of Akt/PKB pathway by heat stress results in survival signals as of ERK pathway. Its activation is linked to PI3K by receptor tyrosine kinases. PI3K activation results in accumulation of PIP3 which grounds Akt to interact with the plasma membrane and causes the phosphorylation by PDK $1 / 2$ on threonine 308 (C.-M. Hung et al. 2012). The treatment of the cells with PIK3 inhibitors completely blocks the activation of Akt and causes the apoptosis of heat shocked cells (Nadeau and Landry 2007; Shaw, Cohen, and Alessi 1998).

GSK3 $\beta$ is another kinase which has important roles in the regulation of heat shock response and HSF1 repression (Takaki and Nakai 2016). Akt phosphorylation has an inhibitory effect on it, therefore indirectly stimulates HSF1. It is also shown to inhibit ASK1 activation of p38, therefore attenuates the apoptotic signals (Zhang et al. 2005). However in the case of severe stress inhibition of Akt by PI3K inhibitors did not result in p38 inhibition nor inhibition of p38 did not block the Akt activation (Bijur and Jope 2000).

Phosphorylation of Akt on Serine 473 in catalyzed by mTOR complex and the stimulation abolished in serum deprived cells (Sarbassov et al. 2005; Bayascas and Alessi 2005). Severe ER stress caused an increase in Ser473 phosphorylated Akt and it is regulated by an ER chaperone GRP78 (Yung et al. 2011). HSP90 and HSP27 are among the binding partners of Akt with similar effects where HSP27 promotes the binding of activating kinases and HSP9O prevents dephosphorylation. HSP70 on the other hand causes Akt degradation (Koren et al. 2010; Konishi et al. 1997; S. Sato, Fujita, and Tsuruo 2000).

\subsection{Heat Shock Response}

Depending on the severity of the stress a decision is made the cells either activate protective mechanisms and induce set of genes that are called heat shock proteins or cell death occurs via activation of apoptotic pathway. Minimal stress proteome 
defines cells capacity and includes proteins involved in sensing of stress, redox control, cell cycle control, macromolecular repair and energy metabolism (Kültz 2005). Essential part of the stress proteome is heat shock proteins. They assure the cellular protein homeostasis (proteostasis) by aiding in the proper folding of de novo synthesized proteins or by preventing aggregation therefore assuring a functional proteome (figure 1.3) (Gidalevitz, Prahlad, and Morimoto 2011).

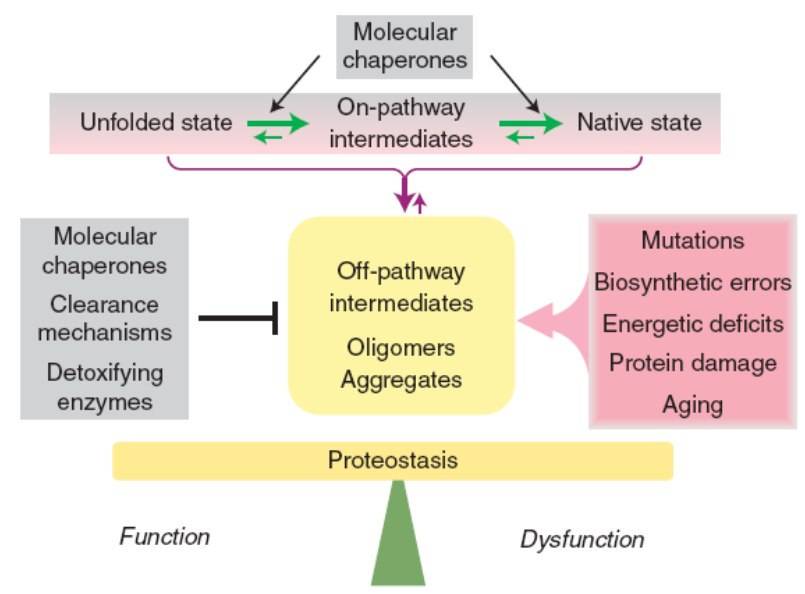

Figure 1.3. Cellular Proteostasis (adopted from Gidalevitz et al., 2011)

\subsubsection{Heat Shock Factor}

Induction of heat shock proteins are tightly regulated at the transcriptional level by heat shock factors. Stress activates HSFs to bind to heat shock elements which are short 14bp promoter elements found upstream of heat shock genes. Binding of HSF1 requires its transition from the HSF monomer-HSP complex to the trimer state. It is still a debate how this transition occurs, however removal of HSPs from the complex and binding of non-coding-RNAs by heat are possible explanations. Among the HSP families, HSP70 and HSP90 are reported to be binding partners of HSF1. When cells are stressed the repression of HSPs on HSF1 activation is released and the chaperones switch their interaction to unfolded protein and protein complexes (Figure 1.4) (Calderwood 2010; Velichko et al. 2013). 


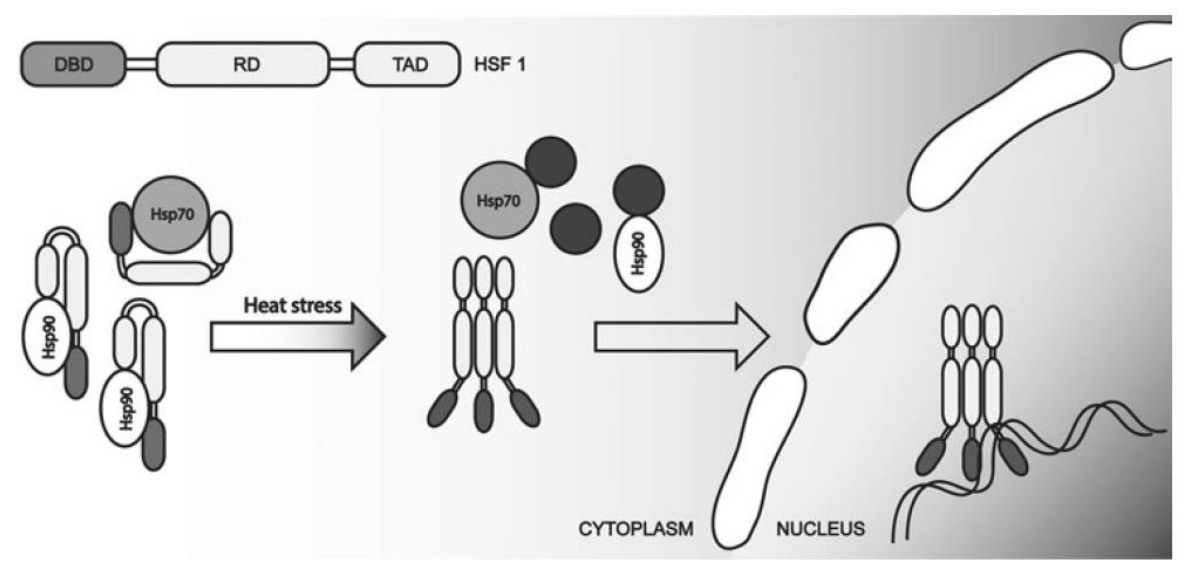

Figure 1.4. HSP interaction with HSF1 upon stress (adopted from Velichko, Markova, Petrova, Razin, \& Kantidze, 2013).

HSF1 is composed of highly conserved DNA binding domain, oligomerization domain, nuclear localization signal and regulatory domain (transcriptional activation domain). Nuclear translocation signals are required for the transport of HSF1 and unique trimer structure allows it to bind to DNA with high (Vihervaara and Sistonen 2014). Activation and regulation of HSF1 is rather complex; sumoylation, acetylation, thiol oxidation and phosphorylation are known to be involved in its regulation (Dayalan Naidu and Dinkova-Kostova 2017). While the formation of HSF1 trimer and its binding to DNA is not sufficient for the transcription of genes , the hyperphosphorylation of HSF1 is shown to be required for the transcriptional competent state and for enhanced activity (Guettouche et al. 2005). On figure 1.5 known phosphorylation sites and the enzymes reported to phosphorylate those sites are shown.

Serine 303 and Serine 307 are the constitutively phosphorylated residues required for the repression of transcriptional activity, stability of HSF1 and further sumoylation at Lysine 298. Phosphorylation on Serine 121 is also causing the repression of HSF1 by promoting HSP90 binding. It is also important to note that without the regulatory domain, HSF1 is constitutively transcriptionally competent, therefore this domain may also be regarded as stress sensor (Dayalan Naidu and Dinkova-Kostova 2017). 


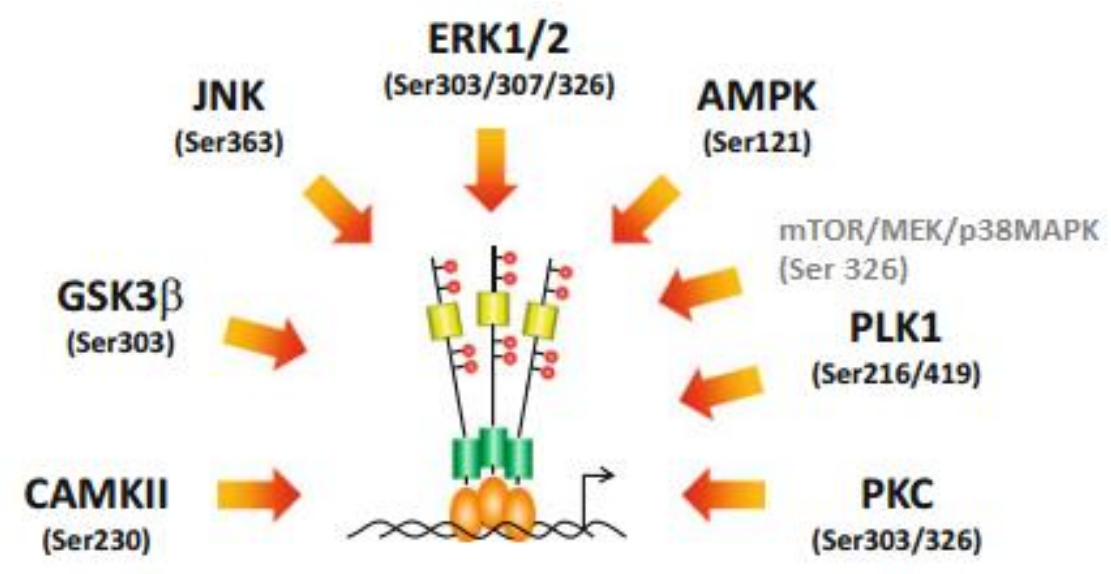

Figure 1.5. Schematic diagram of the structure and post-translational modifications of HSF1 (adopted and modified from Takaki \& Nakai, 2016)

The major activating sites on HSF1 were found to be Serine 230 and Serine 326. Mutational studies showed that disrupting the phosphorylation sites on the regulatory domain changes activation thresholds of HSF1 (Holmberg et al. 2001; Budzyński et al. 2015). Phosphorylation on Serine 230 through calcium/calmodulin dependent protein kinase $\mathrm{II}$ and it is required for the activation of the trimer (Holmberg et al. 2001; R. E. Wang et al. 2009). Serine 326 is shown to be the hallmark of HSF1 activation leading to HSP gene transcription upon stress. Mutations on this site greatly reduced the heat induction of HSP70 (Guettouche et al. 2005). mTOR has a positive effect on this particular site, as it is required for dissociation of HSP9O and release of this negative regulator. Furthermore HSP70 promoter activity is reduced if mTOR signaling is not active (Chou et al. 2012). Moreover RAS-MEK-ERK pathway has divergent effects on HSF1. MEK is in physical contact with HSF1 to phosphorylate its serine 326 whereas ERK suppresses the activity of MEK (Tang et al. 2015). Another very recent finding is that p38 MAPK kinase is active on the very same site with a highlight on the extent and duration of the stress affecting the extent of phosphorylation (Dayalan Naidu et al. 2016). 


\subsubsection{Heat Shock Proteins}

Heat shock proteins (HSP) are highly conserved family of proteins present in all organisms. Their synthesis is induced at high temperatures, therefore the first roles assigned to HSPs were their protein chaperone functions that is their involvement in the folding and inhibiting the aggregation of proteins. However they are also involved in a variety of other important processes ranging from maintaining homeostasis, transport of proteins through membranes, stabilizing protein complexes, signalling, cell cycle to apoptosis (Tkáčová and Angelovičová 2012). HSPs were classified according to their molecular weight and functions. Cellular localizations and functions of major HSP families are shown in Table 1.

HSP90 is a highly conserved ATP-dependent molecular chaperone with a very dynamic homodimer structure and one of the abundantly found proteins in the cells (Pearl and Prodromou 2006). However its main function is not folding of de novo synthesized proteins. It is involved in late stage folding and activation of specific set of proteins. Therefore it is involved in many evets such as signal transduction, cell cycle progression, apoptosis, trafficking of proteins and immunity (Pratt and Toft 2003; Taipale, Jarosz, and Lindquist 2010; Trepel et al. 2010). It is induced by heat stress and has important roles for the survival of the cells.

HSP60 is considered as a mitochondrial chaperone however it is also found in the cytosol. It has important functions in protein folding and signalling pathways (Saibil 2013). HSP60 induction is associated with carcinogenesis and increased survival. It's presence in the extracellular space and peripheral blood makes it a good diagnostic marker for the cancer cells (Cappello et al. 2008).

HSP40 are homodimeric proteins sharing many substrates with HSP70 and involved in processes like protein folding, gene expression, protein degradation and translational initiation (J. C. Young 2010). It regulates the ATPase activity of HSP70 with a direct binding N-terminal ATPase domain but also directs HSP70 towards specific target proteins at precise subcellular locations (Kampinga and Craig 2010). 
Table 1. Cellular localizations and proposed functions of HSPs ladopted from (Zorzi and Bonvini 2011))

\begin{tabular}{|c|c|c|c|c|c|}
\hline Family & Organism & Chaperones & Location & & Function \\
\hline Hsp100 & $\begin{array}{l}\text { E.coli } \\
\text { S.cervisiae }\end{array}$ & $\begin{array}{l}\text { ClpA, B, C } \\
\text { Hspl04 }\end{array}$ & $\begin{array}{l}\text { cytosol } \\
\text { cytosol }\end{array}$ & 6- to 7-mer & $\begin{array}{l}\text { Role in stress tolerance; it helps the } \\
\text { resolubilization of heat-inactivated proteins } \\
\text { from insoluble aggregates }\end{array}$ \\
\hline Hsp90 & $\begin{array}{l}\text { E.coli } \\
\text { S.cervisiae } \\
\text { Humans }\end{array}$ & $\begin{array}{l}\text { HtpG } \\
\text { Hsp83 } \\
\text { Hsp90 } \\
\text { GRP94 } \\
\text { TRAP1 }\end{array}$ & $\begin{array}{l}\text { cytosol } \\
\text { cytosol } \\
\text { cytosol, } \\
\text { nucleus } \\
\text { ER } \\
\text { mitochondria }\end{array}$ & Dimer & $\begin{array}{l}\text { Role in signal transduction (e.g., interaction with } \\
\text { steroid hormone receptors, tyrosine kinases, } \\
\text { serine/threonine kinases); regulation of heat } \\
\text { shock response; role in cell cycle and } \\
\text { proliferation; maintenance of mitochondrial } \\
\text { integrity }\end{array}$ \\
\hline Hsc/Hsp70 & $\begin{array}{l}\text { E.coli } \\
\text { S.cervisiae }\end{array}$ & $\begin{array}{l}\text { DnaK } \\
\text { Ssal-4, } \\
\text { Ssb1,2 } \\
\text { Kar2, Sscl } \\
\text { Hsc70, Hsp70 } \\
\text { BIP, mHsp70 }\end{array}$ & $\begin{array}{l}\text { cytosol } \\
\text { cytosol } \\
\text { ER, } \\
\text { mitochondria } \\
\text { cytosol, } \\
\text { nucleus } \\
\text { ER, } \\
\text { mitochondria }\end{array}$ & Monomer & $\begin{array}{l}\text { Roles in lambda phage replication; regulation of } \\
\text { heat shock response; interaction with nascent } \\
\text { chain polypeptides; functions in interorganellar } \\
\text { transport; roles in signal transduction; refolding } \\
\text { of denatured proteins in vitro; roles in cell cycle } \\
\text { and proliferation; anti-apoptotic activity; } \\
\text { potential antigen-presenting molecule in tumour } \\
\text { cells }\end{array}$ \\
\hline Hsp60 & $\begin{array}{l}\text { E.coli } \\
\text { S.cervisiae } \\
\text { Plants } \\
\text { Humans }\end{array}$ & $\begin{array}{l}\text { GroEL/ES } \\
\text { Hsp60 } \\
\text { Cpn60 } \\
\text { Hsp60 }\end{array}$ & $\begin{array}{l}\text { cytosol } \\
\text { mitochondria } \\
\text { chloroplast } \\
\text { mitochondria }\end{array}$ & 14-mer & $\begin{array}{l}\text { Roles in folding and stability of denatured } \\
\text { protein in vitro; cofactor in diverse proteolytic } \\
\text { systems; role in the assembly of bacteriophages } \\
\text { and plant proteins (Rubisco) }\end{array}$ \\
\hline Hsp40 & $\begin{array}{l}\text { E.coli } \\
\text { S.cervisiae } \\
\text { Humans }\end{array}$ & $\begin{array}{l}\text { dnaJ } \\
\text { Ydj1 } \\
\text { Hdj1, Hdj2 }\end{array}$ & $\begin{array}{l}\text { cytosol } \\
\text { cytosol } \\
\text { nucleus }\end{array}$ & Monomer & $\begin{array}{l}\text { Essential co-chaperone for Hsp } 70 \text { ATPase } \\
\text { activity, substrate binding and release }\end{array}$ \\
\hline $\begin{array}{l}\text { Small } \\
\text { Hsps }\end{array}$ & $\begin{array}{l}\text { E.coli } \\
\text { Humans }\end{array}$ & $\begin{array}{l}\text { IbpA, IpbB } \\
\text { Hsp27 } \\
\text { crystallin }\end{array}$ & $\begin{array}{l}\text { cytosol } \\
\text { cytosol } \\
\text { cytosol }\end{array}$ & $\begin{array}{l}\text { 8- to 24- } \\
\text { mer }\end{array}$ & $\begin{array}{l}\text { Inhibition of in vitro protein aggregation and } \\
\text { heat inactivation in S. cervisiae; Role in cell } \\
\text { thermotolerance through stabilization of actin } \\
\text { microfilaments; anti-apoptotic activity }\end{array}$ \\
\hline
\end{tabular}

HSP70 was discovered by its high induction after heat stress and found in many organisms from bacteria to humans in many cellular localizations e.g. GRP78 a 70kDa ER chaperone (Lindquist 1986). Its cycling ATPase activity is essential in folding and assembly of newly synthesized proteins. The ATPase activity and the stability of HSP70-substrate complex is controlled by co-chaperones and nucleotide exchange factors. It has very diverse functions within the cell (Mayer 2013). It aids the folding of proteins, prevents aggregation, involved in quality control, disassembly of protein complexes, stabilizing regulatory proteins, cell cycle regulation, aiding signal transduction and apoptosis (Kirkegaard et al. 2010; Koren et al. 2010; J. C. Young 2010). Upon stress it is highly induced and this induction often related with increased survival in a subsequent stress (Carper, Duffy, and Gerner 1987). HSP70 localizes to nucleus during stressful conditions and this event is assisted by special nuclear 
transport proteins and binding (Kose and Imamoto 2014; Kose, Furuta, and Imamoto 2012; Velazquez and Lindquist 1984). Besides its chaperoning functions, inside nucleus HSP70 aids formation of an aggregation foci and also protects singlestranded DNA breaks (Kotoglou et al. 2009; Nollen et al. 2001; Shibata and Morimoto 2014).

Small HSPs are a diverse family sharing an $\alpha$-crystallin domain and with a main function of prevention of aggregation. They are small in size however they can form large dynamic oligomers which changes the size upon stress and stabilize proteins to be re-folded by other ATPase chaperone complexes or degradation pathways (Kostenko and Moens 2009). They are generally considered as cytoprotective since their presence can lower the level of irreversible protein aggregation (Vos et al. 2011). The formation of dimers or monomers requires the phosphorylation of HSPs. P38 MAPK is responsible for this phosphorylation and interaction of monomers with actin causes stabilization (Geum, Son, and Kim 2002). During stress, sHSPs localize to nucleus in some cell types to prevent the aggregation. Translocation mechanism is rather controversial; it was shown to be phosphorylation dependent and once inside the nucleus oligomers form but phosphorylation deficient proteins were also shown to translocate to the nucleus (Bryantsev et al. 2002; Bryantsev et al. 2007; Michaud et al. 2008).

\subsubsection{Acquired Thermotolerance}

An intriguing effect of the heat stress is the cells ability to become temporarily more resistant to the subsequent lethal heat treatments. This phenomenon is called acquired thermotolerance (ATT) (Gerner and Schneider 1975). The basis of this enhanced survival is either due to cells increased capacity to cope with the damages that occur during the heat treatment or to attenuate the formation of the damage. Induction of heat shock proteins was shown to be responsible for thermotolerance in prokaryotes, yeast and Drosophila cells (Carper, Duffy, and Gerner 1987; Parsell et al. 1993). Induction of HSPs stabilizes the proteins and preserves proteostasis during the second heat treatment (Kabakov et al. 2002). Increased survival can also be 
attributed to the anti-apoptotic effect of HSPs. Both HSP27 and HSP70 are shown to block apoptotic signalling cascades (Gabai et al. 1997; Mymrikov, Seit-Nebi, and Gusev 2011; Kennedy et al. 2014). HSF1 as the master regulator of heat stress controls the induction of the heat shock proteins and therefore knocking out HSF1 would reduce protein levels as well as survival of the cells in a subsequent stress. (McMillan et al. 1998). Even though no increase in survival was obtained in HSF1-/cell lines, HSP25 and HSP70 constructs did not restore thermotolerance which suggests the involvement of HSF1 related induction of other genes (Luft et al. 2001). Furthermore calcium increase, an important hallmark of stress is when blocked with chelator molecules inhibits the induction of HSPs but not thermotolerance (Burdon 1987). Nonetheless in a given cell only one of the HSPs may correlate to resistance (G. C. Li 1985).

An additional aspect is the severity and the duration of the first preconditioning treatment. Similar level of thermotolerance can be achieved by long treatment of a low temperature and short treatment of a higher temperature (Burgman, Nussenzweig, and Li 1995). Earlier reports point out a possible membrane involvement in the development of ATT since changing the membrane composition alters the sensitivity of cells to heat (Jóźwiak and Leyko 1992; Konings and Ruifrok 1985). However no direct link has been reported between thermotolerance and plasma membrane (Anderson and Parker 1982; Bowler 2005; Harwood and Vigh 1998).

\subsubsection{Membrane Sensor Theory}

As discussed earlier, plasma membrane is a very unique environment; very dynamic and heterogeneous organization making it to be an important platform for many proteins to interact. The fluid behaviour enables molecules to diffuse freely, to rotate and to re-orient within plasma membrane. Interaction of lipids with different fatty acyl chain length and unsaturation, chemical structure of head groups create physico-chemical heterogeneities enabling optimal environments for different proteins or for protein-protein interactions. In addition to these intrinsic properties, 
plasma membrane is in direct contact with the surrounding environment such as extracellular matrix or ligands and with cytoplasm, cortical actin and cytosolic proteins. Due to the temperature controlled lipid phase behaviour and all the interactions that can be linked to it, plasma membrane is an important sensory site for the heat shock. Due to the complex nature of biological membranes it is difficult to capture the spatio-temporal changes in the plasma membrane, however there are numerous experimental evidence for membrane-associated stress sensing (Török et al. 2014).

In recent years, our understanding of the plasma membrane has changed considerably as our knowledge of lipid microdomains has expanded. The level of fluidization induced by the chemical reagents equivalent of fluidity increase seen at $42^{\circ} \mathrm{C}$ resulted in a similar increase of HSP70 (Balogh et al. 2005). The effect of chemical agents such as benzyl alcohol exerts its effects through the dissolving raftlike cholesterol-sphingomyelin domains, therefore a distinct organization of microdomains may be required for the initiation of stress signals (Nagy et al. 2007; Gombos et al. 2011). The inhibition of stress signal integrator Rac1 has effects both on the plasma membrane microdomain organization and heat shock response as such the average diameter size of the microdomains increases at $37^{\circ} \mathrm{C}$ but decreases at $43^{\circ} \mathrm{C}$ with a strong decrease in HSP25 and HSP70 gene expression (Gungor et al. 2014).

Transient receptor potential channels are a large family of cationic channels which contribute to many physiological functions. TRPV1 is shown to be a molecular sensor for environmental stimuli such as chemical reagents (capsaicin, resiniferotoxin), acidity $(<6.0)$ or noxious heat $\left(>43^{\circ} \mathrm{C}\right)$ (Szallasi et al. 2007). It is a plasma membrane protein, however it can be found in ER and endocytic vesicles. PKC mediated phosphorylation can regulate the translocation of the TRPV1 from ER to plasma membrane which is triggered by nerve growth factor or insulin growth factor activation (Ho, Ward, and Calkins 2012). Activation of the TRPV1 channels causes $\mathrm{Ca}^{2+}$ increase in the cytoplasm which is a hallmark of heat stress. Depletion of raft forming lipids; cholesterol by $M \beta C D$, sphingomyelin by sphingomyelinases and ganglioside a complex ceramide by myriocin demolished the activation potential of the channel in 
response to capsaicin and resiniferotoxin (Szoke et al. 2010; Sághy et al. 2015). However as for the heat activation of the TRPV1 has not been shown to be inhibited by $M \beta C D$ even though the data provided supports the capsaicin activation (Jansson et al. 2013). Others reported the PIP2 regulation of TRPV1 channels and the $\mathrm{Ca}^{2+}$ induced PLC $\delta$ activity. PIP2 as mentioned earlier is a minor phospholipid in the plasma membrane and can be converted to signalling molecules inositol phosphate and diacylglycerol by PLC activity to release $\mathrm{Ca}^{2+}$ from ER and activate PKC, respectively (Falkenburger, Dickson, and Hille 2013). $\mathrm{PI}(4,5) \mathrm{P}_{2}, \mathrm{PI}(4) \mathrm{P}$ and $\mathrm{PI}(3,4,5) \mathrm{P}_{3}$ were both shown to activate the TRPV1 channels, although the activation is not as high as capsaicin induced activation in excised patches. Moreover purified PLC $\delta$ which binds to $\mathrm{PI}(4,5) \mathrm{P}_{2}$ inhibits the channel activity causing a feedback inhibition (Rohacs 2015). Nevertheless, in the intact cells there is a dual effect; in the presence of high concentrations of capsaicin PIP 2 activates TRPV1 channel, in the low capsaicin or moderate heat treatment increased $\mathrm{PIP}_{2}$ levels inhibited the channel activity whereas a moderate PIP 2 depletion activated (Lukacs et al. 2007). It is possible that the inhibitory effect is indirect since it is not observed in the excised patches via PIP 2 binding protein that is absent in the patches. In a recent study it has been shown that TRPV1 has a direct effect on the HSP expression. Antagonists of TRPV1 inhibited the heat induced HSP70 in HEK-293, MLE-12, HT-29 and MCF-7 cell lines heat whereas the addition of agonist capsaicin activated HSF-1 without heat treatment in HEK-293 cells. Moreover addition of EGTA a calcium chelator also blocked HSP70 induction by (Bromberg et al. 2013; Saidi et al. 2009).

Growth factor receptors are the other candidates of membrane initiated heat shock response. The connection has been made long ago when increase in lifespan was observed in worms and flies when insulin-like growth factor 1 (IGF-1) signalling was disrupted and resulted in upregulation of the stress resistance genes (Akerfelt, Morimoto, and Sistonen 2010). The insulin or insulin-like growth factor activation causes the activation of serine threonine kinases that down regulate the HSF1 and consequently HSP induction (Longo and Fabrizio 2002). Insulin and Insulin-like growth factor receptors (IR/IGFR) are complex structures of disulphide linked homodimers or heterodimers with an extracellular ligand binding domain and intracellular tyrosine 
kinase domain which when phosphorylated recruits downstream adaptor proteins and other kinases (Kavran et al. 2014). PI3K/Akt and Ras/MAPK are two principal canonical signalling pathways. Briefly, ligand binding induced autophosphorylation of the tyrosine kinase domain of IR/IGF1R recruits PI3K to the plasma membrane through p85 regulatory domain. $\mathrm{PIP}_{2}$ to $\mathrm{PIP}_{3}$ conversion that is catalyzed by $\mathrm{PI} 3 \mathrm{~K}$, recruits another kinase PDK which then phosphorylates and activates Akt. Ras/MAPK activation occurs through another adaptor protein which recruits Ras and Raf to the plasma membrane and phosphorylates ERK1/2 through MEK. The activation of $\mathrm{PI3K} /$ Akt pathway regulates the glucose uptake whereas Ras/MAPK pathway is involved in the regulation of transcription of several genes. Importantly, ligand/receptor complexes are internalized by endosome/lysosome system leading to the degradation of the ligand, inactivation and recycling of receptors (Siddle 2011). The levels and activation of IR/IGF1R are in control of over 500 genes in a ligand concentration dependent manner (Boucher, Tseng, and Kahn 2010). First level of control on the HSF-1 is through a direct binding of DDL1/2 to hinder HSF-1 in an inactive form (bound to a protein complex). The phosphorylation of DDL1/2 complex is inhibited when the IR/IGF1R is active, therefore attenuation of the insulin-IGF1 signalling causes HSF1 to be released and causes more stress induced HSF-1 to be available (Barna et al. 2012; Chiang et al. 2012). The second level of regulation is through the Akt pathway which negatively regulates HSF1 through indirect phosphorylation on Ser303 (Chu et al. 1996; X. Wang et al. 2003). Membrane link to the IR/IGF1R signalling came when stress factors such as osmotic stress was shown to activate the adaptor proteins of IR/IGF1R. Hyperosmolarity failed to induce autophosphorylation of tyrosine kinase domains in kinase dead knock out mutants of IR suggesting that no other kinases are involved in the activation (Ouwens et al. 2001). However, this did not abolish the activation of ERK1/2, JNK and p38 MAPK by osmolarity suggesting an alternative mechanisms to trigger these pathways. An increased IR/IGF1R phosphorylation has been associated with the use of a hydroximic derivative BGP-15 which is also a co-inducer of HSP. On the other hand BGP-15 was also shown to alter the organization of cholesterol-rich membrane domains and prevents transient disintegration of membrane domains (Gombos et al. 2011). The proposed mechanism for the protective effect on IR/IGF1R signaling shows 
similarities. In atrial fibrillation susceptible animal model, depressed IGF1R in atrial samples is correlated with the increase ganglioside levels that reduces membrane fluidity and inhibits phosphorylation of IGF1R. In the presence of BGP-15, membrane fluidity is increased and ganglioside levels are reduced, therefore it is suggested that BGP15 attenuates ganglioside interaction to restore IGF1R signalling (Sapra et al. 2014). Another report is the activation of IGF1R by sheer stress causing the downstream ERK 1/2 activation in an IGF1R dependent manner. Moreover, inhibition of focal adhesion kinases and Rous sarcoma oncogene controls the activation IGF1R (Tahimic et al. 2016).

Focal adhesion kinase 1 is a non-receptor protein tyrosine kinase that has important functions in cell adhesion via providing link between the active cytoskeleton and extracellular matrix proteins, therefore can be a good candidate for the sensing of environment and heat. Growth factors, neuropeptides and lysophosphatidic acid are among those which can cause the phosphorylation of FAK (Schaller, Hildebrand, and Parsons 1999). After its autophosphorylation it is localized to membrane to recruit Grb2 adaptor proteins with $\mathrm{SH} 2$ domain and interacts with the actin proteins. It has anti-apoptotic roles during the cell spreading (Ben Mahdi, Andrieu, and Pasquier 2000). Although it is not a membrane protein, it is a regulatory protein of the focal adhesion complexes and it is shown to be responsive to the fluidity changes in the plasma membrane and has regulatory roles in the calcium influxes. Stabilization of the rafts is linked with the Rac activation and FAK-directed localization of a ganglioside (GM1) to the membrane. FAK also recruits PI3K through its $\mathrm{p} 85$ regulatory domain and increases the generation of $\mathrm{PI}(4,5) \mathrm{P}_{2} \mathrm{~S}$ (Mitra, Hanson, and Schlaepfer 2005). Shear stress is also shown to cause the phosphorylation of FAK and subsequent activation of ERK 1/2 and JNK signalling cascades in a GrB2 adaptor protein dependent manner (S. Li et al. 1997; S. R. L. Young et al. 2009). In stressed cells, HSP27 phosphorylation by p38 MAPK is linked to focal adhesion organization, detachment of the cells and apoptosis. JNK co-localized to focal adhesions in FAK dependent manner whereas a phosphorylation deficient mutant of HSP27 accelerated the stress-induced changes in focal adhesions and apoptosis (De Graauw et al. 2005). In fact, even under non-stressful conditions phosphorylated HSP27 is 
shown to interfere with the migration of the cells (Gerthoffer and Gunst 2001). Finally, HSP72 also interacts with the FAK during the ATP depletion and inhibits its degradation (Mao et al. 2003).

\subsubsection{Lipid Signalling in Heat Stress}

Clues for connecting lipids to the stress response were first provided when thermosensitivity and induction of HSPs were altered due to changes in physical state of the membrane either by chemical agents or by changing the lipid composition of the cells (Konings and Ruifrok 1985; Horváth et al. 1998). It was demonstrated that changing the growth temperature of cyanobacterium Synechocystis caused a significant shifts in the threshold temperatures for the HSP induction. When cyanobacteria were grown at $22^{\circ} \mathrm{C} \mathrm{HSP}$ induction started at $38^{\circ} \mathrm{C}$, however the value is shifted to $44^{\circ} \mathrm{C}$ for $36^{\circ} \mathrm{C}$ grown bacteria. During acclimatization to the heat lipid unsaturation levels has changed suggesting the importance of membrane physical state (Horváth et al. 1998). Moreover addition of fluidizers such as benzyl alcohol and heptanol also caused downshifts of HSP induction thresholds in K562 human lymphoblast cell (Balogh et al. 2005). Therefore the membrane lipid composition is an important determinant of the stress response and it must strictly be regulated. In fact stress itself induces changes in the lipid metabolism to stabilize the heat induced changes in the membranes and also lipids act as mediators for activation of signalling pathways (Balogh et al. 2013).

Sphingolipids are abundant structural elements of the lipid bilayer and their interaction with the membrane domains can modulate the physical state of the lipid bilayers. In addition, they account for regulation of enzyme activities and considered as important mediators for signalling events resulting in apoptosis, differentiation (Breslow and Weissman 2010) (Figure 1.6). The dramatic shift in the sphingolipid metabolism during heat stress was first observed in yeast (Wells, Dickson, and Lester 1998; G M Jenkins et al. 1997). Upon stress ceramide is shown to be accumulated which could be related with cell cycle arrest, activation of pro-survival signalling pathways or apoptosis depending on the severity of the temperature shift. The 
targets of ceramide include PKC and ceramide activated protein kinase. It is reported to activate a major stress signalling pathway MAPK through the activation of MEK (Hannun and Luberto 2000) or Raf1 (Woessmann, Meng, and Mivechi 1999).

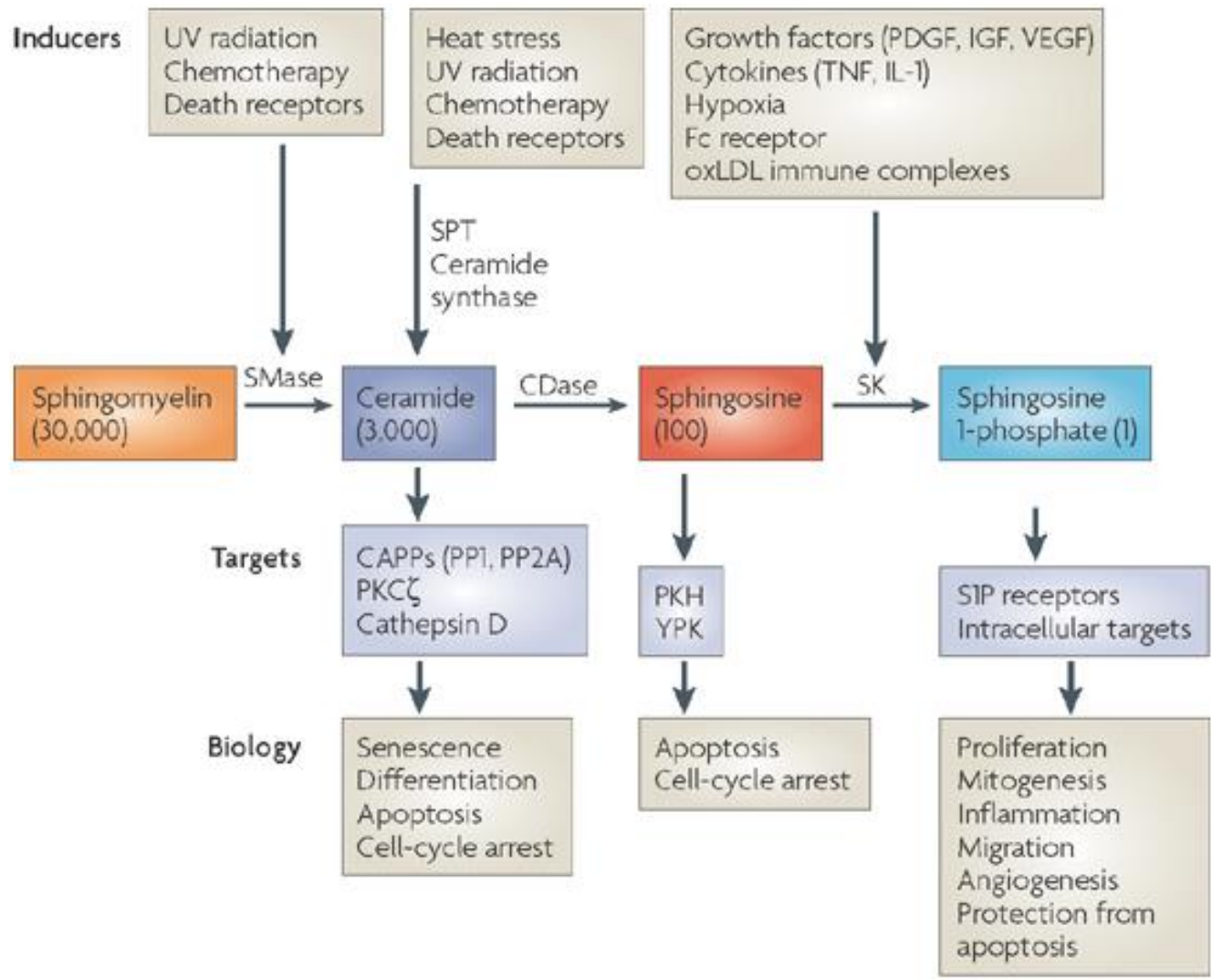

Figure 1.6. Overview of sphingolipid synthesis and sphingolipid dependent signalling (adopted from Hannun \& Obeid, 2008). SMase, Sphingomyelinase; $S P T$, Serine palmitoyl transferase; CDase, ceramidase; SK, sphingosine kinase; CAPP, ceramide-activated Ser-Thr phosphatase; IGF; insulin-like growth factor; IL-1, interleukin-1; oxLDL, oxidized low-density lipoprotein; PDGF; plateletderived growth factor; PKC, protein kinase C; PKH, PKB homologue; TNF, tumour necrosis factor- ; VEGF, vascular endothelial growth factor; YPK, yeast protein kinase. 
It is important to note the impact of ceramide formation on the physical state of the membranes. There are studies pointing out hydrolysis of sphingomyelin to ceramide and activation of sphingomyelinases linked to plasma membrane disruption (Tam et al. 2010). Saturated and long acyl chain ceramides promote formation of gel domains in physiological temperatures therefore has a distinct impact of the membrane lateral organization (Pinto et al. 2011).

Cholesterol is an essential lipid of the plasma membrane. Its hydrophobic interactions with the glycerophospholipids result in the formation of membrane domains. It is a bidirectional regulator of the membrane fluidity as it stabilizes the membranes at high temperatures but prevents stiffening at low temperatures (Silva et al. 2007). It does not act as a signalling mediator however it controls the membrane dependent signalling cascades, trafficking, lipid and protein sorting. Ceramide for example is more soluble in cholesterol rich fluid membranes suggesting the ceramide rich domain formation in cholesterol poor membranes which is a requisite for ceramide induced apoptosis (Castro et al. 2009). Plasma membrane cholesterol can be depleted using methyl- $\beta$-cyclodextrin and results in diverse effect on the signalling activities and membrane trafficking (S. B. Sato et al. 2004). Heat shock response is altered by the cholesterol content of the cells; higher HSP expression was observed when cells contain higher cholesterol levels (Gombos et al. 2011; Csont et al. 2002).

Phosphatidylinositols constitute only $1 \%$ of the membrane phospholipids however they modulate two important signalling cascades; PI3K pathway and PLC to regulate exocytosis, cytoskeletal organization, plasma membrane recruitment and activation of target protein kinases such as Akt (Czech 2000). Heat stress activates PI3K in a time dependent manner which in turn activates Akt pathway (Richard Z. Lin et al. 1997). PI3K activity therefore controls HSF1 phosphorylation indirectly by inactivation of glycogen synthase kinase3 (Calderwood 2010) and HSP induction (Shinohara et al. 2006). 


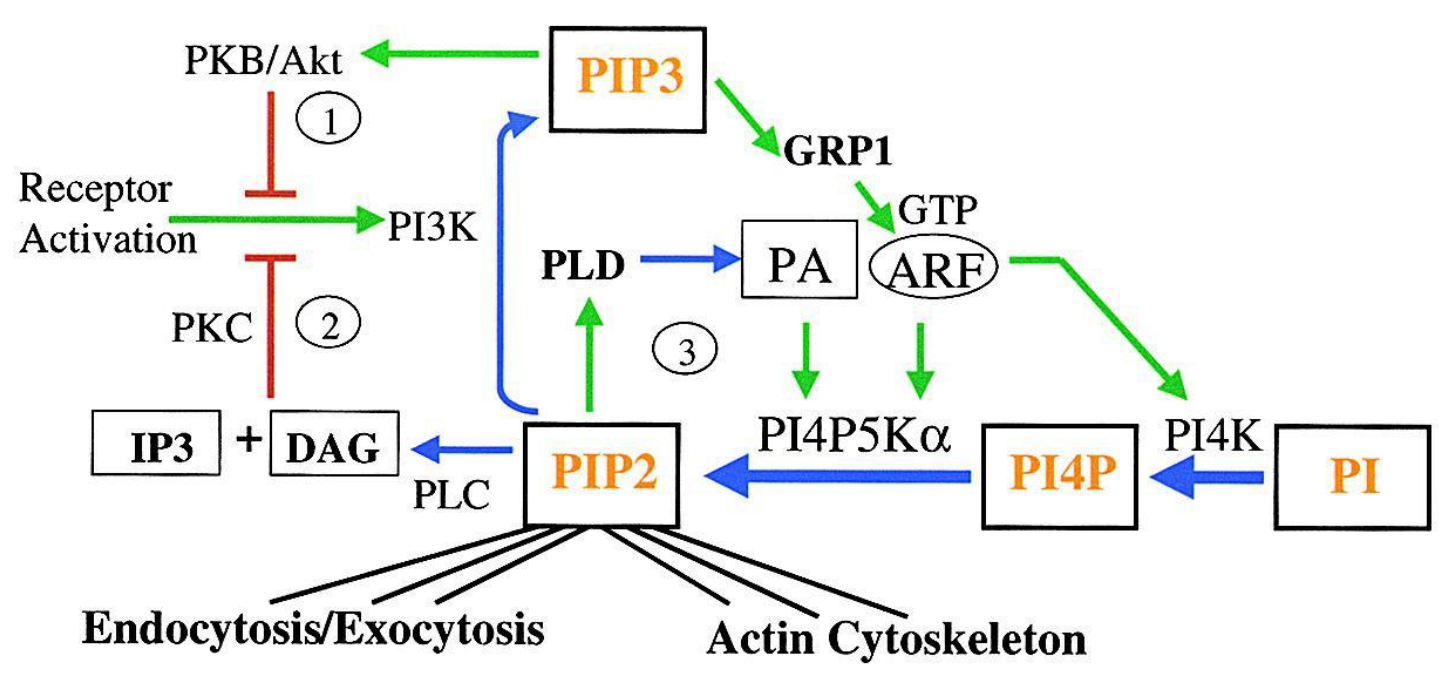

Figure 1.7 Regulation of $\mathrm{PIP}_{2}$ and $\mathrm{PIP}_{3}$ Synthesis. Green arrows denote stimulatory effects; blue arrows denote synthetic pathways; red denotes inhibitory effect. Feedback inhibitory loop (1). Cross-talk between receptor signaling pathways (2). Feed-forward loop (3) (adopted from (Czech 2000)).

\subsubsection{Dependence of HSR on the severity of stress}

As discussed earlier, the damage and the response of the cells are highly dependent on the duration and the severity of the stress. Mild stress is accepted as natural and beneficial to the organism whereas severe stress is mostly destructive. The duration of heat, temperature, cell type, cell cycle phase and environmental conditions can all effect the sensitivity of the cells hence the level of stress. Table 2 describes these factors and regulatory mechanisms based on mild and severe stress.

Mild stress is promoting the cell cycle progression by cyclinD1 through Rac1, ERK $1 / 2$ and PI3K-Akt-GSK3 pathways whereas severe stress causes cell cycle arrest and apoptosis. Rac1 dependent membrane ruffling is similar to growth factor treatment. Moreover mild heat is proposed to activate growth factor receptors which can be linked to pro-survival signals (Park et al. 2005). Transient PI3K activation is observed during heat treatment and it is dose (both temperature and duration) dependent in the absence of apoptotic signals. As a matter of fact, there is interplay between $\mathrm{PI} 3 \mathrm{~K} / \mathrm{Akt}$ and apoptotic pathways which is cell and stressor dependent. Doxorubicin induced apoptosis for example, causes a transient level of Akt phosphorylation which 
is then suppressed resulting in ERK1/2 phosphorylation and cell death (E. R. Lee et al. 2006).

Fever, corresponding to mild heat shock could protect the hosts in several ways; that it is cytotoxic to the pathogens meanwhile causing HSP production in the host cells which confers to a better survival or it can also induce the HSPs in the pathogen which in return stimulates the host immune system and defenses and finally it is important since it optimizes the host cell's immune response and increases the chances of survival (Hasday and Singh 2000).

Activation of T-cells involves the reorganization of the plasma membrane where both the actin and membrane proteins are involved. The changes occurred when cells are exposed to ethanol or mild hyperthermia are identical to the T-cell activation (Zynda et al. 2015). Therefore it is a supportive evidence for membranes being the most upstream of the membrane sensing in a stimulating manner during the mild temperatures and being beneficial to the organism (Gombos and Vígh 2015). The beneficial roles of mild stress were also observed when cells experience glucose deprivation or heat shock prior glucose deprivation. Heat shock treatment leading to upregulation of HSP27 switches cell death by the necrosis to apoptosis. In addition to HSP27, activation ERK $1 / 2$ played a role in preventing necrosis and inhibiting PI3K inhibited this effect which also accounts for the protective signalling caused by PI3K (Lim et al. 2010). 
Table 2. Comparison of mild and severe stress (adopted from Park, Han, Oh, \& Kang, 2005)

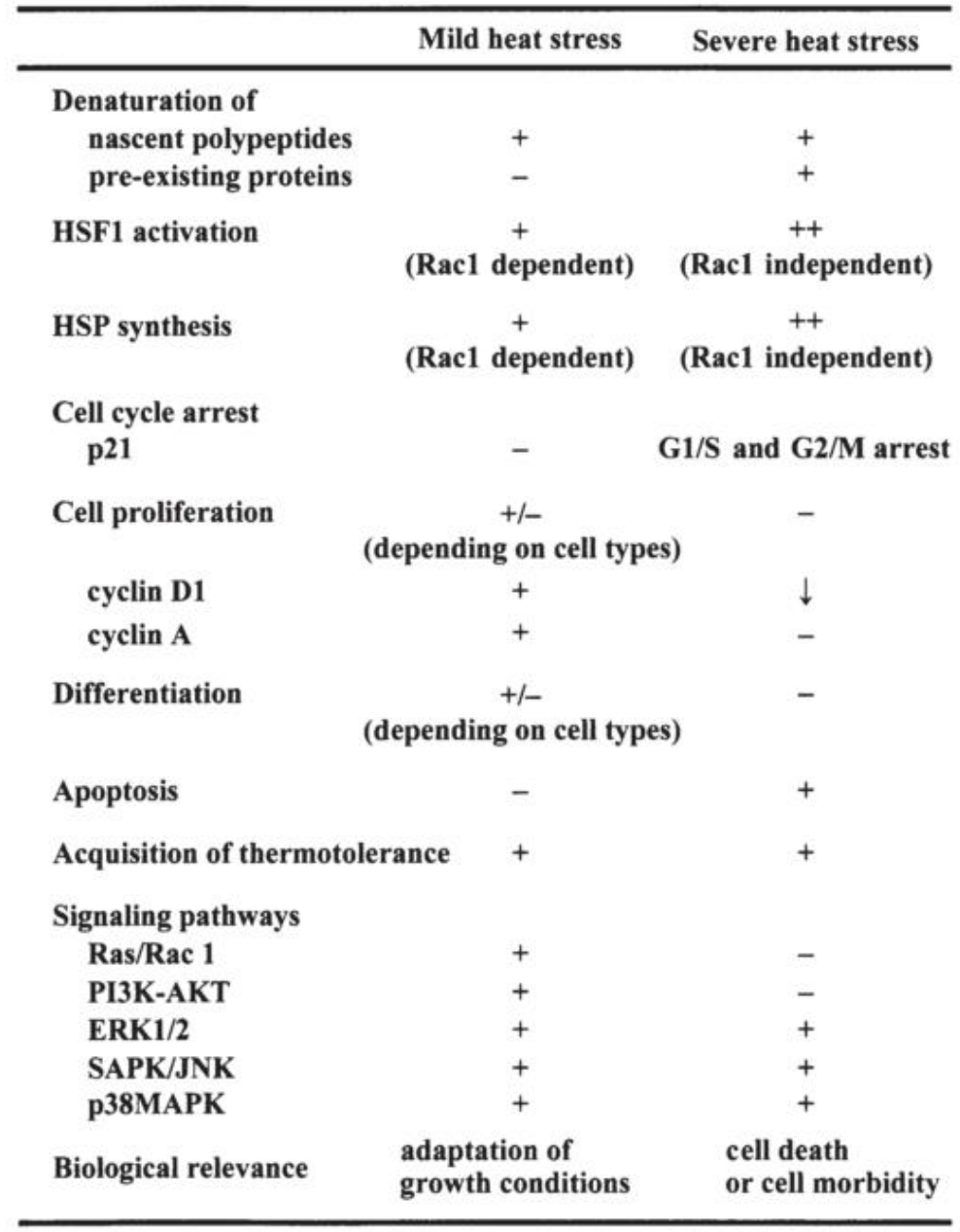

\subsection{Cell to Cell Variation in Stress Response}

Understanding of how cells sense, respond and adapt to environmental changes is of great importance. Knowledge gained by the gene expression of protein analysis is obtained from populations of cells. However, it is a valid question whether all cells in a culture dish suffers the same consequence of stress or whether the response is identical. Treatment of the cells with antibiotics where the persistent cells are shown to regenerate the original population that is a mix of persistent and sensitive cells is a good example for the phenotypic variation observed within the isogenic 
populations (Avery 2006). Therefore, one can expect variations within the population and averaging the measure of gene or protein expressions will be misleading. Secondly, analysis of single cells allows a more direct approach to correlate molecular implications and mechanistic insights can be obtained.

The first single cell studies are obtained by the use of flow cytometers where parameters like cell size, cell cycle and a protein of interest can be monitored simultaneously (Crissman and Steinkamp 1973). Since then major establishments in microscopy, microfluidics, flow cytometry, RNA and DNA sequencing allowed researches to do deeper analysis increasing our understanding on how tumor cells can twist their genome or how a single cell can be a decision point to start an electrical impulse, to migrate or to differentiate (Schubert 2011).

Cell cycle and cell division phenotypes are the important and well-studied factors resulting in population heterogeneity. Reports showed that the cell-to-cell variation in heat survival can partly be explained by the cell cycle. G1 cells are shown to be more tolerant compared to G2/M phase whereas cells in the $S$ phase do not develop thermotolerance at all (Park et al., 2005). Single cell studies are, therefore important to reveal the nature of individuality of stress resistance.

Microscopy based assays, on the other hand provide information about the micro-environment, cell-to-cell interactions in a population context. Use of green fluorescent protein (GFP)-tagged protein constructs reveals the dynamics of protein interactions under the microscope. The repair of double stranded breaks by a novel chromatin associated ubiquitin ligase is identified by analyzing the time lapse data obtained from genotoxic stress induced cells (Doil et al. 2009). In another study, a fluorescent construct is generated to measure the activity of MAPK in single cells. It is shown that when the cell wall integrity is compromised, heterogeneity of the MAPK activation occurs independently of the cell cycle phase but low glucose levels caused a lower activity (Durandau, Aymoz, and Pelet 2015). The analysis of the images and the data mining are concurrently developing fields which have a high importance in retrieving data from high throughput studies and making biological conclusions (Conrad and Gerlich 2010). 
Studies carried by Snijder et al. shows the population context of the virus infection (2009). They define the heterogeneity of the population as a combination of intrinsic and extrinsic factors. Cells grown on the edge of the colonies have higher GM1 content and phosphorylated focal adhesion kinases, which positively correlate with simian virus 40 infection. Moreover, the crowding actively regulates the transcriptional factors and tunes the membrane lipid composition. Cells in the crowded regions shows higher fluidity compared to more ordered counterparts on the sparse regions. Cholesterol content is also higher in the low crowding regions (Frechin et al. 2015).

\subsection{Aim of the study}

The major aim of this study was to understand how cells sense the heat, how membranes contribute to the heat sensing and cellular response to heat. For this purpose, sequence of events during different level of heat stress and the individuality of stress response were studied. The questions addressed are as follows;

- What is the sequence of early events during the perception of temperature stress?

- How different temperature treatments (heat dose) affect the cellular response in terms of membrane dependent changes, protein induction and activation of stress signaling pathways?

- Does the altered membrane structure and composition relate with the heat resistance?

- How cell cycle affects the stress response and to what extent it contributes to it?

- What are the early events of heat sensing? Is it possible to use these as parameters to analyze the individuality of the stress response?

- Is the population heterogeneity of the heat stress signal linked to the membrane? 


\section{MATERIALS AND METHODS}

\subsection{Cell culture}

Chinese Hamster Ovary (CHO) cells and $\mathrm{CHO}$ cells with glycosylphosphatidylinositol (GPI)-mGFP construct (Brameshuber et al., 2010) was a kind gift of Prof. Dr. Gerhard J. Schütz were cultured in F12-K (Gibco-21127022) medium supplemented with $10 \%$ FCS.

Mouse embryonic fibroblasts (MEFs) (a kind gift of Prof. Lea Sistonen) and MCF7 human breast carcinoma cells (a kind gift of Dr. István Krizbai) were grown in DMEM containing $10 \%$ FCS and $4 \mathrm{mM}$ L-glutamine. Cells were maintained at $37{ }^{\circ} \mathrm{C}$ in a humidified $5 \% \mathrm{CO}_{2}$-atmosphere.

\subsection{Treatments}

For heat shock treatments, cells were plated with 250 cells $/ \mathrm{mm}^{2}$ density in complete medium. After 24 hours the plates were sealed with parafilm and immersed in a water bath (with a precision of $\pm 0.1 \mathrm{o} C$ ) set to the indicated temperature for given temperature. Samples were prepared either right after heat shock treatments or after recovery times as indicated.

For Lyso-PC treatments, CHO cells with GPI-mGFP constructs were grown overnight. HBSS was used to wash the cells twice before 10mM 1-Palmitoyl-2hydroxysn-glycero-3-phosphocholine (16:0 Lyso-PC, 855675; Avanti Polar Lipids) were added to the at given final concentrations.

\subsection{Western blot}

Western blot protocol was carried out to determine protein levels. For phosphoproteins and HSF1 cells were harvested right after given treatment, for HSP levels 6 hours recovery time is given unless otherwise stated. Cells were collected in $1 x$ Laemli sample buffer, mixed for 30 minutes at room temperature, incubated at $100^{\circ} \mathrm{C}$ for 10 
minutes and spun down for 5 minutes at 14000rpm (Eppendorf table top centrifuge). Total amount of protein was measured by using Pierce $660 \mathrm{~nm}$ Protein Assay (Thermo Scientific) with the addition of ionic detergent compatibility reagent (Thermo Scientific). 20 ug of protein samples were loaded on $12 \%$ or $10 \%$ SDS polyacrylamide gels (depending on the size of the protein of interest). After separating the proteins, they were transferred onto PVDF membranes $(0.45 \mu \mathrm{m}$, Immobilon-P, Millipore). Primary antibodies as listed in Table 3 were used with overnight incubation at $4^{\circ} \mathrm{C}$ with constant agitation. Secondary antibodies were used in 1:50000 dilutions for 1 hour at room temperature. Equal protein amounts were measured using Pierce $660 \mathrm{~nm}$ protein assay (22660, Thermo Scientific) and loaded on $8 \%$ (for HSF-1) or $10 \%$ SDS gels (all other determinations) for western blotting experiments. Enhanced chemiluminescence was detected and analyzed using Alpha Ease FC Software v6 (San Jose, CA, USA). Anti-GAPDH (G9545, Sigma-Aldrich, Saint Louise, MO) antibody was used to control the protein load and for data normalization.

Table 3. Details of the antibodies used in Western Blot experiments

\begin{tabular}{|l|l|l|}
\hline Antibody & Description & Dilution \\
\hline pSAPK/JNK (thr 183/185) & $\# 9251$-Cell Signalling & $1: 2000$ \\
\hline ERK 1/2 & $\# 9102$-Cell Signalling & $1: 1000$ \\
\hline $\begin{array}{l}\text { phospho ERK1/2 } \\
\text { (pT202/pY204)(pT185/pY187) }\end{array}$ & $\# 16869$-Abcam & $1: 5000$ \\
\hline $\begin{array}{l}\text { phospho p38 MAPK } \\
\text { (Thr180/Tyr182) }\end{array}$ & \#9211 -Cell Signalling & $1: 1000$ \\
\hline $\begin{array}{l}\text { phospho IGF1R } \\
\text { /R3(Tyr1162/1163) }\end{array}$ & \#44804 -invitrogen & $1: 500$ \\
\hline HSF1 & $\begin{array}{l}\text { RT-425-PABX -Thermo } \\
\text { Scientific }\end{array}$ & $1: 1000$ \\
\hline HSF1 phosphoSer326 & $\begin{array}{l}\text { ADI-SPA-902 -Enzo } \\
\text { LifeSciences }\end{array}$ & $1: 1000$ \\
\hline HSP27 phosphoSer15 & SPA-525 -StressGen & $1: 1000$ \\
\hline HSP25 phosphoSer86 & \#44536 -invitrogen & $1: 1000$ \\
\hline HSP70 & $\begin{array}{l}\text { ADI-SPA-810 -Enzo } \\
\text { LifeSciences }\end{array}$ & $1: 1000$ \\
\hline HSP90 & SMC-107A/B -StressMarq & $1: 1000$ \\
\hline HSP25 & $\begin{array}{l}\text { ADI-SPA-801 -Enzo } \\
\text { Lifesciences }\end{array}$ & $1: 1000$ \\
\hline HSP60 & SPC-105 -StressMarq & $1: 1000$ \\
\hline GRP78 & SPC-180 -StressMarq & $1: 2000$ \\
\hline GAPDH & G9545 -Sigma Aldrich & $1: 10000$ \\
\hline
\end{tabular}




\subsection{Colony Formation assay}

For colony formation assay $\mathrm{CHO}$ cells were submitted to heat shock twice. The first (priming) $\mathrm{HS}$ was conducted at different temperatures $\left(40^{\circ} \mathrm{C}, 42.5^{\circ} \mathrm{C}\right.$, and $44^{\circ} \mathrm{C}$ ) for $20 \mathrm{~min}$. After the priming $\mathrm{HS}$, the cells were allowed to recover for $6 \mathrm{~h}$ at $37^{\circ} \mathrm{C}$, in line with other experiments (western blot and immunolocalizations). The second HS comprised a $20-\mathrm{min}$ exposure to $46^{\circ} \mathrm{C}$. Immediately after the second $\mathrm{HS}$, the cells were trypsinized, counted, and serially diluted with media before plating. The plated cells were incubated at $37^{\circ} \mathrm{C}$ for 3-4 days. To visualize and assess colony formation, the cells were fixed in $4 \%$ paraformaldehyde, permeabilized with $2 \%$ Triton X-100, and stained with 500nM propidium iodide (Molecular Probes). Imaging of the colonies was done by using Olympus SZX12 stereomicroscope (Olympus optical, Tokyo, Japan), with 530-560 nm excitation filter and 590-650 nm emission filter.

\subsection{Immunoflourescence Labelling and Microscopy Experiments}

Multi-color imaging experiments were carried out on wild-type $\mathrm{CHO}$ cells. Cells were fixed in $4 \%(\mathrm{w} / \mathrm{v})$ paraformaldehyde for $10 \mathrm{~min}$ immediately after treatment. Cells were permeabilized with $0.5 \%$ Triton-100 for $10 \mathrm{~min}$, and blocked with $1 \%$ bovine serum albumin in PBS for 30 min and incubated with HSP25 (ADI-SPA-801, Enzo) and HSP70 (ADI-SPA-810, Enzo) antibodies, Secondary antibodies from AlexaFluor (Thermo Scientific) were selected according to the host species of the primary antibody, and were used at 1:300 dilution, with incubation for $30 \mathrm{~min}$ at $37^{\circ} \mathrm{C}$. The cells were washed with PBS three times after each treatment. For the detection of both HSP25 and HSP70, 1:50 antibody dilution was used, with Hoechst33342 (Thermo Scientific) as a DNA counterstain. Images were taken using Operetta High Content Imaging system using 40X dry objective (PerkinElmer, Inc. Waltham, MA). 


\subsection{High Content Microscopy Experiments}

Highthroughput assays were imaged using Operetta High-Content Imaging System (Perkin Elmer). Cells grown and labelled in 96-well plates (89626, ibidi, WI,USA) were used to image using 40x dry objective (PerkinElmer). For AlexaFluor 488 detection 475/30nm excitation, 525/50nm emission filter, for AlexaFluor 555 detection 535/30nm excitation, 595/20 emission and for Hoechst 33342 detection 380/40nm excitation, 445/70 emission filter sets were used.

Analysis of the images were carried out using Perkin elmer's Harmony software and MATLAB (Mathworks). Cells were segmented based on the the nuclear intensities and then cytoplasm was detected using Harmony software's own algorithms (Figure 2.1). Hoechst and HSP25 intensities were measured in nucleus and cytoplasm for each single cell. Objects on the border of the image and with very large nucleus were discarded to ensure the quality of the data. For the calculation of HSP25 contrast in the nucleus the following formula was used;

$$
\text { Contrast }=(\text { Fnucleus }- \text { Fcytoplasm }) /(\text { Fnucleus }+ \text { Fcytoplasm })
$$

where $\mathrm{F}$ represents the mean intensity.

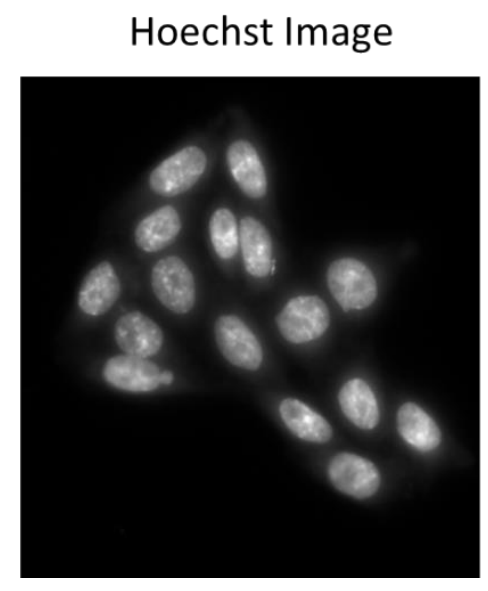

$$
\text { Nucleus Segmentation }
$$

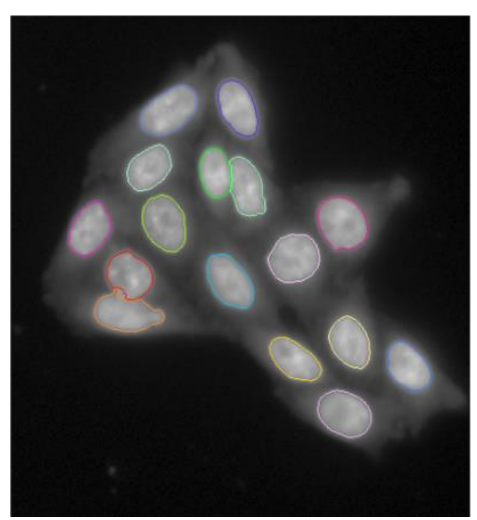

Cytoplasm detection

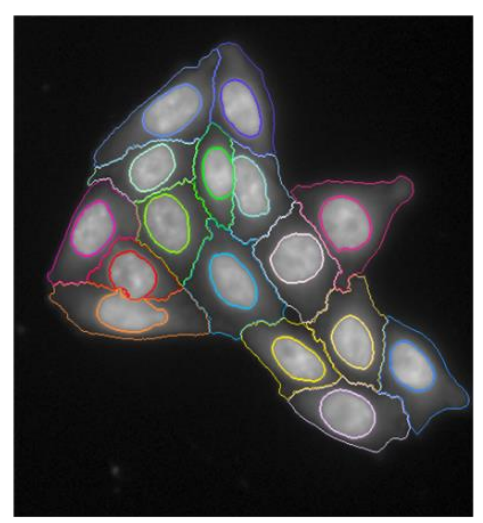

Figure 2.1 Representative images for object analysis in High-throughput assays. Hoechst images were used as a basis of nucleus segmentation which is followed by cytoplasm detection. Detected objects and object borders were drawn by Harmony software algorithms as represented. Data analysis were carried within the determined areas. 


\subsection{Image based Fluorescent Correlation Spectroscopy (ImFCS)}

\section{Labeling and instrumentation}

Cells were seeded into glass bottom dishes (MatTek Corporation,MA, USA) two days before experiment. Measurement was performed in culturing media without phenol red at $37^{\circ} \mathrm{C}$ with $\mathrm{CO}_{2}$ administration for reducing stress conditions. A POC-R cell cultivation system (Zeiss, Jena, Germany) was attached to the stage of microscope for obtaining the growth conditions. This system includes controlled objective heater and $\mathrm{CO}_{2}$ /Air gas chamber. Objective type Total Internal Reflection illumination was used for achieving the thinnest excited sample volume with a high numerical aperture objective (alpha Plan-FLUAR 100, Zeiss). Excitation wavelength $488 \mathrm{~nm}$ from a Spectra-Physics Stabile 2018 (Spectra-Physics, CA, USA) laser as light source was introduced to the microscope (Zeiss Axiovert 200) by two tilting mirrors. The laser beam was focused on the back focal plane of the objective after a $488 \mathrm{~nm}$ cleanup filter and aZT488/647/780rpc-UF1 dichroic mirror (Chroma Technology $\mathrm{GmbH}$, Olching, Germany). Sample signal was collected by the objective and filtered by a 535/70 emission filter (Chroma). For acquisition we used a ProEM512 EMCCD camera (Prinston Instruments, NJ, USA) with $3 \mathrm{~ms}$ effective exposure time and 20x40 pixel acquisition area per measurement (pixel size $0.16 \mu \mathrm{m}$ ) ImFCS plugin (http://www.dbs.nus.edu.sg/lab/BFL/imfcs_image___plugin.html) for ImageJ software was used for data evaluation.

\section{Data analysis}

The autocorrelation functions (ACFs) for every pixels were calculated using a multi-tau correlation scheme (Sankaran et al. 2010). An exponential of polynomial bleach correction was used to correct data before fitting. For obtaining the diffusion coefficient $(D)$ for all pixels ACFs were fitted according to the equation below.

$$
G(\tau)=\frac{1}{N}+\left[\frac{\operatorname{erf}(p(\tau))+\frac{\left(e^{-(p(\tau))^{2}}-1\right)}{\sqrt{\pi p(} \tau)}}{\operatorname{erf}(p(0))+\frac{\left(e^{-(p(0))^{2}}-1\right)}{\sqrt{\pi p(}(0)}}\right]^{2}+G_{\infty} p(\tau)=\frac{a}{\sqrt{4 D \tau+\omega_{0}^{2}}}
$$


Where $G(\tau)$ is the ACF in dependence of the correlation time $(\tau), N$ is the number of detected particles, $a$ is the pixel size and $\omega_{0}$ is the $1 / \mathrm{e}^{2}$ radius of the Gaussian approximation of the point spread function. To identify and describe the mode of membrane organization by investigating the size-dependency of diffusion coefficient we used the Imaging FCS type of FCS diffusion law (Ng, Bag, and Wohland 2015). According to that the diffusion time $\left(\tau_{D}\right)$ of the fluorescent probe depends on the observation area $\left(A_{e f f}\right)$ as it is described by

$$
\tau_{D}\left(A_{e f f}\right)=\tau_{0}+\frac{A_{e f f}}{D}
$$

where $A_{\text {eff }}$ means that area of the membrane where the labeled particle travels which is calculated by the convolution of the detection area with the point spread function. $\tau_{0}$ is the intercept of the diffusion law plot on the $y$ axis of $A_{\text {eff }} / D$ against $A_{\text {eff }}$. This parameter provides information about diffusion confinement. Diffusion law can be plotted by using different $A_{e f f}$ values which were calculated by postinquisitional binning of pixels. In the case of free diffusion $D$ is constant regardless of $A_{\text {eff }}$ so it shows a straight line passes through the origin $( \pm 0.1 \mathrm{~s})$ in the diffusion law graph. A heterogeneous system where exists membrane domains or meshwork, however allows spatial scale dependent diffusion which results remarkable different diffusion law plot with positive or negative intercepts for domain partitioning or meshwork diffusion, respectively ( $\mathrm{Ng}$, Bag, and Wohland 2015).

\subsection{Thinning out clusters while conserving stoichiometry of labeling (TOCCSL) experiments}

TOCCSL experiments were carried as described by Brameshuber et al.(2010) in Institute of Applied Physics, Technical University of Vienna. A Zeiss Axiovert 200 microscope equipped with a 100× NA=1.46 Plan-Apochromat (Zeiss, Oberkochen, Germany) was used to excite cells in objective-based total internal reflection fluorescence (TIRF) configuration via the epiport using $488 \mathrm{~nm}$ light from an optically pumped semiconductor laser (Sapphire; Coherent, Santa Clara, CA). The power was adjusted to $2-10 \mathrm{~kW} / \mathrm{cm}^{2}$ on the sample. A slit aperture (Thorlabs, Newton, NJ) with 
a width of $\sim 7 \mu \mathrm{m}$ in the object plane was used as the field stop. For exact timings, an acousto-optic modulator (Isomet, Springfield, VA) was used. Timing protocols were generated and controlled by an in-house-written program package implemented in LABVIEW (National Instruments, Austin, TX). After the appropriate filtering (dichroic mirror: ZT488/640rpc 2 mm, Chroma, Bellows Falls, VT; emission filter: FF01538/685-25, Semrock, Rochester, NY), fluorescence images were recorded using a back-illuminated, nitrogen-cooled CCD camera (Roper Scientific Micro Max 1300-PB; PI Acton, Trenton, NJ). The temperature during experiments was maintained at $37^{\circ} \mathrm{C}$ by means of an in-house-built incubator box equipped with a heating unit and an objective heater (PeCon, Erbach, Germany). Briefly, after recording a pre-bleach image with a power density of $\sim 2 \mathrm{~kW} / \mathrm{cm}^{2}$ and an illumination time of $t_{\text {ill }}=2 \mathrm{~ms}$, the sample was bleached for $t_{\text {bleach }}=400 \mathrm{~ms}$ with a 5-fold higher power density. After an adjustable recovery time, $t_{\text {recover }}=0.5-3 \mathrm{~s}$, up to 20 images with a typical delay of 20 ms were recorded with same settings as used for the pre-bleach image. To confirm that bleaching was complete, an optional experiment was carried out with a recovery time of $t_{\text {recover }}=1 \mathrm{~ms}$. Then the recovery time was increased to allow for the reentry of unbleached GPI-mGFP molecules from the shielded region. The first recorded image after the adjustable recovery time, $t_{\text {recover }}$ was used for brightness analysis (TOCCSL image), and the last image was used to determine the single-molecule brightness of mGFP. Due to the low bleach stability of GFP, the probability of observing more than one active GPI-mGFP per diffraction-limited spot in the last image is negligible.

\subsection{Measurement of Intracellular Calcium Levels}

For calcium measurements MCF-7 cell line was used. Cells were loaded with $10 \mu \mathrm{M}$ Fura-2 AM (F1221, Thermo Scientific) at a final concentration of $10 \mu \mathrm{M}$ for 45 minutes at $37^{\circ} \mathrm{C}$ followed by a 30 minutes incubation at $37^{\circ} \mathrm{C}$ without the probe. Cells suspensions with an optical density of 0.15 at $380 \mathrm{~nm}$ were measured for change in fluorescence ratio of $\mathrm{Ca}^{2+}$ bound and $\mathrm{Ca}^{2+}$ free probe as described in manufacturers protocol. Heat treatments were carried in the heated sample holders of fluorimeter. 
The fluorescence signal was measured with a PTI spectrofluorometer (Photon Technology International, Inc., South Brunswick, NJ, USA) with emission at $510 \mathrm{~nm}$ and dual excitation at 340 and $380 \mathrm{~nm}$ (slit width $5 \mathrm{~nm}$ ). The autofluorescence from the cells not loaded with the dye was subtracted from the Fura-2 signal. Calculations for the calcium concentration was carried as described in Palmer and Tsien (2006). Briefly measurements were carried in $0.05 \%$ Triton in HEPES buffered HBSS containing $3 \mathrm{mM}$ EGTA for the completely ion-free indicator and $10 \mathrm{mM} \mathrm{CaCl}_{2}$ for ionsaturated indicator using the given formula;

$$
\left[\mathrm{Ca}^{2+}\right]=\mathrm{K}_{\mathrm{d}} \mathrm{Q} \frac{\left(\mathrm{R}-\mathrm{R}_{\min }\right)}{\left(\mathrm{R}_{\max }-\mathrm{R}\right)}
$$

where $R$ represents the fluorescence intensity ratio $F \lambda_{1} / F \lambda_{2}$, in which $\lambda 1(\sim 340 \mathrm{~nm}$ ) and $\lambda 2(\sim 380 \mathrm{~nm})$ are the fluorescence detection wavelengths for the ion-bound and ion-free indicator, respectively. Ratios corresponding to the titration end points are denoted by the subscripts indicating the minimum and maximum $\mathrm{Ca}^{2+}$ concentration. $Q$ is the ratio of $F_{\min }$ to $F_{\max }$ at $\lambda_{2}(\sim 380 \mathrm{~nm}) . \mathrm{Kd}$ is the $\mathrm{Ca}^{2+}$ dissociation constant of the indicator described by the manufacturer as $0.14 \mu \mathrm{M}$.

\subsection{Lipidomics Analysis by MS-MS}

GPI-mGFP-expressing $\mathrm{CHO}$ cells were treated at specified temperatures for 20 min, washed twice with cold PBS, collected in Eppendorf tubes $\left(1.4 \times 10^{6}\right.$ cells per tube), and centrifuged. The pellets were shaken in $1 \mathrm{~mL}$ of methanol containing $0.001 \%$ butylated hydroxytoluene as an antioxidant, for $10 \mathrm{~min}$, and centrifuged at $10,000 \times g$ for $5 \mathrm{~min}$. The supernatant was transferred into a new Eppendorf tube and stored at $-20^{\circ} \mathrm{C}$ (Péter et al. 2017).

Lipid standards were obtained from Avanti Polar Lipids (Alabaster, $A L$ ). The solvents used for extraction and for MS analyses were of liquid chromatographic grade (Merck, Darmstadt, Germany) and Optima LCMS grade from Thermo Scientific 
(Waltham, MA). All other chemicals were purchased from Sigma-Aldrich (Steinheim, Germany) and were of the best available grade.

MS analyses were performed using an LTQ-Orbitrap Elite instrument (Thermo Scientific, Bremen, Germany) equipped with a robotic nanoflow ion source TriVersa NanoMate (Advion BioSciences, Ithaca, NY). Lipid classes and species were annotated according to the lipid classification systems (Fahy et al. 2009), and the lipids were identified by LipidXplorer software (Herzog et al. 2011). Further measurement details are provided in the Supplementary methods. Lipidomics data are presented as the mean $\pm S D$; statistical significance was determined by Student's t-test and was accepted for $p<0.05$. O-PLS-DA and cluster analyses of lipidomics datasets were performed using MetaboAnalyst (Xia and Wishart 2011).

The LTQ-Orbitrap Elite instrument (Thermo Fisher Scientific Bremen, Germany) equipped with a robotic nanoflow ion source TriVersa NanoMate (Advion BioSciences, Ithaca, NY), using chips with $5.5 \mu \mathrm{m}$ diameter spraying nozzles. The ion source was controlled by Chipsoft 8.3.1 software (Advion). The ionization voltages were $+1.3 \mathrm{kV}$ and $-1.9 \mathrm{kV}$ in positive and negative mode, respectively, and the backpressure was set at 1 psi in both modes. The temperature of the ion transfer capillary was $330^{\circ} \mathrm{C}$. Data acquisition was performed at the mass resolution $\mathrm{Rm} / \mathrm{z} 400=240,000$.

Phosphatidylcholine (PC, diacyl, and PC-O, alkyl-acyl), lysophosphatidylcholine (LPC), and sphingomyelin (SM) were detected and quantified in the positive ion mode; phosphatidylethanolamine (PE, diacyl, and PE-PI, alkenyl-acyl), lysophosphatidylethanolamine (LPE), phosphatidylinositol (PI), lysophosphatidylinositol (LPI), phosphatidylserine (PS), phosphatidic acid (PA), phosphatidylglycerol (PG), cardiolipin (CL), ceramide (Cer), glucosyl ceramide (GICer), and ganglioside (GM3) were detected and quantified in the negative ion mode.

For quantification, $10 \mu \mathrm{L}$ of the lipid extract was diluted with $140 \mu \mathrm{L}$ of the infusion solvent mixture (chloroform:methanol:iso-propanol, 1:2:1, by vol.) containing an internal standard mix (71 pmol PC d31-16:0/18:1, 25 pmol PE d3116:0/18:1, 11 pmol PI d31-16:0/18:1, 19 pmol PS d31-16:0/18:1, 2.5 pmol PG d31- 
16:0/18:1, 1 pmol PA d31-16:0/18:1, 1.5 pmol CL 56:0, 5 pmol SM d18:1/17:0, 2 pmol Cer d18:1/17:0, 3 pmol GICer d18:1/12:0 and 5 pmol GM3 d3-d18:1/18:0). Next, the mixture was split in two, and 5\% dimethylformamide (additive for the negative ion mode) or $3 \mathrm{mM}$ ammonium chloride (additive for the positive ion mode) were added to the sample halves. Each quantified lipid species accounted for more than $0.5 \%$ of the respective lipid class. The mass tolerance was $3 \mathrm{ppm}$. Data files generated by LipidXplorer queries were further processed by in-house Excel macros.

\subsection{Plasma Membrane Isolation}

Plasma membrane was isolated from CHO-GPI-mGFP cells right after given heat shock treatment to investigate the changes in the total lipid composition. This isolation method was carried out as described in Maeda et al. (1983). Briefly, 5 x 10 $\mathrm{cm}$ plates were seeded with 250 cells $/ \mathrm{mm}^{2}$ density and grown in complete medium for 24 hours. After given heat treatments cells were washed 3 times with ice cold PBS, scraped and collected in $1 \mathrm{ml}$ ice cold TNM buffer $(10 \mathrm{mM} \mathrm{NaCl}, 1.5 \mathrm{mM} \mathrm{MgCl} 2,10$ $\mathrm{mM}$ Tris- $\mathrm{HCl} \mathrm{pH} \mathrm{7.4).} \mathrm{Cell} \mathrm{lysis} \mathrm{carried} \mathrm{out} \mathrm{using} \mathrm{glass} \mathrm{beads.} \mathrm{After} \mathrm{inspecting} \mathrm{lysate}$ under the microscope, it was spun at $3000 \mathrm{rpm}$ for 5 minutes at $4^{\circ} \mathrm{C}$. Supernatant was collected and centrifuged at $8800 \mathrm{rpm}, 4^{\circ} \mathrm{C}$ for $15 \mathrm{~min}$ in $\mathrm{F} 28 / 13$ rotor in a Sorwall super-speed centrifuge (RC28C). Supernatant was discarded and pellet was resuspended gently in $8 \mathrm{~mL}$ of TNM buffer. Parallel to this $36 \%$ sucrose in TNM buffer was prepared and $4 \mathrm{ml}$ filled in ultra-centrifuge tubes on top of which re-suspended pellet was delicately layered. The tubes were centrifuged at $27000 \mathrm{rpm}, 4^{\circ} \mathrm{C}$ for $3 \mathrm{~h}$ in SW41 rotor (sorvall WX Ultra Series, Thermo Fischer Scientific). Interphase of each sample was collected into TNM buffer and centrifuged again at $27000 \mathrm{rpm}, 4^{\circ} \mathrm{C}$ for 1 $\mathrm{h}$ in SW41 rotor. Supernatant was removed and the pellet (PM fraction) was dissolved in 10uL ultrapure water for further analysis. 


\subsection{Plasma membrane sheet preparetion}

Cells were grown on poly-L-lysine treated coverslips over night. Cells were rinsed with ice-cold PBS and rinsed with cold hypotonic buffer $(23 \mathrm{mM} \mathrm{KCl}, 10 \mathrm{mM} \mathrm{HEPES} \mathrm{pH}$ 7.5, $2 \mathrm{mM} \mathrm{MgCl}$, 1mM EGTA) three times which causes cells to swell are then placed into sonication buffer (70 mM KCl, $30 \mathrm{mM}$ HEPES pH 7.5, $5 \mathrm{mM} \mathrm{MgCl} 2,3 \mathrm{mM}$ EGTA) containing beaker. Sonication was carried out with 19mm-tip fitted Branson sonifier cell disruptor B-30 with optimized operation settings (power 1.5, duty cycle $80 \%$ ) for 3 times. Finally sonicated coverslip was rinsed with sonication buffer to be further used for the microscopy experiments.

\subsection{Cell sorting}

Sorting experiments were carried on using BD FACSJazz instruments. $\mathrm{CHO}$ cells expressing GPI-mGFP construst grown in normal growth conditions for $24 \mathrm{~h}$ were stained with $20 \mathrm{ug} / \mathrm{mL}$ Hoechst 33342 for 30 minutes and trypsinized. 300.000 cells were sorted based on the cell cycle stages according to Hoechst histogram using $450 / 50 \mathrm{~nm}$ filter set excited by $405 \mathrm{~nm}$ laser. To remove doublets and triplets from sorting, hoechst intensity versus signal duration graph was used as discussed in Wersto et al. (2001) (Figure 2.2) and only the Unsorted and unstained samples were also analyzed to confirm experimental artifacts. 
A

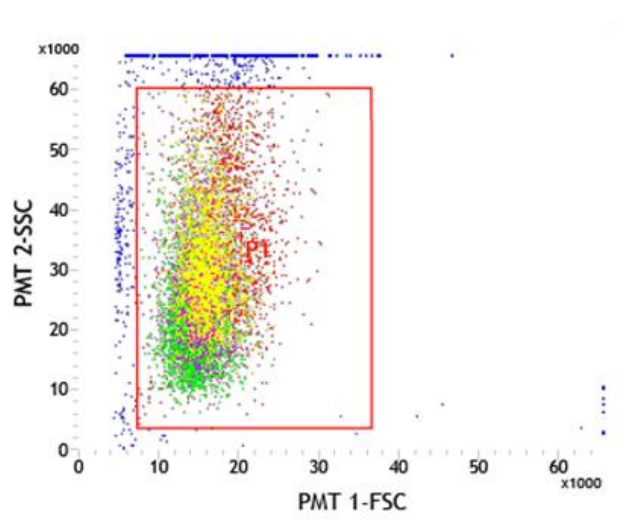

B

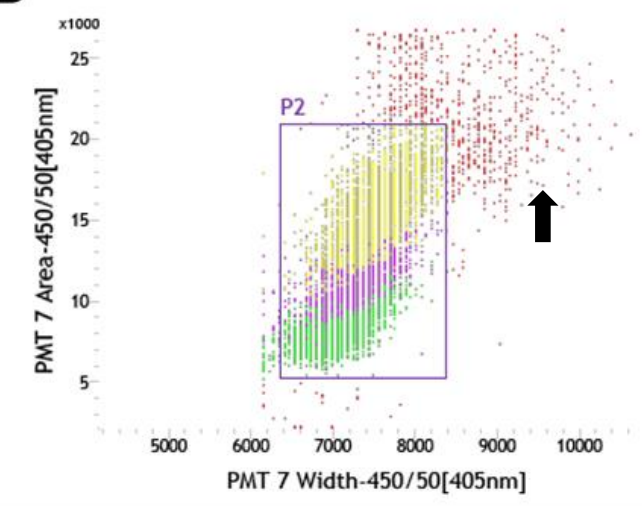

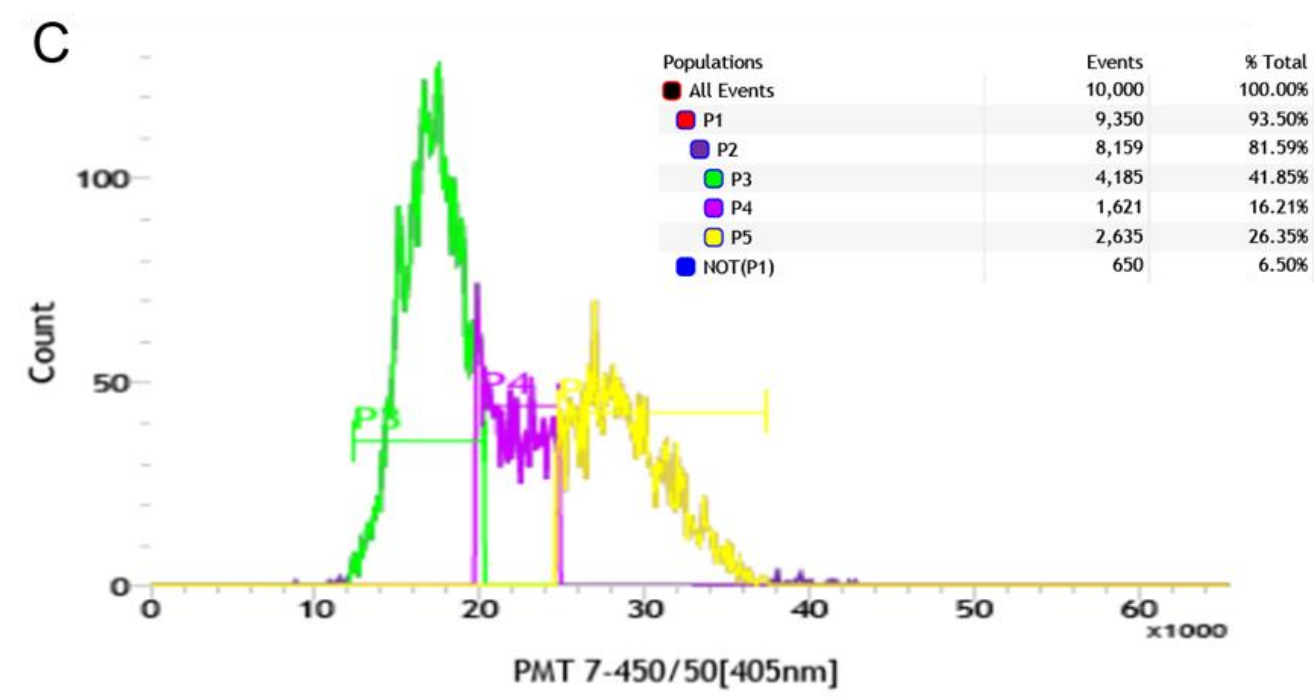

Figure 2.2 Representative data for fluorescence activated cell sorting. $\mathrm{CHO}$ cells expressing GPI-mGFP construct were sorted based on the given selection. For separating cells from cellular debris forward scatter (FSC) and side scatter (SSC) plots were drawn $(A)$ and 93.5\% (P1) of the objects were selected for the subsequent cell cycle analysis. As doublets and G2 phase cells have the same amount of DNA, area (Hoechst intensity) and width (time) of the detected intensity were plotted (B) to separate the doublets (marked with arrow) on P2 (81.5\%). G1 (P3-41.85\%), S (P416.21\%) and G2 (P5-26.35\%) were selected based on the Hoechst intensity histogram (C). 


\section{RESULTS AND DISCUSSION}

\subsection{HEAT-STRESS SENSING}

In order to create a better understanding on how cells sense and respond to stress, the effect of heat on HSP induction was analyzed in parallel with the changes in the membrane structure, acquired thermotolerance, lipid composition and stress signalling pathways.

\subsubsection{Heat shock proteins are induced differentially during heat stress}

Heat stress induces the HSPs depending on the level and the duration of the treatment that is the dose of heat. How the signals are generated during heat treatment and initiation of the induction of proteins are very much dependent on the dose. We therefore conducted systematic experiments to reveal the protein induction patterns of different doses of treatments using $\mathrm{CHO}$ cells with GPI-mGFP reporter construct. GPI linked proteins are preferentially localized in the ordered microdomains of plasma membrane, therefore they are useful tools to study the changes in the organization of the plasma membrane. For that reason, $\mathrm{CHO}$ line expressing GPI-mGFP construct was used in all experiments unless it is stated otherwise.

Westerblot analysis experiments revealed a distinct profile of HSP induction (Figure 3.1). $40^{\circ} \mathrm{C}$ did not increase the level of HSPs whereas $42.5^{\circ} \mathrm{C}$ which is indicated as moderate stress resulted in increase in both HSP25 and HSP70 to a different extent. 10 minutes treatment was sufficient to raise HSP25 and HSP70 levels for CHO cells. The minimal heating time was app. 20 minutes for B16 F10 cell type (data not shown) for the HSP induction suggesting cell type dependence. For HSP70, there was a biphasic behaviour. The initial increase started after 10 minutes however a major ramp was observed after 40 minutes (Figure 3.1). These findings suggest a differantial regulation for HSP25 and HSP70 expressions. Minimum recovery time for HSP25 and HSP70 to be synthesized were measured to be 3 hours and 5 hours respectively after 1 hour heat treatment at $42.5^{\circ} \mathrm{C}$ (data not shown), therefore 6 hours recovery time is sufficient for the protein synthesis pointing a regulational difference at the 
transcriptional level. Moreover intron free HSP70 mRNA by-passes splicing machineries which is repressed during heat stress on the post-transcriptional level and also cap-dependent translation on the pre-translational level (Silver and Noble 2012). HSF1 binding and initiation of transcription however can be altered as reported by Trinklein et al. (2004). Chromatin co-immunoprecipitation experiments revealed a very different and specific pattern of HSF1 and HSF2 binding to several HSP promoter regions depending on the heat treatment or differentiation all of which could be possible regulatory mechanisms. Therefore further experiments are needed for a better understanding of the phenomenon. It is also important to note that a similar biphasic bahviour was observed in temperature dependent inductions of HSP70 (Figure 3.2); initial increase started at $42.5^{\circ} \mathrm{C}$ but the major increase was observed at $44^{\circ} \mathrm{C}$ after 20 minutes of treatment. Other HSPs, HSP60 and HSP9O showed minor but significant increase at $42.5^{\circ} \mathrm{C}$ and $44^{\circ} \mathrm{C}$. GRP78 an endoplasmic reticulum chaperone was induced only at $44^{\circ} \mathrm{C}$ that can be linked to protein unfolding/denaturation dependent trigger (Fulda et al. 2010).

A
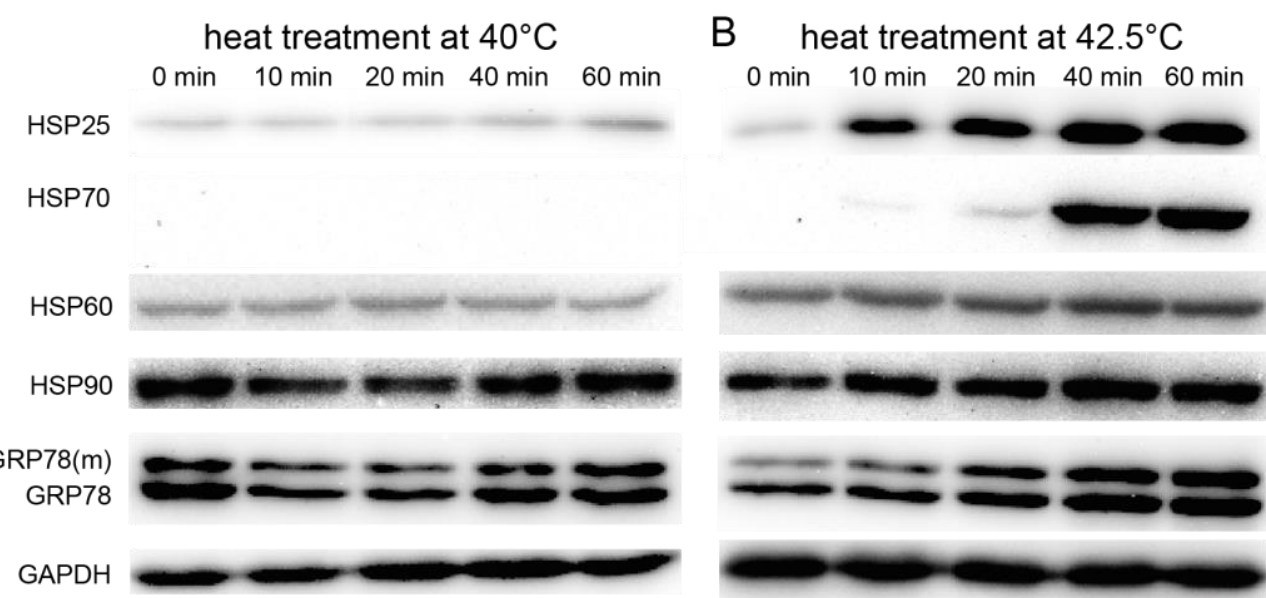

Figure 3.1 The effect of heat shock duration on HSP induction. A GPI-MGFP expressing $\mathrm{CHO}$ cell line was subjected to $40^{\circ} \mathrm{C}(\mathrm{A})$ and $42.5^{\circ} \mathrm{C}(\mathrm{B})$ heat for the specified time periods, and samples were prepared for western blotting after $6 \mathrm{~h}$ of recovery at $37^{\circ} \mathrm{C}$. 

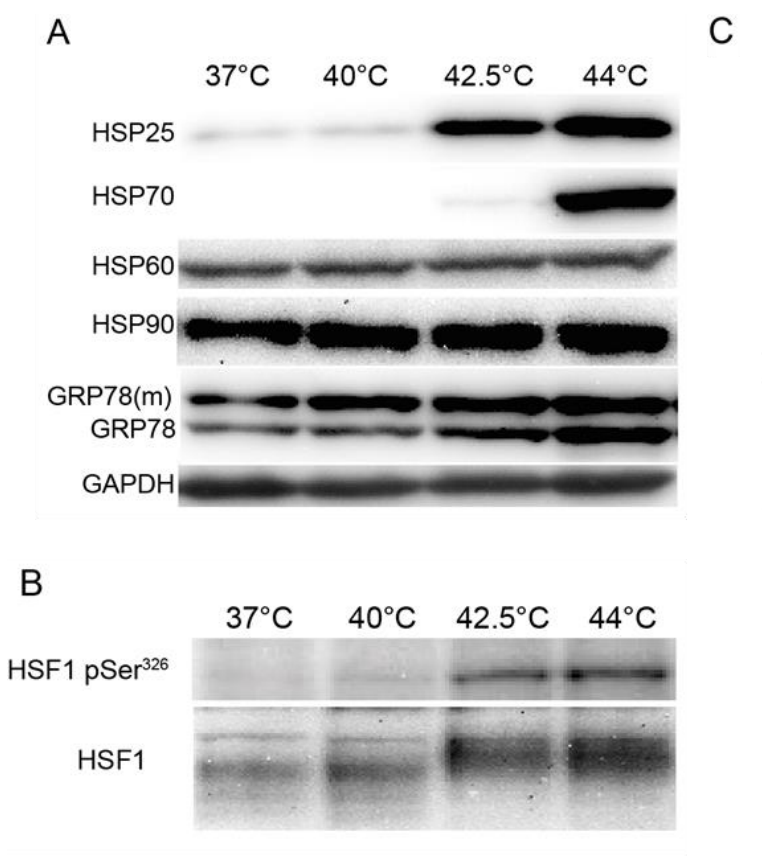

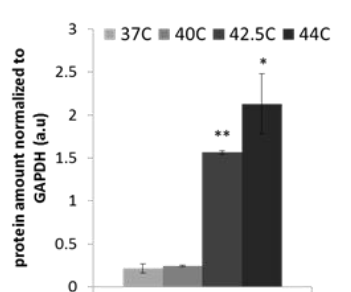

HSP25

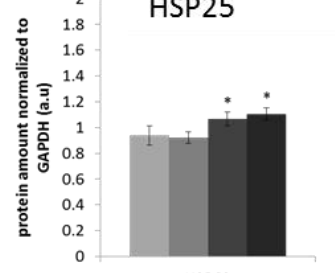

HSP60

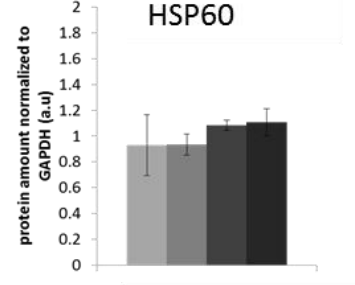

GRP78(m)

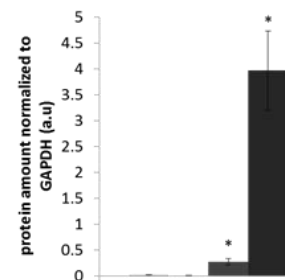

HSP70

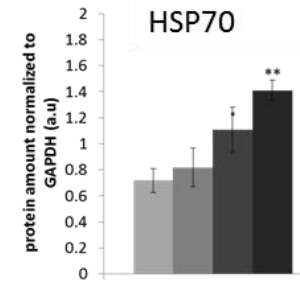

HSP90

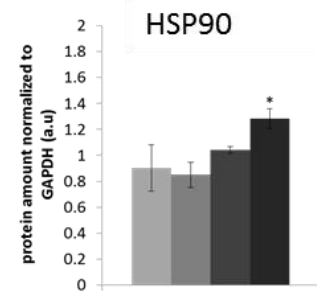

GRP78

Figure 3.2 The effect of temperature on HSP induction and HSF1 activation. (A) A GPI-mGFP-expressing CHO cell line was subjected to a 20-min of incubation at the specified temperatures; the samples were prepared for western blotting after $6 \mathrm{~h}$ of recovery at $37^{\circ} \mathrm{C}$. (B) HSF1 phosphorylation was analyzed in samples after 20 min of heat treatment without recovery. Data are represented as Mean $\pm S E M, N=3, * p<0.05$ and ${ }^{* *} p<0.01$ compared to $37^{\circ} \mathrm{C}$.

HSF1, the major orchestrator of the HSP synthesis is modified before it interacts with heat shock elements and then starts the transcription of heat shock proteins. Not all the modifications result in HSP transcription, but a specific phosphorylation site on Serine 326 is shown to be correlated with HSP induction (Guettouche et al. 2005) Therefore we investigated both the total HSF1 modifications as bandshift and phosphorylation on Ser326. In these experiments, sample collection was done right after 20 minutes of heat treatment. The observed phosphorylation and increase in the molecular weight of HSF1 was observed at $42.5^{\circ}$ and $44^{\circ} \mathrm{C}$ seemingly in a comparable extent. No change was observed at $40^{\circ} \mathrm{C}$ in HSF-1 post translational modifications in line with abscence of HSP induction (Figure 3.2 (B)). 


\subsubsection{Heat shock protein redistribution is dependent on the level of heat}

stress

One of the concequence of HSR is the redistribution of HSPs within the cellular compartments to prevent and protect the protein aggregation (Velazquez and Lindquist 1984). In order to investigate redistribution patterns of the most heat inducible HSPs; HSP25 and HSP70 were monitored after 20 minutes heat treatment which was found to be sufficient to cause an increase in protein levels at $42.5^{\circ} \mathrm{C}$ (Fig 3.1). Both HSP25 and HSP70 were found to be transiently localized to nucleus in a dose dependent manner (Figure 3.3).

HSP70 localization in the nucleus was reported to protect thermo labile proteins while forming a large insoluble loci for aggretated proteins. Its translocalization is aided and specific through binding partners and carrier proteins (Kose and Imamoto 2014; Velazquez and Lindquist 1984). At $40^{\circ} \mathrm{C}$ in the majority of the cells HSP70 showed nuclear accumulation which was enhanced further at $42.5^{\circ} \mathrm{C}$ with the apperance of nuclear spots. At $44^{\circ} \mathrm{C} \mathrm{HSP70}$ was localized in the particular spots in the perinuclear area.

Heat induced HSP25 relocalization was in a similar fashion; increased nuclear localization at $40^{\circ} \mathrm{C}$ and $42.5^{\circ} \mathrm{C}$ but a perinuclear appearance at $44^{\circ} \mathrm{C}$. Interestingly, HSP25 was more heterogenous at $40^{\circ} \mathrm{C}$ and less reponsive compared to HSP70 in terms of nuclear enrichment. This effect was also not in line with protein induction experiments where HSP25 was shown to be more responsive to heat with a significant induction at a lower stress dose. HSP25 slows down the heat induced aggregation in vitro and binding of heat denatured nucleosolic proteins may serve for the subsequent chaperoning or degradation of the bound proteins (Bryantsev et al. 2007; Hayes et al. 2009). Although some reports suggests a phosphorylation dependent translocalization, both the phosphorylation mutant version and treatment with kinase inhibitors are failed to inhibit accumulation in the nucleus in support of our results (Figure 3.4) where major phosphorylation was observed at $44^{\circ} \mathrm{C}$ in two possible residues Serine 15 and Serine 86. 


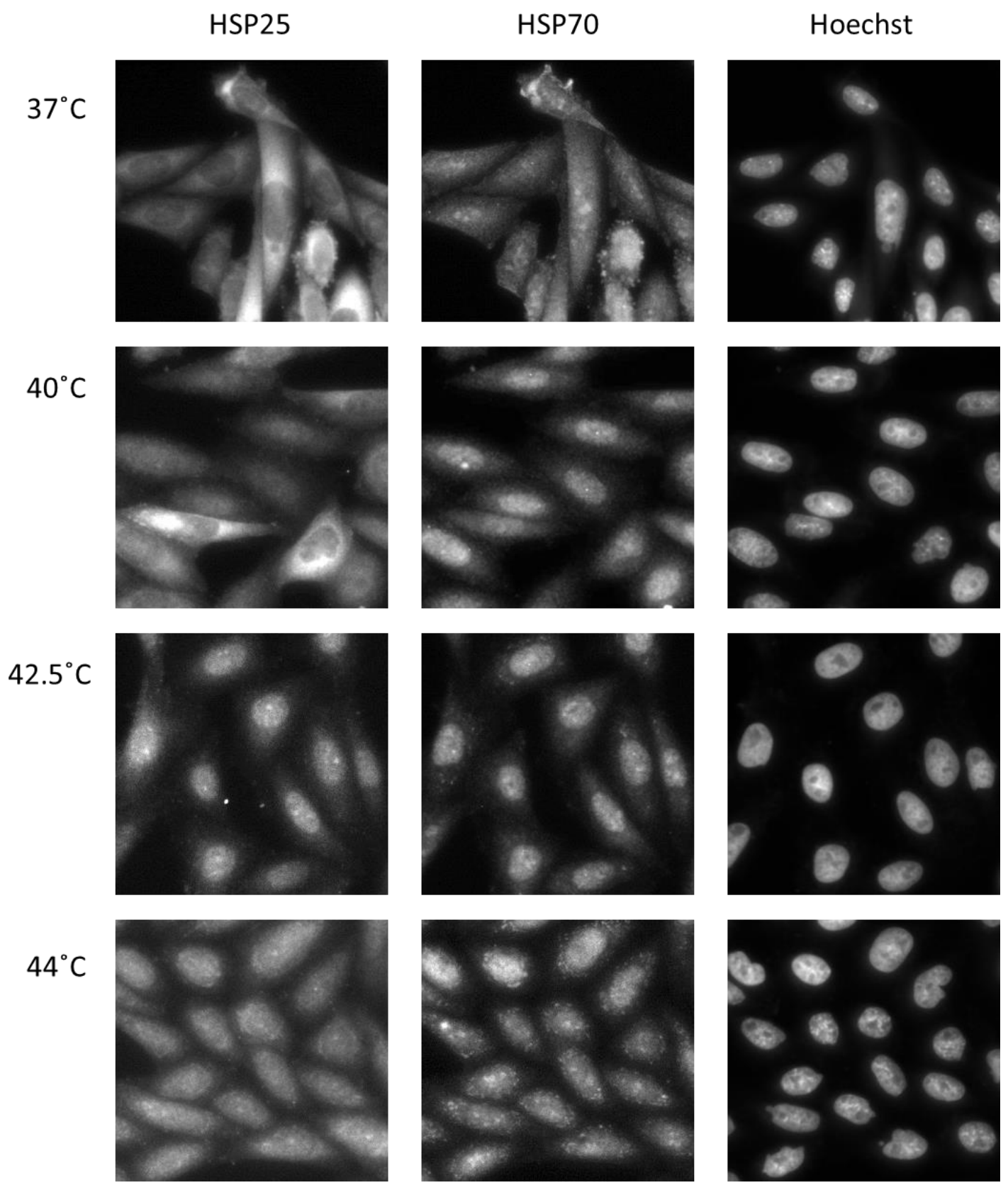

Figure 3.3 Redistibution of HSPs is dose dependent. Representative images $(n=40)$ of $\mathrm{CHO}$ cells after a 20-min heat treatment at the indicated temperatures are shown. 
HSP27 pSer15

HSP25 pSer86

GAPDH

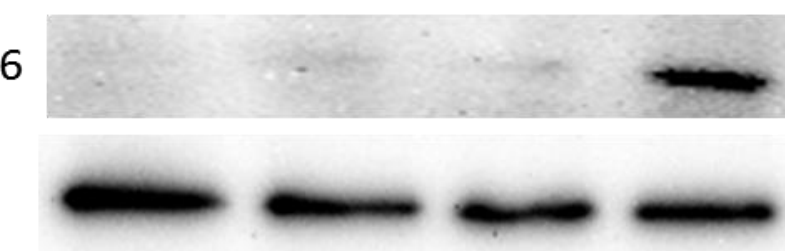

Figure 3.4 The effect of heat treatment on the phosphorylation status of HSP25. CHO cells harboring the GPI-mGFP construct were treated at a given temperature for 20 min before sample preparation for western blotting.

\subsubsection{Acquired thermotolerance is highly dependent on stress dose}

Ability to withstand a subsequent stress is observed in the heat shocked cells. Acquired thermotolerance is often related with the induction of HSPs and their antiapoptotic functions (Yokota et al. 2003; Kennedy et al. 2014). HSF-1 knock-out cell lines are shown not to gain thermotolerance, and transfecting HSP25 and HSP70 constructs to HSF-1 knock out cell line does not restore ATT (Luft et al. 2001). In order to test the effect of heat dose on the increased survival ATT assay was carried out. $\mathrm{CHO}$ cells were treated with $40^{\circ} \mathrm{C}, 42.5^{\circ} \mathrm{C}$ and $44^{\circ} \mathrm{C}$ for 20 minutes. After recovery period at $37^{\circ} \mathrm{C}$ for 6 hours, a lethal heat treatment was performed at $46^{\circ} \mathrm{C}$ for 20 minutes. Cells which were not heat shocked before showed very poor survival after (Fig 3.5A). As expected at $42.5^{\circ} \mathrm{C}$ and $44^{\circ} \mathrm{C}$ where HSP induction was observed, survival was above $50 \%$. However, $40^{\circ} \mathrm{C}$ treatment resulted in significant ATT (Figure 3.5A) suggesting the involvement of other factors which can contribute to better survival. Moreover at $42.5^{\circ} \mathrm{C}$ treatment for 20 minutes resulted in an increase of HSP25 (Figure 3.1C), whereas at $44^{\circ} \mathrm{C}$ both HSP25 and HSP70 were induced (Figure 3.1C). Therefore it is not possible to link the survival to either HSPs alone. 

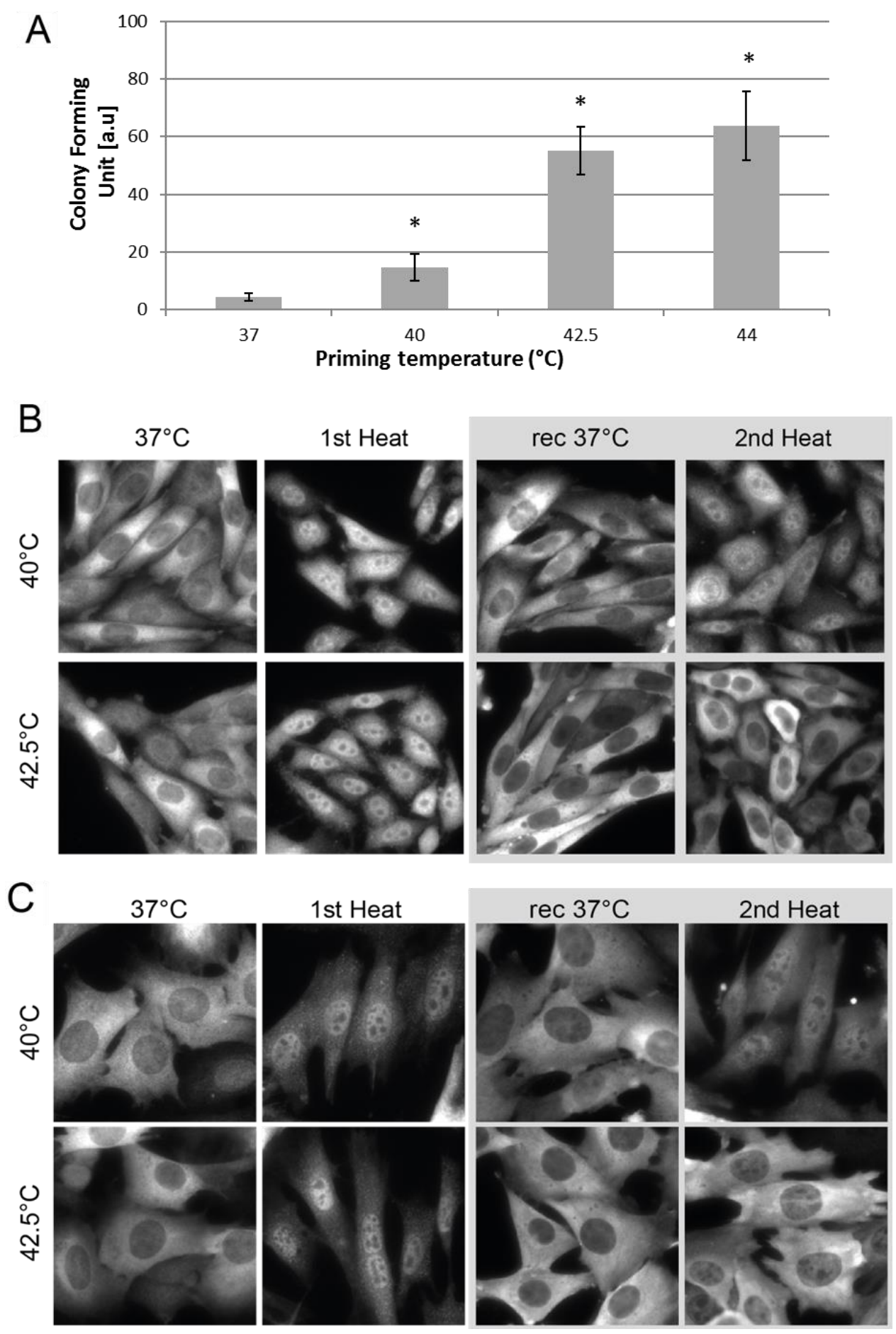

Figure 3.5 Different heat treatments affect ATT in a distinct manner. CHO cells were treated at given temperatures for 20 minutes followed by a recovery period of 6 hours at $37^{\circ} \mathrm{C}$ and a subsequent heat treatment at $46^{\circ} \mathrm{C}$ in order to test the survival $(A)$. Cellular localizations of HSP25 were tested after two subsequent heat treatments separated with 6 hours of recovery at $37^{\circ} \mathrm{C}$ in $\mathrm{CHO}(B)$ and $M E F(C)$ cells. All treatments were carried out for 20 minutes at given temperatures. 
Next, the effect of thermotolerance was tested on HSP25 translocation to the nucleus in a modified thermotolerance assay. $\mathrm{CHO}$ cells were treated with $40^{\circ} \mathrm{C}$ and $42.5^{\circ} \mathrm{C}$ for 20 minutes and returned back to $37^{\circ} \mathrm{C}$ for recovery period of 6 hours in order to allow HSP25 synthesis to occur. Then a second heating cycle was carried out with the same temperatures. As expected translocation to nucleus occurred at $40^{\circ} \mathrm{C}$ in a more heterogeneous context whereas at $42.5^{\circ} \mathrm{C}$ it occurred more uniformly (Figure 3.5B). After the recovery period, at both $40^{\circ} \mathrm{C}$ and $42.5^{\circ} \mathrm{C}$ treatments, nuclear HSP25 was lowered and cytoplasmic signal was observed. Moreover, at $42.5^{\circ} \mathrm{C} \mathrm{HSP} 25$ signals increased supporting Western blot experiments (Figure 3.1C). After the second heating cycle, the effect of $40^{\circ} \mathrm{C}$ was similar to the first heating cycle. As for $42.5^{\circ} \mathrm{C}$, nuclear enhancement did not occur despite the fact that the nuclear HSP25 signals were found to be comparable (data not shown).

\subsubsection{Cells promptly respond to heat by remodelling plasma membrane}

Heat stress is shown to induce the alterations in the physical properties of plasma membrane such as fluidity and microdomain organization (Török et al. 2014). In order to reveal the temperature dependent changes at mild and moderate stress camera based type of Fluorescence Correlation Spectroscopy (FCS) was used to monitor lateral diffusion and confinement properties of fluorescent probes in relatively high temporal resolution. Total internal reflection fluorescence microscopy allows to carry the measurements with a depth of $100 \mathrm{~nm}$ into the sample, therefore restricting the observations to the plasma membrane region. After post-analysis of the images, diffusion coefficients $(D)$ and diffusion times $\left(\tau_{0}\right)$ were calculated which describe the lateral diffusion of the probe and the membrane organization, respectively. In the membrane there are three diffusion modes; hop diffusion $\left(\tau_{0}<0\right)$, free diffusion $\left(\tau_{0}=0\right)$ and confined diffusion $\left(\tau_{0}>0\right)$ ( $\mathrm{Ng}, \mathrm{Bag}$, and Wohland 2015).

In $\mathrm{CHO}$ cells imaging GPI-mGFP revealed a significantly increased diffusion coefficient at $42.5^{\circ} \mathrm{C}$ whereas unexpectedly at $40^{\circ} \mathrm{C}$ it remained unchanged (Figure 3.6A). A possible explanation for sustained fluidity is the cells' ability to maintain the membranes by lipid modelling which was supported by the elevation of long chain 
sphingolipids and removal of lysophospholipids (Figure 3.9 and 3.10). In order to test this hypothesis, plasma membrane sheets were prepared by removing all the cellular structures with the use of sonication except the plasma membrane attached to the bottom of the coverslip. This methods allows the measurement of fluidity and lateral organization without any maintanance provided and it resulted in constant temperature dependent increase in diffusion coefficients including $40^{\circ} \mathrm{C}$ (Figure 3.6 C).

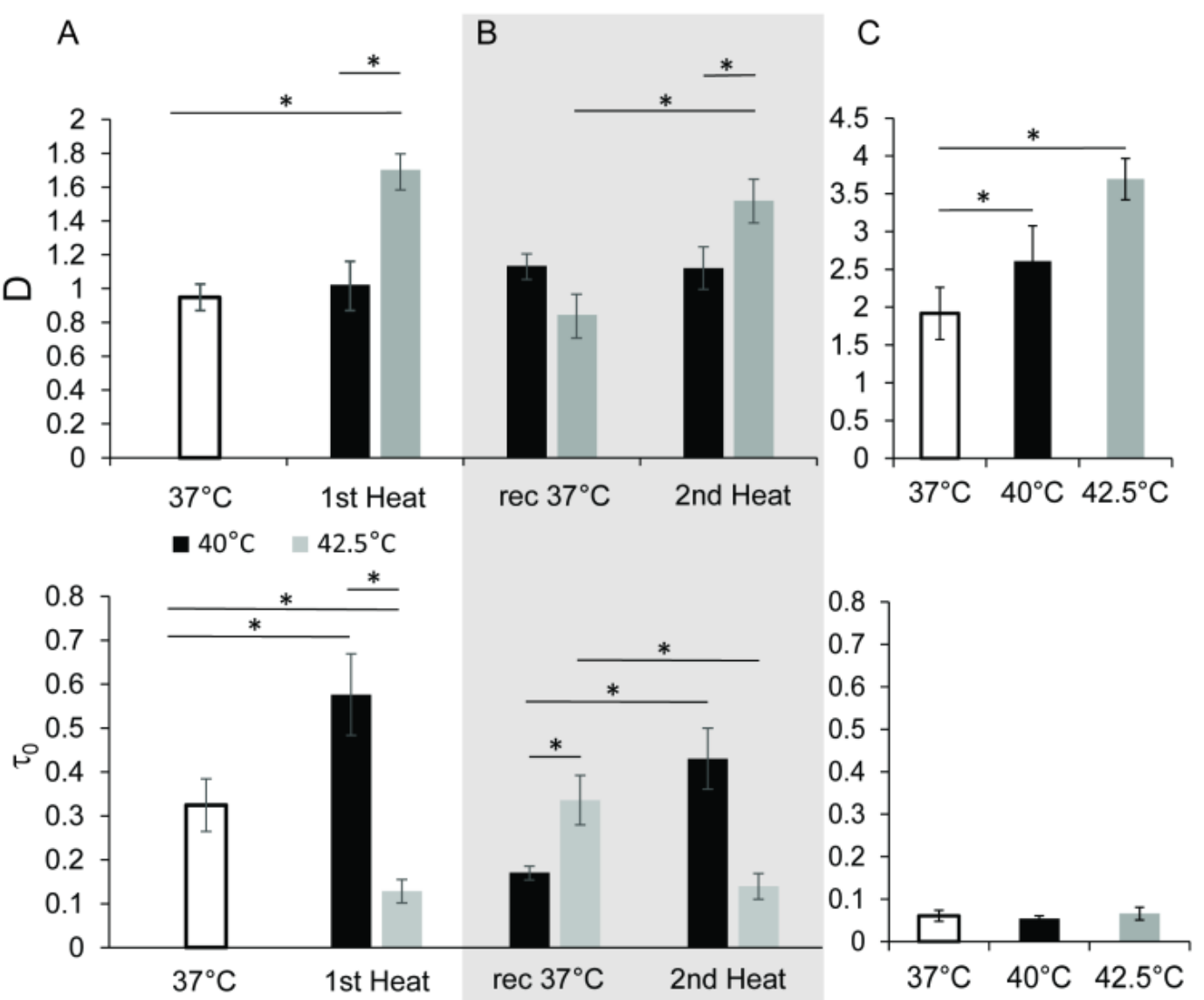

Figure 3.6 Lateral diffusion of GPI-mGFP behaves differently upon mild and moderate heat in live cells. Diffusion coefficient $(D)$ and diffusion time ( $\left.\tau_{D}\right)$ of GPImGFP on the surface of $\mathrm{CHO}$ cells at $37^{\circ} \mathrm{C}$ (white bars), $40^{\circ} \mathrm{C}$ (black bars) and $42.5^{\circ} \mathrm{C}$ (grey bars) after given heat treatments $(A)$, second heat cycle after 6 hours recovery period (B) and on CHO plasma membrane sheets (C). Error bars represents the standard error of mean $(S E M)(n=8, p<0.05)$. 
Positive diffusion time hence confined diffusion was observed at all temperatures, but under the effect of heat an increase confinement was observed at $40^{\circ} \mathrm{C}$ which was below the normal at $42.5^{\circ} \mathrm{C}$ (Figure $3.10 \mathrm{~A}$ ). Approximately $20-40 \%$ of GPI-anchored proteins on the membrane are present as clusters and the rest are monomers which are in a dynamic movement towards in and out of the relatively immobile nanoclusters (Sharma et al. 2004; Sengupta et al. 2011). Therefore the measured confinement is possibly due to these interactions with relatively immobile platforms. Increase confinement at $40^{\circ} \mathrm{C}$ can be due to cellular regulation and nucleation of GPI-mGFP clusters. Moreover, this effect was lost when the plasma membrane sheets were exposed to elevated temperature.

In order to understand the effect of second heating cycle on the membrane biophysics, experiment was repeated on the samples recovered for 6 hours after the first heating cycle with the same temperature regime. The heat induced changes were very similar to the first heating cycle for both $\mathrm{D}$ and $\tau_{\mathrm{D}}$ (Fig. 3.10B). On the other hand, in case of second $40^{\circ} \mathrm{C}$ treatment the GPI-mGFP diffusion was significantly less confined then before the first heating cycle (smaller $\tau_{\mathrm{D}}$ ).

\subsubsection{Lipidomics reveals distincts stress lipidomes}

In order to asses lipid changes occurring during heat shock comprehensively, electrospray ionization mass spectrometry based lipidomics analysis was carried out using total cellular membrane lipid extracts. Approximately 160 molecular species were identified and analyzed using this high-sensitivity and high-resolution shotgun lipidomics approach. Sparse partial least squares discriminant analysis revealed a clear separation of 4 temperature treatments; $37^{\circ} \mathrm{C}, 40^{\circ} \mathrm{C}, 42.5^{\circ} \mathrm{C}$ and $44^{\circ} \mathrm{C}$. Hierarchical clustering analysis was illustrated on the heat map depicts the changes occured in different temperatures (Figure 3.7). Mild $\left(40^{\circ} \mathrm{C}\right)$ and moderate $\left(42.5^{\circ} \mathrm{C}\right)$ stress resulted in $30 \%$ of the lipidome to be altered whereas severe $\left(44^{\circ} \mathrm{C}\right)$ stress altered $50 \%$ of the lipidome. 


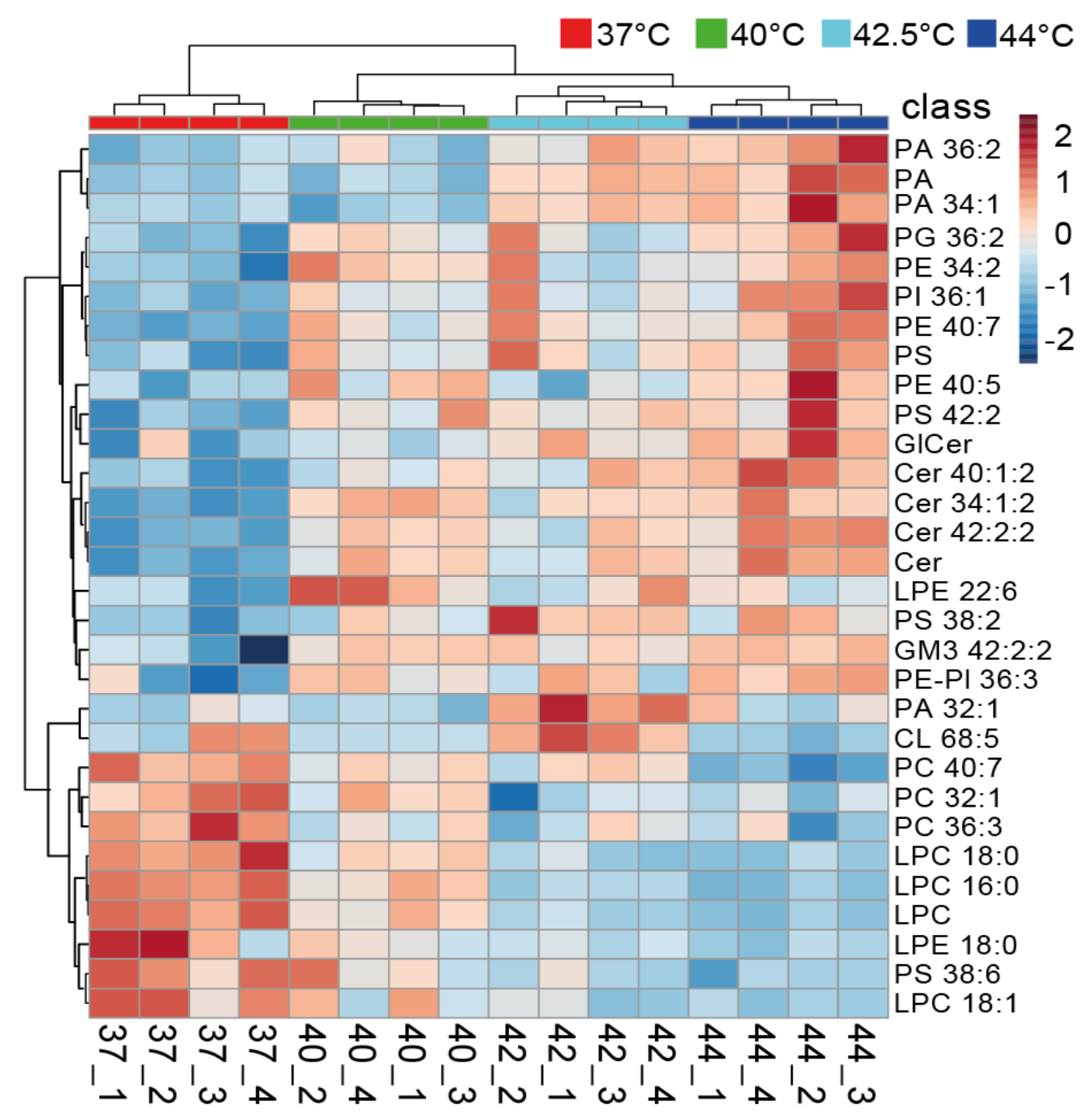

Figure 3.7 Characterization of lipidomes of GPI-mGFP-expressing CHO cells exposed to different levels of HS. Heatmap representation of hierarchical clustering of lipid profiles at $37^{\circ} \mathrm{C}, 40^{\circ} \mathrm{C}, 42.5^{\circ} \mathrm{C}$ and $44^{\circ} \mathrm{C}$. The top 30 most significant species were selected using ANOVA, Euclidean distance, and clustering algorithm Ward. The heat color-code represents normalized values (z-scores), ranging between [-2] (darkest shade of blue) and [+2] (darkest shade of red). Data from four independent experiments with control and HS-treated cells are shown. 
All mild, moderate and severe stress treatments resulted in distinct alterations in the lipid compositions. PA is a low abundant lipid of cellular membranes which can act as a second messenger and precursor for other lipids. Increase of intracellular PA is found to be linked to phosphorylation of Akt and mTOR-dependent signalling (Bromberg and Weiss 2016). Our results showed an increase in PA at moderate stress with further gradual increase as the temperature increases (Figure 3.8). Increase in PA is often related with the activation of PLD which hydrolyzes PC and PLC (Y. Liu, Su, and Wang 2013).
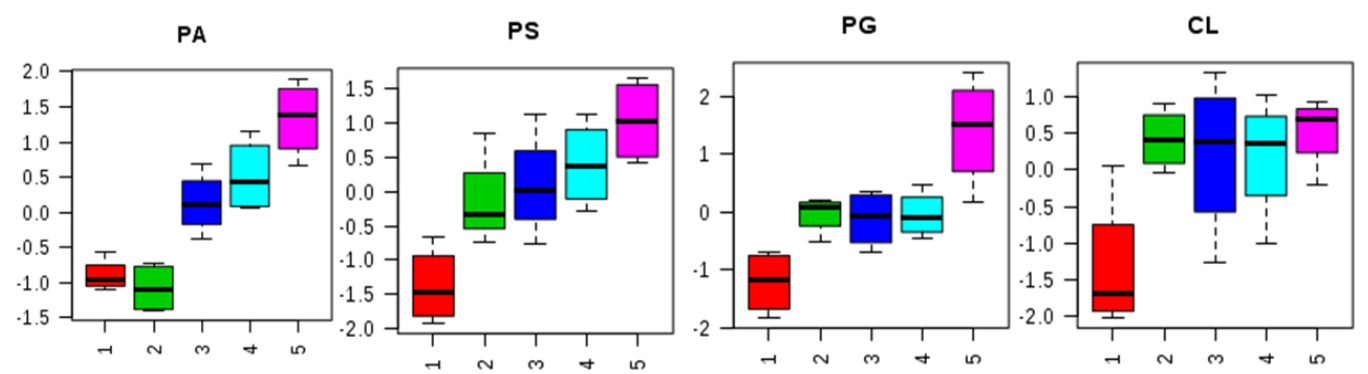

Figure 3.8 Key features of $\mathrm{HS}$-associated lipid remodeling of $\mathrm{CHO}$ lipidomes. $\mathrm{CHO}$ cells with GPI-mGFP constructs were either unstressed $\left(37^{\circ} \mathrm{C}(1)\right)$ or stressed at $40^{\circ} \mathrm{C}$ (2), $42.5^{\circ} \mathrm{C}$ (3), $44^{\circ} \mathrm{C}$ (4) and $46^{\circ} \mathrm{C}$ (5) for $20 \mathrm{~min}$. Phosphatidic acid (PA), phosphatidiyl serine (PS), phosphotidyl glycerol (PG) and cardiolipin (CL) levels were shown in arbitraty units normalized by mean-centering and dividing by the standard deviation of each variable.

At mild temperature $40^{\circ} \mathrm{C}$, a significant increase was observed in $\mathrm{PS}, \mathrm{PG}$ and $\mathrm{CL}$ (Figure 3.8). PS is a negatively charged phospholipid mainly found on the inner leaflet of the plasma membrane unless the cell enters the apoptotic pathway in which outer leaflet localization of PS is the hallmark. Increase of PS on the plasma membrane can have two outcomes; first it can attract membrane domains that can recognize the head group stereospecifically, secondly its negative charge can attract number of signalling molecules such as small GTPases (Kay and Grinstein 2013). CL which is a unique lipid mainly found in the mitochondrial membranes and has fundamental functions in maintaining functional integrity and mitochondrial dynamics. Alterations 
in the $\mathrm{CL}$ has very important consequences in the cell such as triggering apoptosis and causing an increase in ROS (X.-X. Li et al. 2015). In eukaryotes, the synthesis of CL is catalyzed from PG. Mutation of the enzyme responsible for this reaction causes the perturbation of mitochondrial metabolism, increased mitophagy and vacuolar defects under stress conditions (de Paepe, Lemaire, and Danon 2014). During mild stress, the accumulation of $\mathrm{CL}$ and its biosynthetic precursor $\mathrm{PG}$ is related to temperature induced mitochondrial biogenesis, aiding increased cellular respiration to supply the elevated energy demand of the cells during stressful conditions (C.-T. Liu and Brooks 2012).

Ceramide is a well documented lipid which are not only the constituents of the cell membranes but also second messengers. They can trigger specific responses that can reprogram the gene expressions causing the cell to poliferate, differentiate or undergo apoptosis. In addition sphingolipids are found to be one of the early responders to the stress (Chen et al. 2015). 

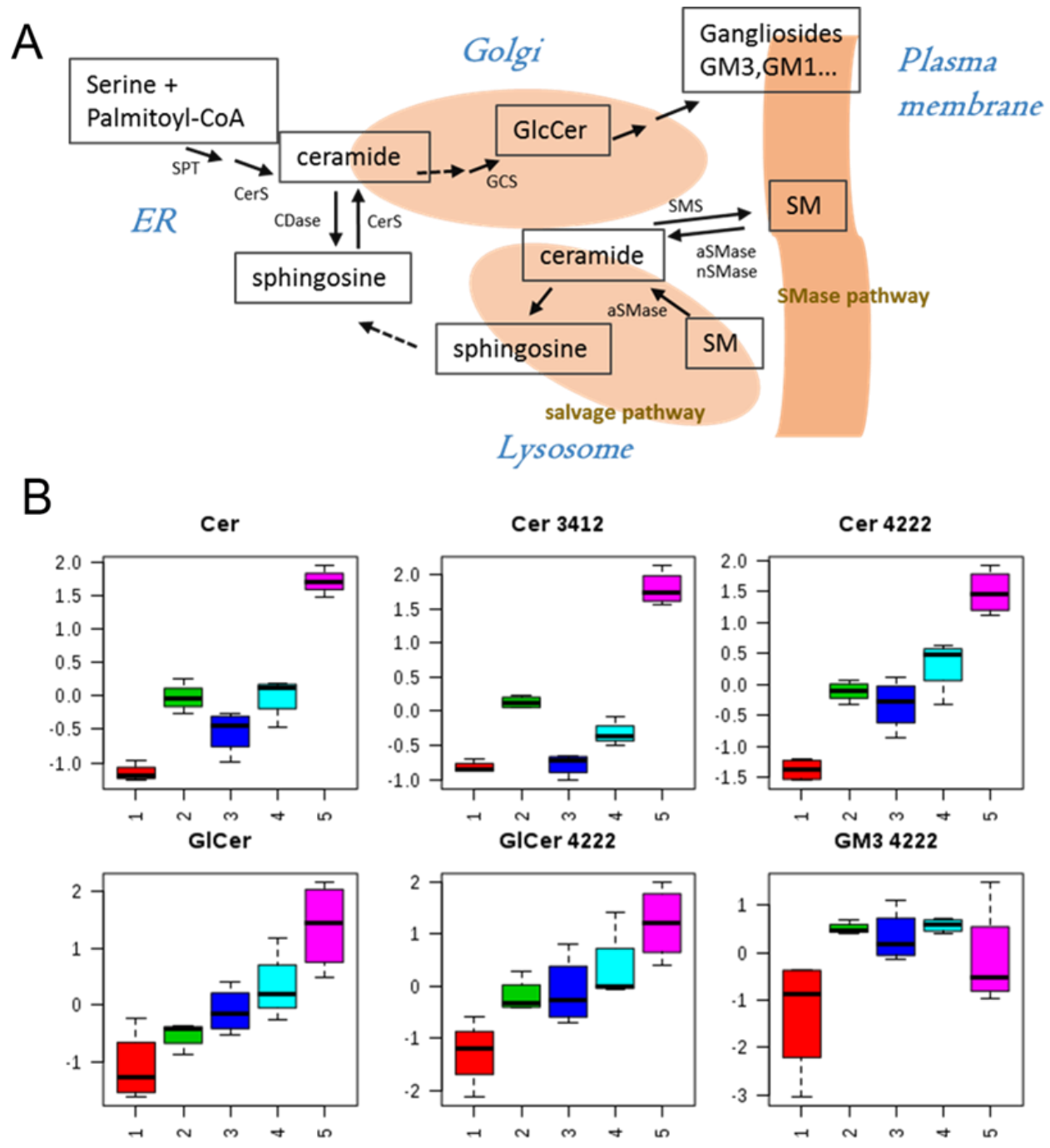

Figure 3.9 Heat induced changes in the ceramide metabolism. Biosynthetic pathways for ceramide synthesis are shown based on cellular compartments (A). Heat induced alterations after 20 minutes of treatment at $37^{\circ} \mathrm{C}(1), 40^{\circ} \mathrm{C}(2), 42.5^{\circ} \mathrm{C}$ (3), $44^{\circ} \mathrm{C}$ (4) and $46^{\circ} \mathrm{C}$ (5) in CHO cells with GPI-mGFP construct. Ceramide (Cer), Ceramide 34:1:2 (Cer 3412), Ceramide 42:2:2 (Cer 4222), Glucosylceramide (G/Cer), Glucosyceramide 42:2:2 (GLCer 4222) and Ganglioside GM3 42:2:2 (GM3 4222) levels were shown in arbitraty units normalized by mean-centering and dividing by the standard deviation of each variable. (Serine palmitoyltransferase (SPT), ceramide synthase (CerS), neutral (n) or acid (a) sphingomyelinase (SMase), ceramidase (CDase), glucosylceramide synthase (GCS), sphingomyelin synthase (SMS)). 
Our results showed a significant increase in ceramide levels (Figure 3.9B). Specially in the case of mild heat treatment at $40^{\circ} \mathrm{C}$, two ceramide species $34: 1: 2$ and 42:2:2 were significantly elevated as well as the total ceramide. At $42.5^{\circ} \mathrm{C}$ there was no further increase observed except Cer 34:1:2 where no change was measured. At $46^{\circ} \mathrm{C}$, the increase was much higher, however this treatment was carried to measure the change in a lethal, apoptosis inducing heat shock. Moreover complex sphingolipids were also shown to be elevated. Glucosyl ceramide and ganglioside GM3 elevation was measured to start at $40^{\circ} \mathrm{C}$ and increase further with increasing temperature (Figure 3.9B). A simplified illustration of the very complex sphingolipid metabolism is shown on Figure 3.9A. Briefly de novo ceramide synthesis occurs in the ER and then transported to Golgi apparatus either by vesicles or ceramide transfer proteins. Ceramide can be converted to glycosphingolipids either in ER or in golgi apparatus whereas sphingomyelin synthesis occurs either in golgi apparatus or in plasma membrane. However, there is evidence on ceramide synthesis in the plasma membrane from sphingosine through $\mathrm{Ca}^{2+} / \mathrm{Mg}^{2+}$ dependent ceramide kinases (Gault, Obeid, and Hannun 2010). Another pathway for ceramide synthesis in plasma membrane is the conversion of sphingomyelin to ceramide via sphingomyelinases. ASMase is predominanly a lysosomal enzyme, after its secretion into the extracellular space it can metabolize outer leaflet SM on the plasma membrane. An important regulation on this mechanism is reported to be $\mathrm{Ca}^{2+}$ directed endosomal trafficking to a specific area in the plasma membrane (Tam et al. 2010). nSMase can be found either in golgi or in plasma membrane and has preference for $\mathrm{C} 24: 0$ to $\mathrm{C} 24: 1$ species. Due to the complexity of the sphingomyelin synthesis, it is not possible to reveal the cellular compartment which is responsible for ceramide increase. Inhibitor based studies yet reports de novo synthesis pathway to be responsible (Gary M. Jenkins et al. 2002). Nevertheless independent of its origin, ceramide is capable of triggering signal transduction pathways which is highly important in lipid controlled heat shock response. JNK is a pro-apoptotic signalling pathway, PKC $\zeta$ and Ras can be activated with increased ceramide levels whereas PKC $\alpha$ and Akt can be inhibited (Ruvolo 2001). The activation of the signal transduction pathways can arise from the impact of ceramide in the biophysical features of the membranes since it has capability of promoting lateral segregation of lipid domains. It was shown that very long chain 
unsaturated ceramides ( $\mathrm{C} 24: 1$ ) can drive the formation of gel domains (Castro, Prieto, and Silva 2014) which is supported in our results as $42: 2: 2$ ceramide species shown to be increased both at $40^{\circ} \mathrm{C}$ and further within 10 minutes of treatment (Figure 3.9).
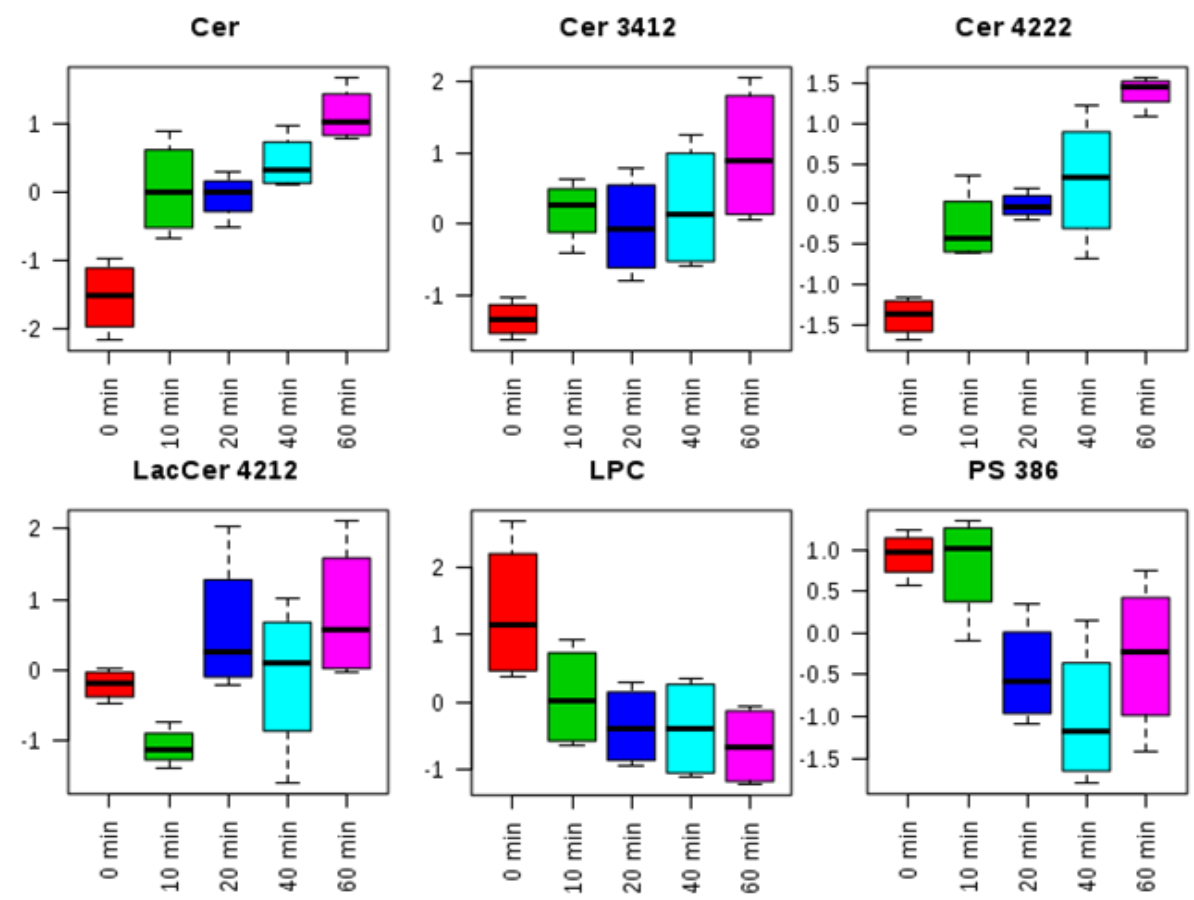

Figure 3.10 Time dependent key lipid changes in CHO cells with GPI-mGFP construct. Heat induced changes were measured at $42.5^{\circ} \mathrm{C}$ at $0,10,20,40$ and 60 minutes. Ceramide (Cer), Ceramide 34:1:2 (Cer 3412), Ceramide 42:2:2 (Cer 4222), Lactosylceramide 42:1:2 (LacCer 4212), Lysophosphatidylcholine (LPC), Phosphatidylserine 38:6 (PS 386) levels were shown in arbitraty units normalized by mean-centering and dividing by the standard deviation of each variable.

In order to investigate the time based differences, lipidomics analysis was performed at $42.5^{\circ} \mathrm{C}$ at different time points. As early as 10 minutes, changes in sphingolipid metabolism was observed (Figure 3.10). Ceramide species were elevated as the duration of stress increased. The prompt decrease in LacCer can be explained by catalysis of it for the formation of Cer, however further analysis are needed to prove the direct link and effect. Rapid elevation of sphingolipid species has been proposed to to trigger changes in several cellular processes, including transcription, translation, growth, and actin organization (Meier et al. 2005). Prompt increase in 
long FA containing complex sphingolipid (Figure 3.9 and 3.10) may support the reorganization of plasma membrane domains (Chen et al. 2015).

Another significant change was observed in lysoPC which was gradually decreased with time (Figure 3.10) and with the increased heat treatment (Figure 3.7). Due to its inverted cone shape, LysoPC is a strong curvature inducing and destabilizing lipid class. It is formed by the hydrolysis of PC by phospholipases. Therefore, these results suggest the activation of phospholipases by heat. Due to its curvature inducing properties, change in the plasma membrane structure can also be expected and in order to stabilize the heat induced fluidity, decreasing LysoPC species can be a good strategy of the cell. Therefore, the effect of exogenous addition of LysoPC on plasma membrane organization was tested. Although the increase of LysoPC was analyzed and confirmed by lipidomics analysis (Figure 3.11B), no effect on the integrity of GPImGFP nanoplatforms were observed (Figure 3.11A) (Brameshuber et al. 2016). There are reports on the effects of lysolipid induced phosphorylation of focal adhesion kinase (Schaller, Hildebrand, and Parsons 1999) and a possible transient receptor potential channel modulation (Taberner et al. 2015). Further experiments are needed in order to understand the baccground of heat induced changes in lysophospholipids. 

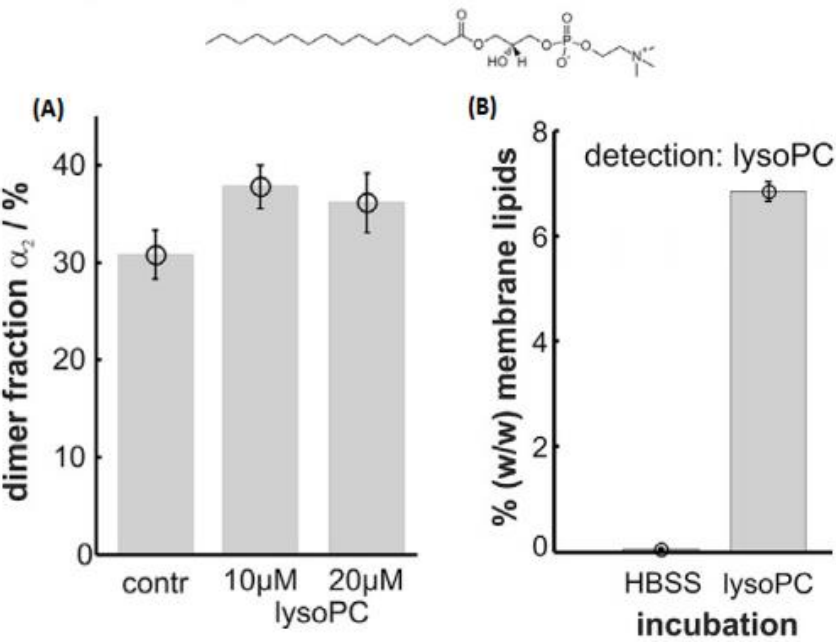

Figure 3.11 Effect of Lyso-PC addition on plasma membrane of CHO cells with GPImGFP construct. After 20 minutes of exposure to $10 \mu \mathrm{M}$ Lyso-PC, GPI-mGFP dimer fraction was measured $(A)$ and MS analysis was carried to measure the incorporation of Lyso-PC (B).

\subsubsection{Stress signalling is linked to plasma membrane remodelling}

The observations on the heat induced changes on the plasma membrane biophysical properties and in the cellular lipidome supports the "membrane sensor hypothesis" which suggests that the alterations in the plasma membrane can affect the level of HSPs. Plasma membrane localized calcium channels and insulin receptors are good candidates for possible membrane sensors which can get activated due to surrounding lipid changes (Török et al. 2014; Nagy et al. 2007).

\section{Calcium signalling}

TRPV channels are studied intensively for their involvement in the heat shock response. Not only their prescence on the plasma membrane and mechano-sensitive properties but also the stress induced $\mathrm{Ca}^{2+}$ increase makes TRPV channels a possible membrane sensor of heat (Bromberg and Weiss 2016). In support of this hypothesis blocking $\mathrm{Ca}^{2+}$ entry to the cytosol by using molecular chelators was shown to have negative effect on the plant heat shock response (Saidi et al. 2009) and 
acclimatization to higher temperatures results in lowered $\mathrm{Ca}^{2+}$ peaks (Saidi et al. 2010).

Therefore, we monitored temperature dependent increases in cytosolic calcium by measuring Fura-2 fluorescence which is a ratiometric indicator. It's excitation shifts in the prescence of $\mathrm{Ca}^{2+}$ allowing a concentration independent measurement. MCF-7 cells were used instead of $\mathrm{CHO}$ cells, because the multidrug resistance transporters extrude the fluorescent probe from CHO cells (Homolya et al. 1993). By applying a general phosphatase inhibitor sodium orthovanadate, the effect was reversed and $\mathrm{CHO}$ cells were loaded efficiently (data not shown), however due to possible intervention with the heat shock signalling pathways experiments were carried out using MCF-7 cells.

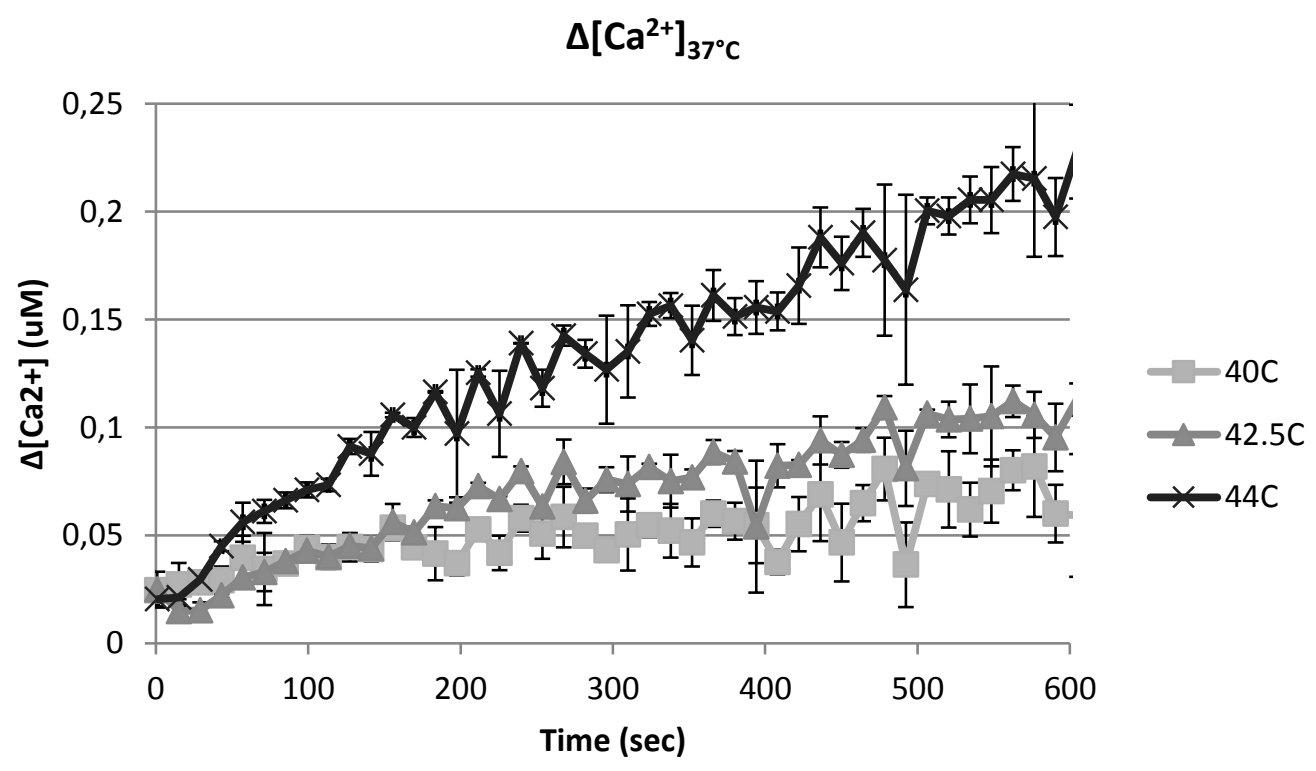

Figure 3.12 Heat dose dependent $\mathrm{Ca}^{2+}$ increase in MCF-7 cells. Cells were loaded with Fura-2 AM and the intracellular calcium increase was measured in a heated fluorimeter. $\Delta\left[\mathrm{Ca}^{2+}\right]_{37^{\circ} \mathrm{C}}$ was calculated by subtracting the basal levels at $37^{\circ} \mathrm{C}(\mathrm{N}=6$ and error bars represents standard deviation).

Intracellular $\mathrm{Ca}^{2+}$ concentration was $0.11 \pm 0.02 \mu \mathrm{M}$ in MCF7 cells at $37^{\circ} \mathrm{C}$. Figure 3.12 shows the change of intracellular $\mathrm{Ca}^{2+}$ as a function of time at different temperatures. Elevation to $40^{\circ} \mathrm{C}$ or $42.5^{\circ} \mathrm{C}$ resulted in comparable change of cytosolic 
$\mathrm{Ca}^{2+}$ concentrations while in case of severe $44^{\circ} \mathrm{C}$ stress intracellular $\mathrm{Ca}^{2+}$ increase was more pronounced. These findings lend support to a possible sensing of environmental changes by the calcium channels. Further analysis of the agonist and antagonists to modify the channel activity however did not resulted in any affect on the HSP25 translocation (data not shown). Moreover at $40^{\circ} \mathrm{C}$ observed $\mathrm{Ca}^{2+}$ increase does not cause the HSP induction in MCF-7 cells (data not shown). However, the effect of $\mathrm{Ca}^{2+}$ sensitive/dependent changes such as activation of phospholipases and subsequent release of lipid mediators can be linked to the perturbation of the plasma membrane (Balogh et al. 2005). Another important finding was the difference in the level of $\mathrm{Ca}^{2+}$ with mild/moderate and severe stress. The source of cytoplasmic $\mathrm{Ca}^{2+}$ increasecan be external through plasma membrane and/or the internal stores of ER and mitochondria. The consequences of the depletion of internal stores has been linked to induction of apoptotic pathways (Kaufman and Malhotra 2014; Görlach et al. 2015) and therefore in order to understand if the higher increase in $\mathrm{Ca}^{2+}$ with higher temperature is linked to depletion of internal stores, further experiments are needed.

\section{IGF1R signalling}

One of the most probable candidates for membrane sensors under these conditions are receptors or receptor networks, since specific receptors are inconsistent with the lack of stress response specificity for the stressor itself. The structural changes in the members of this putative stress sensing receptor network could provide both a rapid signal and an immediate feedback to control the effectiveness of the cellular stress response. For instance the nonspecific clustering of growth factor receptor tyrosine kinases and cytokine receptors during osmotic, UV-radiation and oxidative stress can activate these receptors and downstream stress signalling in mammalian cells (Rosette and Karin 1996; Ouwens et al. 2001; Handayaningsih et al. 2011; Tahimic et al. 2016). We chose IGF1R/IR receptors as models since these receptors were implicated many times in stress signalling in C.elegans (Barna et al. 2012), hyperosmotic stress in CHO (Ouwens et al. 2001). 
We observed that IGF1R/IR receptor was significantly activated upon mild heat treatment (Figure 3.13$)$. At a moderate heat $\left(42.5^{\circ} \mathrm{C}\right)$ the phosphorylation of this receptor shows a transient pattern having an increased activity for a few minutes followed by a downregulation in parallel with ERK1/2 activation (Figure 3.13 and Figure 3.14). It is well established that glucose deprivation induces HSP synthesis through the downregulation of IGF1R/IR pathway (Chiang et al. 2012; Barna et al. 2012; Hsu, Murphy, and Kenyon 2003; Hooper and Hooper 2005). This effect is completely antagonized by dexamethasone, the synthetic glucocorticoid which is a well know membrane fluidizing agent with the ability to remodel cellular lipid composition (Kasambalides and Lanks 1985). A more general role for insulin in the heat shock response has already been provided by the finding that cell surface insulin binding is reduced by heat shock in $\mathrm{HA}-1 \mathrm{CHO}$ cells. It has been suggested that the fate of insulin receptor mirrors intimately the ultimate destiny of the cells after heat treatment (Calderwood and Hahn 1983). Alteration in the microenvironment of the receptor might cause allosteric effects and lead to changes in its equilibrium binding properties. However, the affinity constants of thermotolerant cells were similar, thereby it was proposed that heat induced receptor depolimerization could be responsible for the observed effect. Their explanation was based on an earlier observation on the lipid composition and membrane fluidity dependent dimerization of the insulin receptor (Ginsberg, Jabour, and Spector 1982). Receptor tyrosine kinases were suggested to be connected to HSP signalling pathways in NIH3T3 fibroblasts by Lin et al (R. Z. Lin et al. 1997). Their results indicated that the signal pathways used by heat shock to activate MAPK and p70 S6 kinase resemble those used by growth factors, and heat shock activation of MAPK is blocked by suramin, a tyrosine kinase receptor inhibitor. Protein perturbation caused by hyperthermia may in some way stimulate cell surface receptor tyrosine kinases to initiate the downstream signaling events. Indeed, inhibition of heat shock activation MAPK by tryphostin AG1478 and a dominant negative EGFR mutant strongly suggests that EGFR may also be involved in the heat shock response. Integrin signaling also regulates activation of IGF1R and downstream targets in response to both IGF1 and a mechanical stimulus (Tahimic et al. 2016). 
Further supporting that insulin signalling is involved in membrane sensing of heat the protection of a small molecule, BGP-15 against heart failure and atrial fibrillation was associated with an increased phosphorylation of the insulin-like growth factor 1 receptor (IGF1R) (Sapra et al. 2014). Since BGP-15 was also shown to be an HSP coinducer and its ability to activates stress signal transduction pathways by remodeling plasma membrane rafts (Gombos et al. 2011).

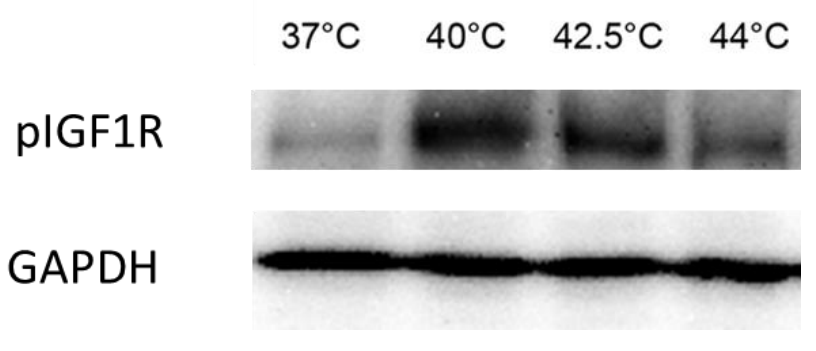

Figure 3.13 Mild stress activates the IGF1R. CHO cells with GPI-mGFP construct were treated with heat for 20 minutes at given temperatures. $(N=3)$

\section{MAPK signalling}

Cells activate signalling pathways in order to transmit the signals from external stimuli and to make critical decisions on poliferation, migration etc. MAPK pathway is three layer signalling cascade which involves several tyrosine kinase domains and regulatory tyrosines. Growth factor receptors and stress are known activators for these pathways (Cargnello and Roux 2011).ERK 1/2, JNK and p38 MAPK are three major branches which are shown to be activated through different signals. ERK1/2 and partially JNK can be activated due to activation of growth factor receptors that is also a possible stress sensor in mild temperatures (Katz, Amit, and Yarden 2007). Our results showed a low level of activation at $40^{\circ} \mathrm{C}$ of ERK1/2 and JNK due to phosphorylation (Figure 3.14). With increasing temperature, the phosphorylation levels were elevated with a strikingly high phosphorylation at $44^{\circ} \mathrm{C}$ (Figure 3.14). For ERK $1 / 2$ and JNK the unstabilized phosphatases were shown to be responsible for the phosphorylation at protein denaturing temperatures (Nadeau and Landry 2007). 
At mild temperatures, ERK1/2 activation at $40^{\circ} \mathrm{C}$ is possible through the receptor activation due to change in plasma membrane physical properties (confinement and fluidity) (Figure 1.2 and 3.6). It has been shown recently by Zhou and coworkers that PS maintains the lateral segregation of Ras nanoclustering and therefore a potential mediator for a lipid mediated signaling (Zhou et al. 2014; Zhou and Hancock 2015). In addition to that, treating human fibroblasts by PS resulted in an increased ERK 1/2 signaling which is known to be activated through Ras (Donyo et al. 2016). On the otherhand JNK can be actviated through the activation of small GTPases with increasing PS on the plasma membrane as well (Figure 3.8) (Han et al. 2001; Kay and Grinstein 2013). However, in the mild temperature range $\left(39^{\circ} \mathrm{C}\right)$, a small GTPase Rac1 was shown to inhibit the activation of SAPK/JNK in a Rac1 dominant negative mutant containing Rat- 2 fibroblast cell line, whereas temperatures above that $\left(41-43^{\circ} \mathrm{C}\right)$ preserved the activation of SAPK/JNK which suggests another level of regulation. Another supporting evidence for that is inhibition of SAPK/JNK activity in the first 10 min treatment of $41^{\circ} \mathrm{C}$, however due to the inhibition after $20 \mathrm{~min}$ SAPK/JNK activation was observed (Han et al. 2001). Correspondingly the induction of HSPs were affected negatively in a similar manner without any effect on heat induced HSF1 phosphorylation (Gungor et al. 2014; Han et al. 2001).

Activation of p38MAPK by stress is distinct from both ERK and JNK. EGFR activation, inhibition by the specific inhibitors does not effect the p38 MAPK and inactivation of phosphatase is not involved (Nadeau and Landry 2007). Under oxidative stress, endoplasmic reticulum stress, infection and calcium influx specific set of kinases are involved in the activation of p38MAPK, namely ASK-1 (Shiizaki, Naguro, and Ichijo 2013; Matsukawa et al. 2004). Upon increase in sphingosine and ceramide during heat stress, ASK1 is titrated from its repressor glutathione Stransferase and activates the p38MAPK pathway (Nadeau and Landry 2007). Moreover p38MAPK is a known upstream effector of HSP25 phosphorylation (Vertii et al. 2006). Therefore, we inverstigated the level of p38MAPK in CHO cells expressing GPI-mGFP construct in a dose dependent manner. Westernblot analysis was carried out after 20 minutes of given heat treatment and no recovery time was given. Our results showed a highly enhanced p38MAPK phosphorylation at $44^{\circ} \mathrm{C}$ whereas a 
minimal activation was also observed at $42.5^{\circ} \mathrm{C}$ (Figure 3.14). Furthermore increase in p38MAPK phosphorylation correlated well with the HSP25 phosphorylation levels at $44^{\circ} \mathrm{C}$ (Figure 3.4 ).

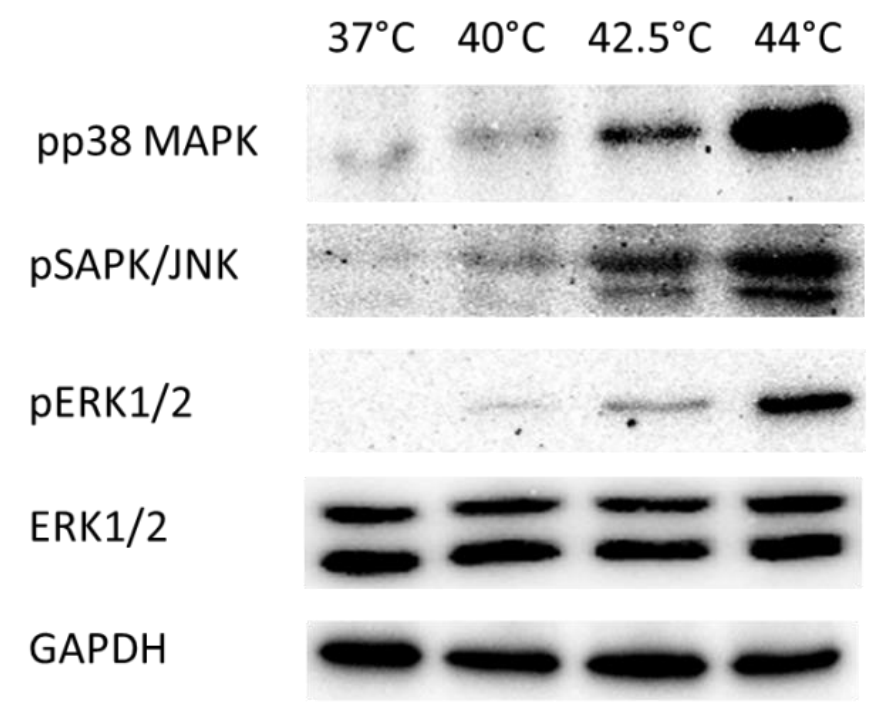

Figure 3.14 Dose dependent activation of stress signaling pathways. CHO cells expressing GPI-mGFP construct were treated at given temperatures for 20 minutes and collected for western blot experiments $(N=3)$.

\subsection{CELL TO CELL VARIATION OF HEAT SHOCK RESPONSE}

\subsubsection{Stress response of individual cells}

It is a fundamental question whether all cells in a populations sense the imposed stress on the same level and whether they respond in the same manner. Majority of our knowledge on the cellular responses such as gene and protein expression are derived from the averages of a population of cells. The appearence of two subpopulations with different expression characteristics can result in the same mean of the big population, however the information is lost during the averaging process. Therefore single cell studies has the power of preventing information loss in that way. Furthermore, the correlation between the measured effect and the source of 
heterogeneity e.g. gene expression profile and plasma membrane structure allows a better understanding of a biological phenomenon. In order to investigate the cell-tocell variations and population context based differences in stress sensing and the stress response, single cell experiments were carried out following different approaches.
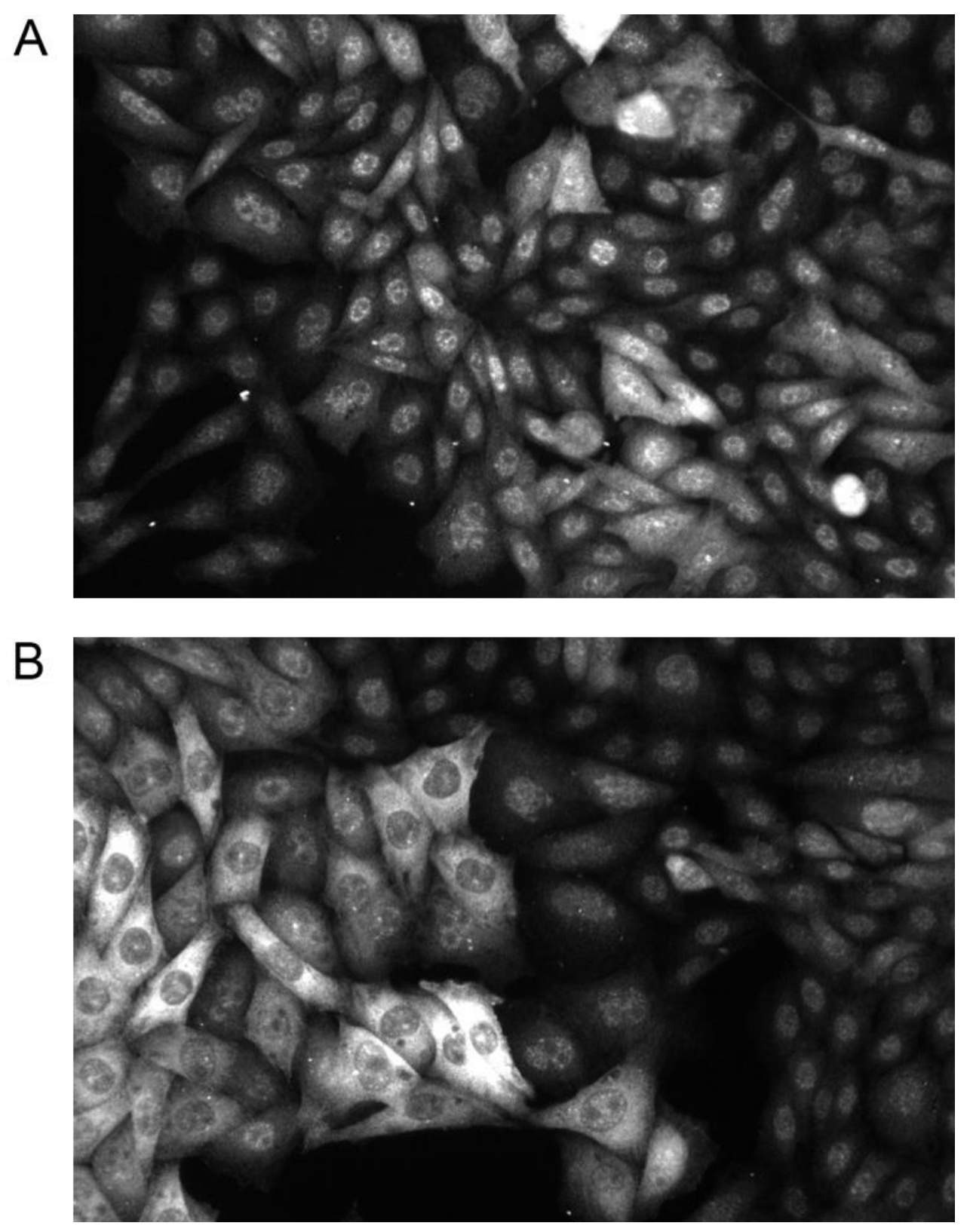

Figure 3.15 Cell to cell variation is observed in cellular heat shock response. Immunolocalization of HSP25 after 20 minutes heat treatment at $40^{\circ} \mathrm{C}$ in $\mathrm{CHO}(\mathrm{A})$ and MEF (B) cells was represented. 
Fluorescent imaging is a powerful tool to investigate cell-to-cell variability. It allows the visualization of protein localization, intensity based differences of the probes in use and gives information about the surroundings of the cells such as local cell crowding. Therefore we applied fluorescence microscopy to analyze the individuality of heat-shock response in two cell lines by following the redistribution of HSPs into the nucleus as described in figure 3.2. Our results showed a pronounced heterogeneity in HSP25 redistribution (Figure 3.15). Since cell cycle phase is considered as a source of heterogeneity, cell cycle dependence of heat induced HSP25 redistribution was further investigated. Lipidomics of cell populations in different cell cycle phases were also analysed after isolating them using fluorescence activated cell sorter.

\subsubsection{HSP25 translocation reveals the heterogeneity within the population}

As described in stress models, the probability of a genotype/phenotype increases in the population with the highest fitness. However, if the stress levels are permitted to rise too far, the stress threshold may be reached. This causes the mass die-off, sterility and possible a local extrinction in studies carried using fruitflies (Krebs and Loeschcke 1994; Clark and Fucito 1998; Jackson, Nielsen, and Singh 2015). In order to understand how population distribution is affected with heat dose, stress sensitivity was analyzed with HSP25 translocation to nucleus as a function of HSP25 intensity contrast in nucleus. The measurement of contrast allows an unbiased comparison of nuclear and total intensity obtained from HSP25 immunolocalization and the normalization of different samples. The heat dose dependent HSP25 translocation (contrast) indeed showed a greater variance when cells were treated with mild $40^{\circ} \mathrm{C}$ (Figure 3.16). As the temperature increased and cells reached to the stress threshold the variance dropped drastically $\left(44^{\circ} \mathrm{C}\right)$. In accordance to these observations, the single cell experiments were carried out at moderate stress level $\left(42.5^{\circ} \mathrm{C}\right)$ to be able to detect both low and high thresold of stress. An additional observation obtained was the continuous profiles of the population distribution. Subpopulations could not 
be dissected at this resolution, however catagories could be obtained by futher image analysis of multiple parameters.

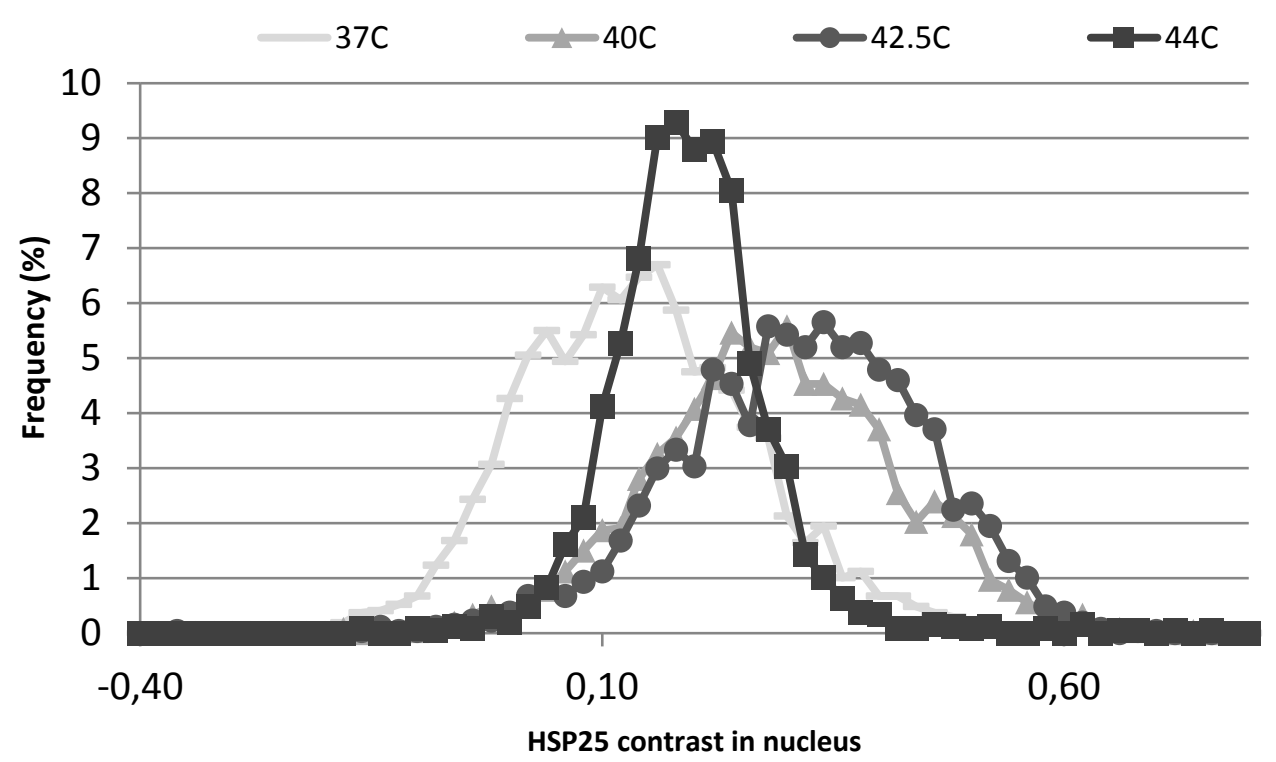

Figure 3.16 Stress dose controls the individual variation. CHO cells with mGFP-GPI construct were treated at given temperatures for 20 minutes and then immunofluorescence images of HSP25 were analyzed for contrast in nucleus (N 2000).

\subsubsection{Lipidomics reveals cell cycle dependent lipidomes}

Heterogeneity of the "seemingly identical" isogenic cell populations are always present. One of the major contributor for this cell-to-cell variation is considered to be the cell cycle. Even after mitosis, the protein, DNA and mitochondria content of the two daughter cells are unequal and the cellular programs differ through the stages of cell cycle (Darzynkiewicz et al. 1982).

In order to understand the effect of cell cycle in the lipid profile of the cells and the stress response, $\mathrm{CHO}$ cells with mGFP-GPI construct were sorted based on the DNA (Hoechst intensity) content and lipidomics analysis were carried out. As membrane lipid compositions are sensitive to changing environments, first the effect of sorting and staining of DNA was tested. These procedures did not altered the 
cellular lipidomes significantly (data not shown). However a clear separation of lipid profiles were possible based on cell cycle (Figure 3.14). Heat map representation of G1, S and G2 phase lipid profiles reflects distinct patterns (Figure 3.14 A) supported by the well separated O-PLS-DA scores (Figure 3.14 B).

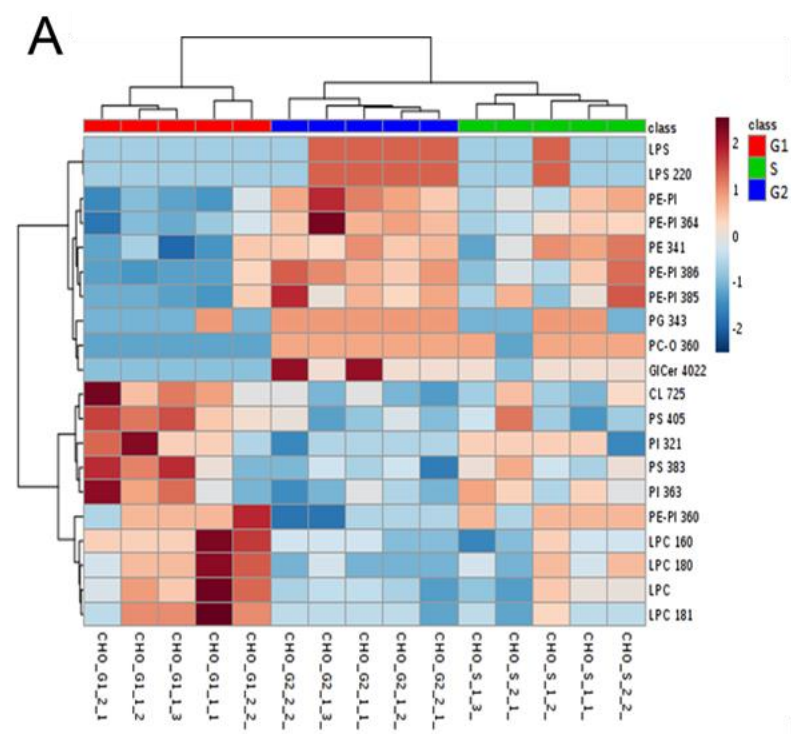

B

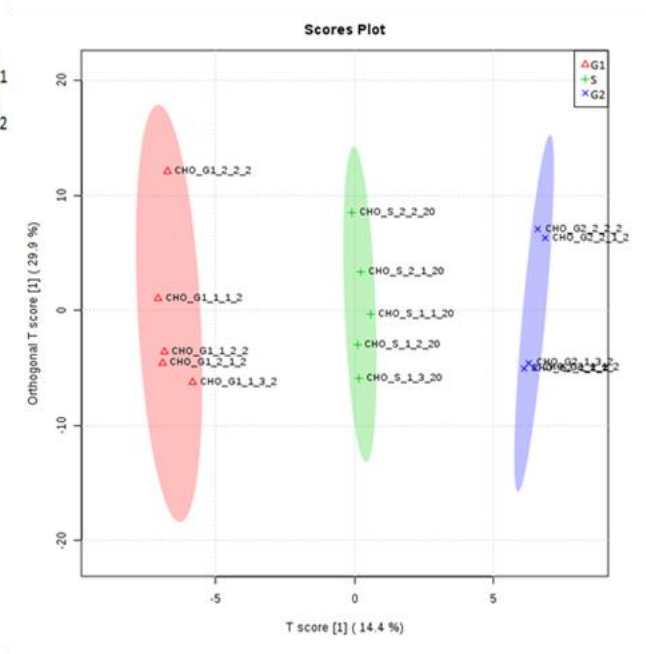

Figure 3.17 Lipidome of $\mathrm{CHO}$ cells are shaped by the cell cycle. Heat map representation of top 20 most significant lipid classes based on ANOVA in G1 (red), S (green) and G2 (blue) phases with heat color-code of normalized values ( $A$ ) and $O$ PLS-DA score.

G1 phase was found to have higher cardiolipin (CL), phosphatidyinositol (PI) and phosphatidylserine (PS) content. CL is a mitochondrial lipid and may indicate the biogenesis of mitochondria to support the energy requirements of G1 phase (Paradies et al. 2014). Higher phosphodatiyglycerol (PG), phosphatidylethanolamine $(\mathrm{PE})$ and lyso phosphatidylcholine (LPC) were measured in $\mathrm{G} 2$ cells which could result in structural consequences in the plasma membrane, therefore may relate to a differential heat sensing and signalling. 


\subsubsection{A microscopy-based method to analyze cell cycle phases in non- synchronized mammalian cells to dissect the effect of cell cycle on heterogenous HSR}

Nutritional and metabolic status of a cell must be assesed to ensure the progression of cell cycle and succession of the cell division. Therefore extrenal stimuli and conditions are important factors that manipulates cell cycle span. The challange to investigate the effects of cell cycle in stress sensing or response is the counterinteraction of both; stress causes delays in the cell cycle and cell cycle states have different metabolisms that in turn may result in different responses. When cells experience stress, the usual outcome is the induction of HSPs which occur after a period of time that is required to initiate transcriptional and translational processes making it difficult to link the level of induction with the initial cell cycle state. Methods like starvation and chemical treatments to synchronize cells, on the other hand are stressors for the cells and can influence the cellular response. For these reasons, unsynchronized cells were analyzed based on their DNA content simultaneously with the early stress response of HSP25 translocation to the nucleus (Figure 3.2).

Microscopy-based analysis of cell cycle we developed is based on the analysis carried out in flow cytometry where the histogram of a ratiometric DNA stain is used to determine whether cells are in G1, S and G2 phase (Dolbeare et al. 1983). The DNA histograms were plotted after image analysis described under "Materials and Methods" (Figure 3.15). The first peak which corresponds to the highest percentage of the cells is $\mathrm{G} 1$ phase that takes longest in the cycle. The second peak has almost double the intensity of the first peak hence the DNA amount corresponds to $G 2$ phase. In between is the S phase where Hoechst intensity varies. This classification of cells were used in subsequent analysis of cell cycle dependent HSR (HSP25 translocation to the nucleus). 

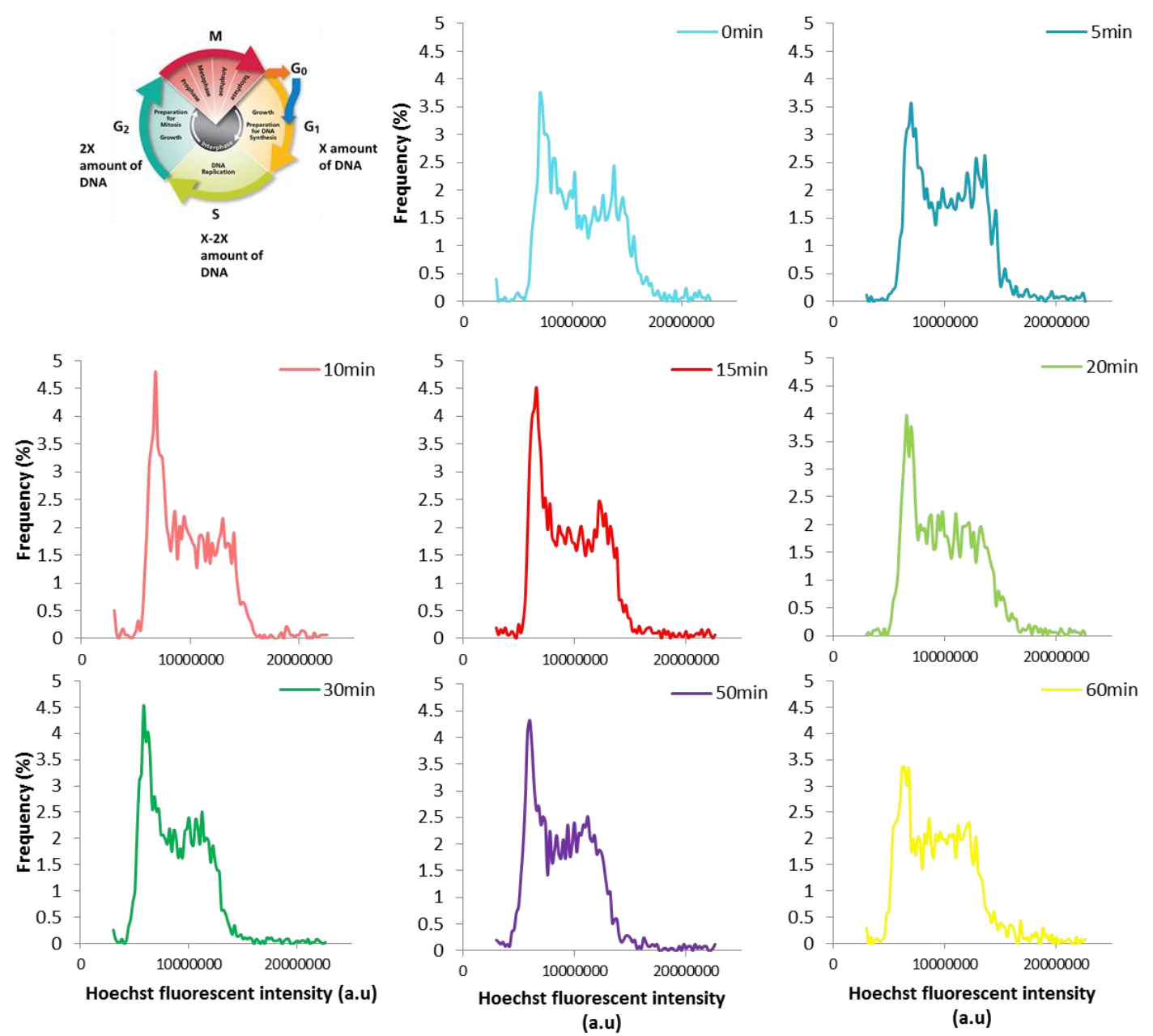

Figure 3.18 Image analysis of DNA content reveals the cell cycle phases. DNA histogram was plotted to analyze the cell cycle phases from the microscopic analysis of $\mathrm{CHO}$ cells with GPI-mGFP construct. Cells were stained with Hoechst 33342 and fluorescent intensity was measured from single cells ( $N \sim 2000)$.

Transient localization of HSP25 from cytosol to nucleus is a protective mechanism for the cells to prevent heat induced irreversible aggregation of nuclear proteins (Bryantsev et al. 2007). Figure 3.2 shows a heterogeneous profile of the translocation whereas HSP70 translocation was more uniform throughout the population. Therefore, the time lapse analysis was carried out to investigate when the translocation starts and how the single cell differences were organized within the population (Figure 3.15A). During the first 10 minutes a bell shaped distribution curve was observed with a lower HSP25 localization in the nucleus. A striking increase of translocation is detected at 15 minutes followed by a gradual increase reaching a 
maximum level at $30 \mathrm{~min}$. The most heterogeneous response was observed 15 minutes suggesting that at this heat dose there are still resistant cells present in the population that may not require the protection of HSP25 in the nucleus.
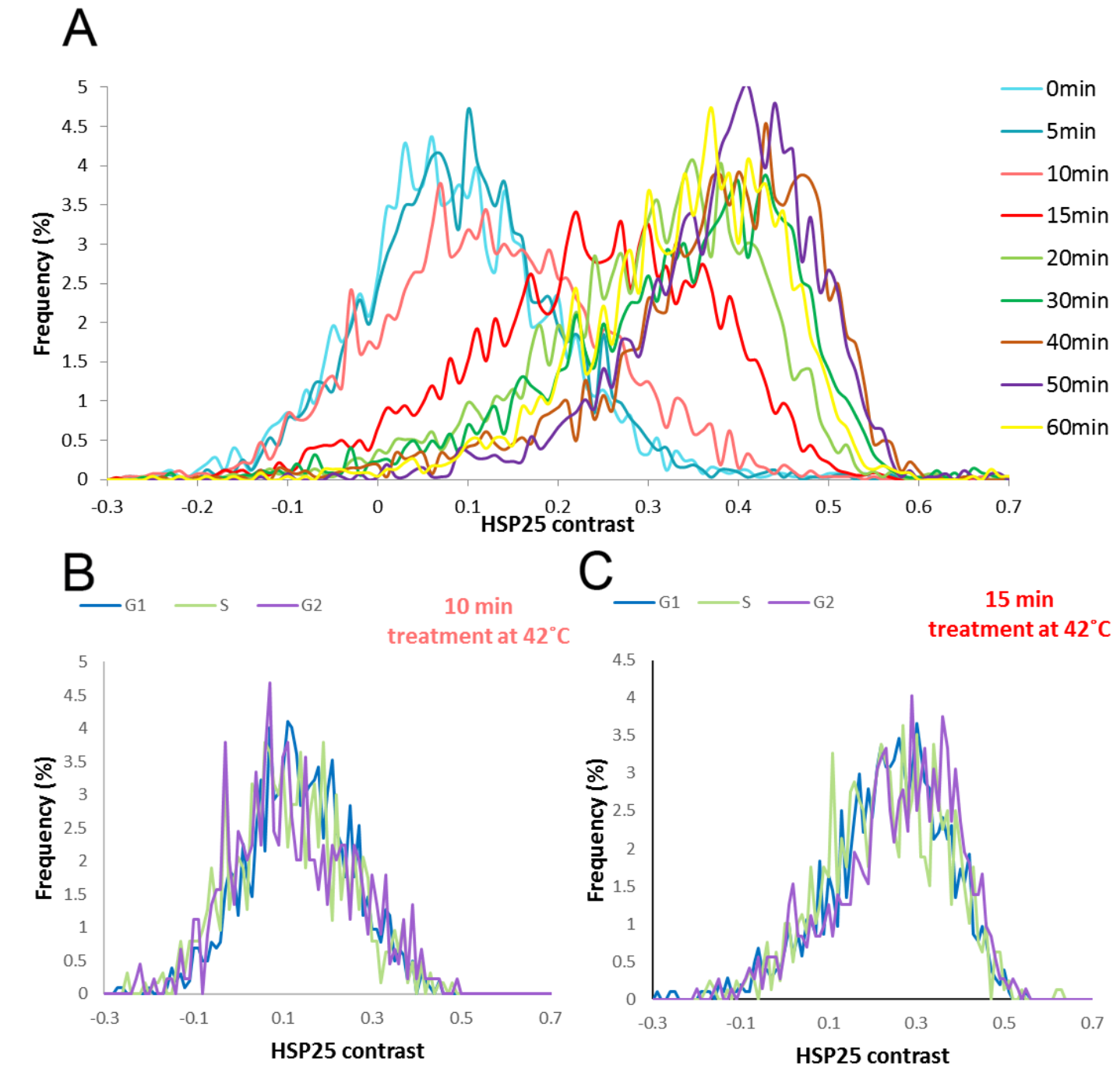

Figure 3.19 Variability of stress response is dependent on the heat dose but not cell cycle phase. CHO cells expressing GPI-mGFP construct were heat shocked at $42^{\circ} \mathrm{C}$. Immunofluorescence labelling was carried out for HSP25 and images were analyzed to measure the HSP25 contrast at given time points (A). Cell cycle stages were analyzed using the Hoechst 33342 intensity of the same images by plotting the DNA histogram at 10 minutes $(B)$ and 15 minutes $(C)$. ( $N \sim 2000)$ 
Next analysis of the cell cycle was carried out at 10 and 15 minutes where the shift towards higher nuclear signal started. Cells were analyzed for their DNA histogram (Figure 3.15) and HSP25 contrast distributions were plotted based on the cell cycle states G1, S or G2 (Figure 3.16 B and C). Cell cycle phase did not influence HSP25 translocation and its heterogeneity. However, it is still possible that the effect of cell cycle can be observed in the extent of protein induction or gene expression. Along with the HSP25 translocation, HSF1 and kinases involved in MAPK signalling (p38MAPK, JNK, ERK 1/2) were tested by high content microscopy. Neither the localization nor the intensity was found to be changed during the treatments (data not shown). The use of other antibodies or assays, however, can be a promising tool to define the source of heterogeneity in the populations.

\subsubsection{Single-cell analysis of the calcium peaks of heat shocked CHO cells reveals the heterogeneity of heat shock sensing/response}

TRPV1 channels are proposed plasma membrane sensors of heat and their activation results in the increase of intracellular $\mathrm{Ca}^{2+}$ (Bromberg et al. 2013). Therefore, we analyzed the increase of $\mathrm{Ca}^{2+}$ on the single cell level. $\mathrm{CHO}$ cells expressing GPI-mGFP construct was labelled with an $\mathrm{Ca}^{2+}$ indicator dye Fura-2AM. Cells were heat shocked under the microscope using a temperature controller. Our results showed a high degree of individuality on the $\mathrm{Ca}^{2+}$ response of the cells (Figure 3.20). The intracellular $\mathrm{Ca}^{2+}$ signals can be classified into slowly rising signal (Figure 3.20 A (red and blue lines) and B (yellow and purple lines)), transient sustained peak (Figure 3.20A (green line)) and spiking $\mathrm{Ca}^{2+}$ signals (Figure $3.20 \mathrm{C}$ ). Understanding of these different signal characteristics are not trivial and requires further analysis. It can be important to link these behaviours to the plasma membrane re-organization and heat induced signalling pathways. A recent study adressed the source of variability in $\mathrm{Ca}^{2+}$ transients in epithelial tissue damage by using an automated algorithm to examine in detail (Appleby et al. 2015), therefore can be a great base for further analysis. 

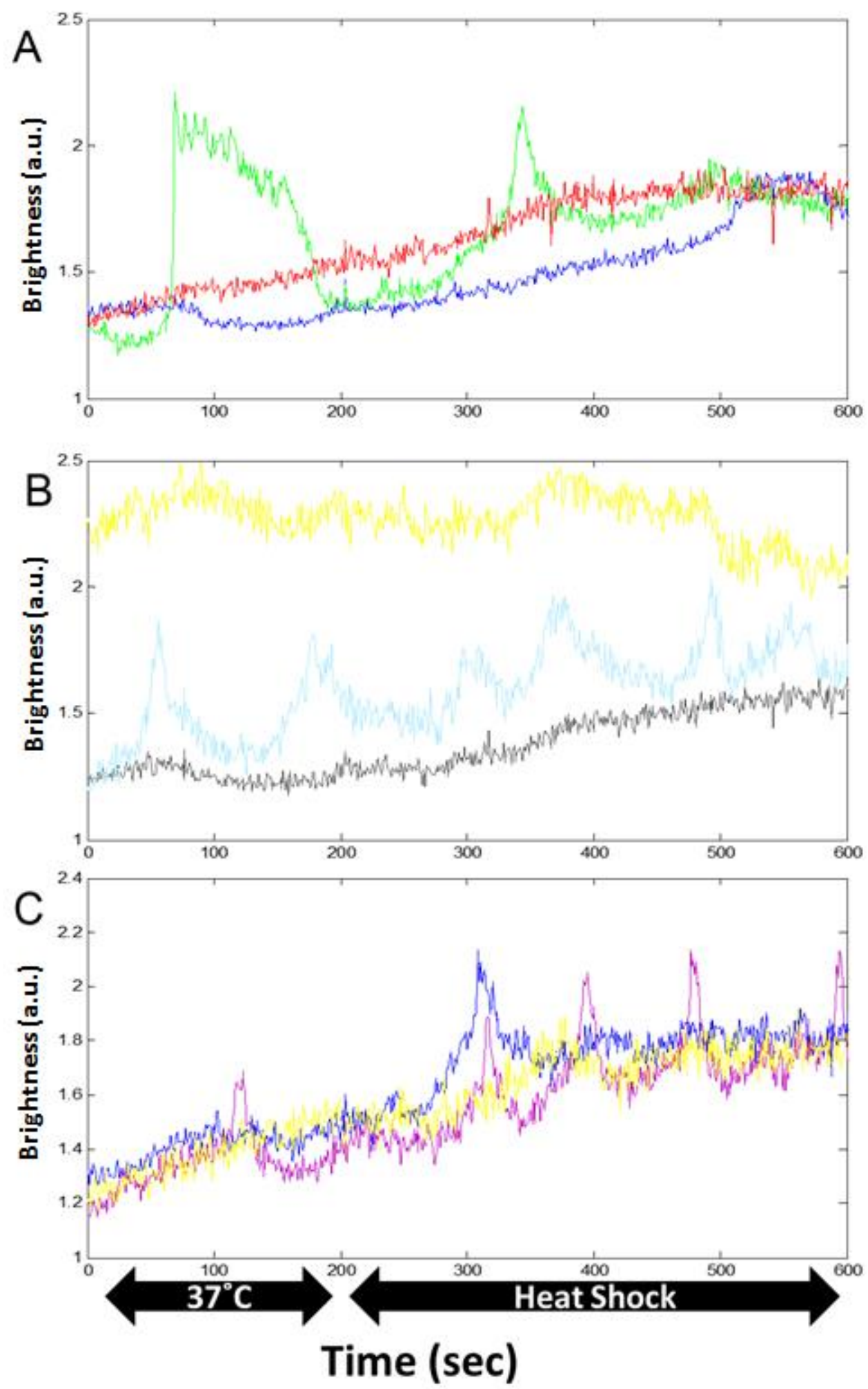

Figure 3.20 Heat induced calcium peaks shows individuality. $\mathrm{CHO}$ cellx expressing GPI-mGFP construct was labbeled with $10 \mu \mathrm{M}$ Fura-2AM and calcium signals were measured on the fluorescent microscope heated to $42.5^{\circ} \mathrm{C}$. Each plot represents an individual cell. 


\subsubsection{Heat shock response is dependent on cell density}

Previous work carried out by our lab revealed a cell density dependent HSR. Cultured cells of B16 melanoma cell line showed a decreased proportions of polyunsaturated fatty acids, decreasing cholesterol content on the plasma membrane microdomains and decrease in HSR measured by mRNA synthesis of HSP genes with increasing cell density (Péter et al. 2012). There is also evindence on the cell density dependent promoter activation of HSP70 genes where cells are less inducible at high cell densities (Noonan et al. 2007). The authors suggested that the source of this altered responses can be the nutritional media itself. Noonan and coworkers analyzed the effect of the conditioned media from low cell density cultures on the high cell density cultures and observed an enhanced promoter activation. Péter and coworkers analyzed the fatty acid de novo synthesis and fatty acid incorporation from the media and observed that the fatty acid synthesis is dependent on the cell density. As a result, from the population analysis of cell number dependence of heat shock response it is not straightforward to asses information on the cellular state and to reveal a direct link to the stress response. A recent study investigating the effect of local cell density on viral infection using single cell analysis is a pioneer work to reveal a media independent differences. In other words, intrinsic differences are obtained since cells are grown on the same plate with no differences on the media input. Their results suggest that simian virus 40 infection is increased in the cells experiencing low local crowding. Moreover, crowding affects the GM1 levels and the focal adhesion kinase activation in a negative direction (Snijder et al. 2009). A follow-up work carried by Frechin et al. identified that in cells experiencing low crowding a more active PI3K and Akt signalling is observed whereas cells in high crowding areas have increased ABC transporter A1 activity (2015). Importantly, lipid droplet levels are droped as the cell density increased and the fluidity of the total membranes increased due to crowding. Therefore it is important to analyze populations based on the crowding.

As a preliminary effort, the effect of cell density on IGF1R/IR, ERK signalling and HSF1 phosphorylation on Ser326 was analyzed in parallel with HSP induction (Figure 3.21). CHO cells expressing GPI-mGFP construct were seeded in low cell density (LCD) 
at 250 cells $/ \mathrm{mm}^{2}$ and high cell density at 750 cells $/ \mathrm{mm}^{2}$ (HCD). In order to adapt the cells to these density conditions and to prevent depletion of nutrients each day cells were splitted into same cell number. After 3 days of adaptation, each stock of cells are splitted to LCD and HCD cultures to carry out westernblot analysis after given heat treatments for 20 minutes. For the analysis of phosphorylation cells were collected right after the heat shock and for the analysis of HSP levels sample collection was carried out after an additional recovery time of 6 hours .

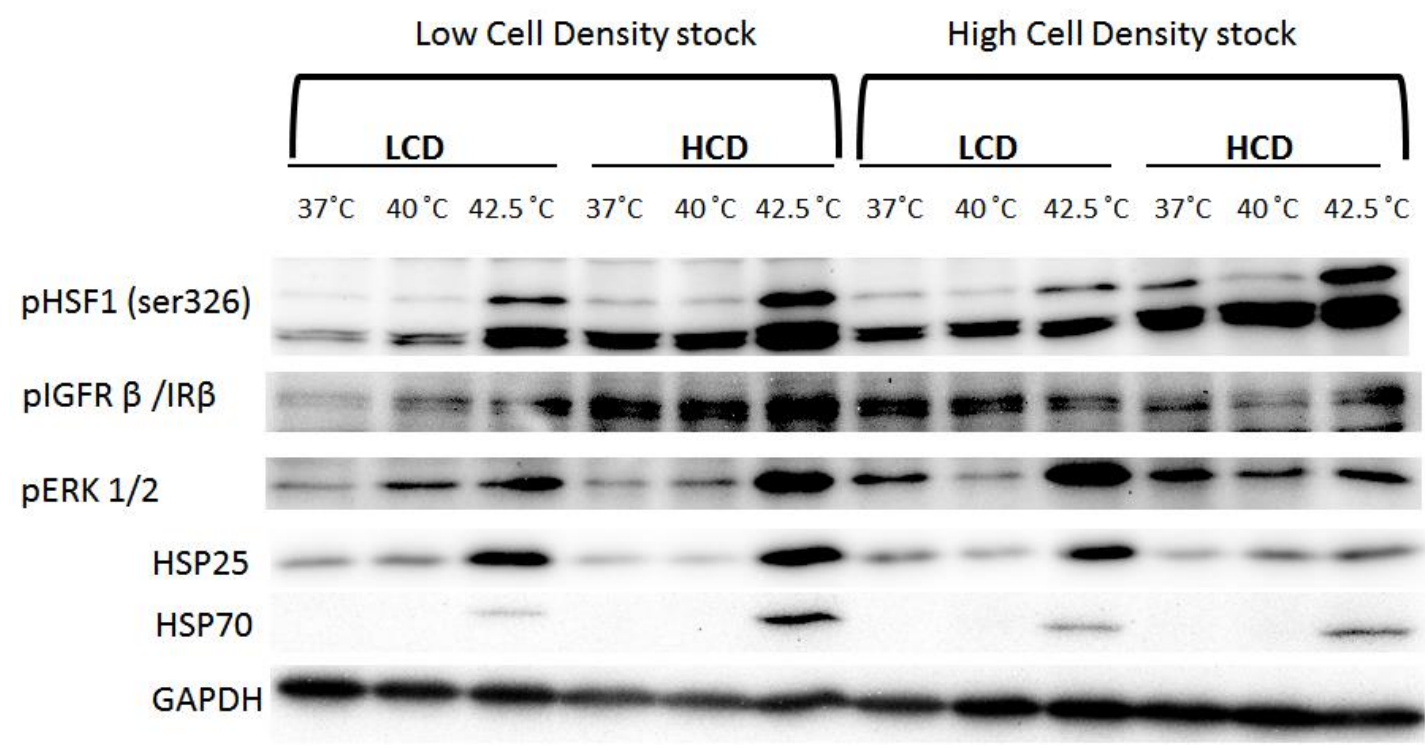

Figure 3.21 Cell density regulates the HSR. CHO cells expressing GPI-mGFP construct were seeded with 250 cells $/ \mathrm{mm}^{2}$ (Low cell density(LCD) stock) and 750 cells $/ \mathrm{mm}^{2}$ (High cell density ( $H C D$ ) stock) for 3 days keeping the cell density constant transfered to subsequent $L C D$ and $H C D$ cultures. $p H S F 1, p / G F 1 R \beta / I R \beta$ experiments were carried out 20 minutes after the heat treatment, HSP25 and HSP70 levels were detected after 6 hours of recovery. $(N=2)$

Our results showed a density dependent HSP induction. HSP25 and HSP70 level increase was more pronounced on HCD sample obtained from a LCD stock. The lowest induction of HSPs were observed when samples were on HCD all the time. HSF1 phosphorylation did not correlated with the induction of HSP25 and HSP70 opposing our previous observations shown on figure 3.2. Further experiments are needed to be carried in order to understand the HSF1 phosphorylation on Ser326 and 
its effect on the promoter regions of HSP25 and HSP70. The activation of IGF1R/IR and ERK $1 / 2$ showed a cell density dependence as well. On HCD stock, the phosphorylation of IGF1R/IR was low and unaffected by temperature elevation. Further analysis on the signalling pathways described in this work (Figure 3.14) and HSP levels on population context can be a promising approach to understand the cell crowding based lipid and plasma membrane differences, hence the signalling events and ultimately the cellular response to heat. 


\section{CONCLUSIONS}

The most important conclusions that can be derived from this thesis work can be listed as follows;

- Early events during the perception of temperature stress involve the remodeling of the plasma membrane and cellular lipidome, hyperphosphorylation of HSF1, activation of MAPK signalling pathways and redistribution of HSPs that is followed by an increase in HSP protein levels and gain of acquired thermotolerance.

- Cellular response of $\mathrm{CHO}$ cells to heat is both temperature and duration dependent.

- Distinct heat stress levels, namely mild $\left(40^{\circ} \mathrm{C}\right)$, moderate $\left(42.5^{\circ} \mathrm{C}\right)$ and severe $\left(44^{\circ} \mathrm{C}\right)$ can be classified based on distinct cellular lipidomes, plasma membrane organizations, HSP response and signalling pathways.

- Mild stress induces ERK1/2 signalling whereas JNK and p38 MAPK pathways are more active at higher temperatures

- Cells promptly respond to heat by remodeling their plasma membrane. Heat exposure significantly increases the lateral diffusion of fluorescent membrane probes in the plasma membrane of $\mathrm{CHO}$ cells at moderate, but not mild temperatures. While the effect of mild heat is successfully balanced by an active microdomain rearrangement (i.e., increased domain confinement), moderate heat resulted in both, an increased diffusion and reduced confinement of GPImGFP.

- Cells instantly respond to heat by remodeling their lipidome. PA, PS, PG, CL, LPC and Ceramide changes has been identified as key features while PA is distinctive for moderate and severe stress

- Re-distribution of HSP25 and HSP70 into nuclear and perinuclear compartments is an acute effect of heat and reflects dose dependent stress response.

- HSP25 and HSP70 protein levels are controlled with a different threshold or possibly through different mechanisms that is not connected to HSF1 phosphorylation on Ser326. 
- Our results delineated the molecular details of a novel mild type of cellular eustress, when the mammalian cells adapt to fever-type mild heat by maintaining membrane homeostasis, activating lipid remodeling, and redistributing chaperone proteins, leading to acquired thermotolerance; strikingly, these processes occur in the complete absence of the induction of HSPs. At higher temperatures, additional defense mechanisms are activated, including elevated expression of molecular chaperones, contributing to an extended stress memory and acquired thermotolerance.

- At mild temperatures, heat treatment alters lipid composition and plasma membrane structure and it results in a significant increase of acquired thermotolerance therefore pointing out a possible interrelationship of the two.

- Individual variation of the cellular heat shock response is observed in translocation of HSPs to the nucleus (early response) and in induction of HSPs (late response).

- Cell-to-cell variation of heat induced HSP25 redistribution is a cell cycle independent event whereas distinct lipid profiles of $G 1, S$ and $G 2$ phases are observed.

- Single cell analysis of heat induced $\mathrm{Ca}^{2+}$ signalling indicates that the population heterogeneity of the heat stress signalling can be linked to membranes, but further studies are required in order to better understand this phenomenon. 


\section{ACKNOWLEDGEMENTS}

First of all, I would like to express my sincere gratitude to my supervisor Dr. Zsolt Török for his invaluable guidance, encouragement and contributions throughout my studies and my stay in Szeged. It was a great pleasure to discuss science with him. I would also like to thank Prof. László Vígh for giving me the opportunity to work in such a productive and friendly environment. I am sincerely grateful to him and Dr. Ibolya Horváth for their advices and constructive critics.

For the lipidomics part of this study I owe a big thank to Gábor Balogh and Mária Péter. Through them I get to know more about lipids. The discussions and their suggestions were always delightful, helpful and precious.

I would like to thank Imre Gombos for carrying imFCS measurements to begin with, but also for his contributions and friendship. It was a great pleasure to work with him.

I feel obliged to be part of the Molecular Stress Biology team in BRC. I appreciate the help, the contribution and the valuable friendships of Ana-Maria Pilbat, Ákos Hunya, Tim Crul, Bálint Csoboz, Atilla Glatz, Péter Gudman, Ádám Tiszlavicz and László Vígh Jr. I would also like to thank our technicians Erika Zuric for her help in lipid extraction, Gabi Bogdánné for her help in Western blot analysis, Aranka Gondáné and Éva Bartha for their help during my work.

It was a great experience to work with our collaborators from Technical University of Vienna, Prof. Gerhard Schütz and Dr.Mario Brameshuber. I am thankful to Dr. Péter Horváth for allowing me to carry out high-content screening experiments in his lab and also to the members of Microscopic Image Analysis and Machine Learning Lab.

I would like to thank Dr. Csaba Csonka and Dr. Balasz Veres for reviewing my thesis and for their contributions.

Besides the scientific part, it is essential to thank my friends Orsolya Méhi and Stier Ildiko for their precious friendship and encouragement. At last but not least, I am very thankful for the endless support, unconditional love and the patience of my family. It wouldn't be possible for me to complete my work without these. 


\section{REFERENCES}

Akbarian, Abdollah, Joris Michiels, Jeroen Degroote, Maryam Majdeddin, Abolghasem Golian, and Stefaan De Smet. 2016. "Association between Heat Stress and Oxidative Stress in Poultry; Mitochondrial Dysfunction and Dietary Interventions with Phytochemicals." Journal of Animal Science and Biotechnology 7: 37. doi:10.1186/s40104-016-0097-5.

Akerfelt, Malin, Richard I Morimoto, and Lea Sistonen. 2010. "Heat Shock Factors: Integrators of Cell Stress, Development and Lifespan." Nature Reviews. Molecular Cell Biology 11 (8). Nature Publishing Group: 545-55. doi:10.1038/nrm2938.

Anderson, Robin L., and Robert Parker. 1982. "Analysis of Membrane Lipid Composition of Mammalian Cells During the Development of Thermotolerance." International Journal of Radiation Biology and Related Studies in Physics, Chemistry and Medicine 42 (1): 5769. doi:10.1080/09553008214550911.

Appleby, Peter A, Saqib Shabir, Jennifer Southgate, and Dawn Walker. 2015. "Sources of Variability in Cytosolic Calcium Transients Triggered by Stimulation of Homogeneous Uro-Epithelial Cell Monolayers." Journal of the Royal Society, Interface / the Royal Society 12 (105): 20141403-. doi:10.1098/rsif.2014.1403.

Avery, Simon V. 2006. "Microbial Cell Individuality and the Underlying Sources of Heterogeneity." Nature Reviews Microbiology 4 (8): 577-87. doi:10.1038/nrmicro1460.

Balch, William E, Richard I Morimoto, Andrew Dillin, and Jeffery W Kelly. 2008. "Adapting Proteostasis for Disease Intervention." Science (New York, N.Y.) 319 (5865): 916-19. doi:10.1126/science.1141448.

Balogh, Gábor, Ibolya Horváth, Enikõ Nagy, Zsófia Hoyk, Sándor Benkõ, Olivier Bensaude, and László Vígh. 2005. "The Hyperfluidization of Mammalian Cell Membranes Acts as a Signal to Initiate the Heat Shock Protein Response." FEBS Journal 272 (23): 6077-86. doi:10.1111/j.1742-4658.2005.04999.x.

Balogh, Gábor, Mária Péter, Attila Glatz, Imre Gombos, Zsolt Török, Ibolya Horváth, John L. Harwood, and László Vígh. 2013. "Key Role of Lipids in Heat Stress Management." FEBS Letters.

Bański, Piotr, Mohamed Kodiha, and Ursula Stochaj. 2011. "Exploring the Nucleolar Proteome: Novel Concepts for Chaperone Trafficking and Function." Current Proteomics 8 (1): 59-82. doi:10.2174/157016411794697345.

Barna, János, Andrea Princz, Mónika Kosztelnik, Balázs Hargitai, Krisztina Takács-Vellai, and Tibor Vellai. 2012. "Heat Shock Factor-1 Intertwines insulin/IGF-1, TGF- $\beta$ and cGMP Signaling to Control Development and Aging." BMC Developmental Biology 12: 32. doi:10.1186/1471-213X-12-32.

Bayascas, Jose R., and Dario R. Alessi. 2005. "Regulation of Akt/PKB Ser473 Phosphorylation." Molecular Cell 18 (2): 143-45. doi:10.1016/j.molcel.2005.03.020.

Belhadj Slimen, Imen, Taha Najar, Abdeljelil Ghram, Hajer Dabbebi, Moncef Ben Mrad, and Manef Abdrabbah. 2014. "Reactive Oxygen Species, Heat Stress and Oxidative-Induced Mitochondrial Damage. A Review." International Journal of Hyperthermia 30 (7). Taylor \& Francis: 513-23. doi:10.3109/02656736.2014.971446.

Bernardino de la Serna, Jorge, Gerhard J. Schütz, Christian Eggeling, and Marek Cebecauer. 2016. "There Is No Simple Model of the Plasma Membrane Organization." Frontiers in Cell and Developmental Biology 4 (September): 1-17. doi:10.3389/fcell.2016.00106.

Bijur, G N, and R S Jope. 2000. "Opposing Actions of Phosphatidylinositol 3-Kinase and Glycogen Synthase Kinase-3beta in the Regulation of HSF-1 Activity." Journal of 
Neurochemistry 75 (6): 2401-8. http://www.ncbi.nlm.nih.gov/pubmed/11080191.

Boucher, Jeremie, Yu H. Tseng, and C Ronald Kahn. 2010. "Insulin and Insulin-like Growth Factor-1 Receptors Act as Ligand-Specific Amplitude Modulators of a Common Pathway Regulating Gene Transcription." Journal of Biological Chemistry 285 (22). American Society for Biochemistry and Molecular Biology: 17235-45. doi:10.1074/jbc.M110.118620.

Bowler, K. 2005. "Acclimation, Heat Shock and Hardening." Journal of Thermal Biology. doi:10.1016/j.jtherbio.2004.09.001.

Brameshuber, Mario, Eva Sevcsik, Benedikt K. Rossboth, Christina Manner, Hans-Peter Peter Deigner, Begüm Peksel, Mária Péter, Zsolt Török, Albin Hermetter, and Gerhard J. Schütz. 2016. "Oxidized Phospholipids Inhibit the Formation of Cholesterol-Dependent Plasma Membrane Nanoplatforms." Biophysical Journal 110 (1). Biophysical Society: 205-13. doi:10.1016/j.bpj.2015.11.018.

Brameshuber, Mario, Julian Weghuber, Verena Ruprecht, Imre Gombos, Ibolya Horváth, László Vigh, Paul Eckerstorfer, Endre Kiss, Hannes Stockinger, and Gerhard J. Schütz. 2010. "Imaging of Mobile Long-Lived Nanoplatforms in the Live Cell Plasma Membrane." Journal of Biological Chemistry 285 (53). American Society for Biochemistry and Molecular Biology: 41765-71. doi:10.1074/jbc.M110.182121.

Breslow, David K, and Jonathan S Weissman. 2010. "Membranes in Balance: Mechanisms of Sphingolipid Homeostasis." Molecular Cell. doi:10.1016/j.molcel.2010.10.005.

Bromberg, Zohar, Pierre Goloubinoff, Younousse Saidi, and Yoram George Weiss. 2013. "The Membrane-Associated Transient Receptor Potential Vanilloid Channel Is the Central Heat Shock Receptor Controlling the Cellular Heat Shock Response in Epithelial Cells." PLOS ONE 8 (2): 1-12. doi:10.1371/journal.pone.0057149.

Bromberg, Zohar, and Yoram Weiss. 2016. "The Role of the Membrane-Initiated Heat Shock Response in Cancer." Frontiers in Molecular Biosciences 3 (April). Frontiers: 12. doi:10.3389/fmolb.2016.00012.

Bryantsev, Anton L., Svetlana Yu. Kurchashova, Sergey A. Golyshev, Vladimir Yu. Polyakov, Herman F. Wunderink, Bart Kanon, Karina R. Budagova, Alexander E. Kabakov, and Harm H. Kampinga. 2007. "Regulation of Stress-Induced Intracellular Sorting and Chaperone Function of Hsp27 (HspB1) in Mammalian Cells." Biochemical Journal 407 (3): 407-17. doi:10.1042/BJ20070195.

Bryantsev, Anton L, Svetlana A Loktionova, Olga P Ilyinskaya, Eduard M Tararak, Harm H Kampinga, and Alexander E Kabakov. 2002. "Distribution, Phosphorylation, and Activities of Hsp25 in Heat-Stressed H9c2 Myoblasts: A Functional Link to Cytoprotection." Cell Stress \& Chaperones 7 (2): 146-55. doi:10.1379/14661268(2002)007<0146:DPAAOH>2.0.CO;2.

Budzyński, Marek A, Mikael C Puustinen, Jenny Joutsen, and Lea Sistonen. 2015. "Uncoupling Stress-Inducible Phosphorylation of Heat Shock Factor 1 from Its Activation." Molecular and Cellular Biology 35 (14): 2530-40. doi:10.1128/MCB.00816-14.

Bulleid, Neil J. 2012. "Disulfide Bond Formation in the Mammalian Endoplasmic Reticulum." Cold Spring Harbor Perspectives in Biology 4 (11). Cold Spring Harbor Laboratory Press. doi:10.1101/cshperspect.a013219.

Burdon, R H. 1987. "Thermotolerance and the Heat Shock Proteins." Symposia of the Society for Experimental Biology 41: 269-83. http://www.ncbi.nlm.nih.gov/pubmed/3332487.

Burgman, P., A. Nussenzweig, and G. C. Li. 1995. "Thermotolerance." In , 75-87. Springer Berlin Heidelberg. doi:10.1007/978-3-642-57858-8_3.

Calderwood. 2010. "Signal Transduction Pathways Leading to Heat Shock Transcription." Signal Transduction Insights 2: 13. doi:10.4137/STI.S3994. 
Calderwood, Stuart K, and George M Hahn. 1983. "THERMAL SENSITIVITY AND RESISTANCE OF INSULIN-RECEPTOR BINDING IN THERMOTOLERANT CELLS" 734: 76-82.

Cappello, Francesco, Everly Conway De Macario, Lorenzo Marasà, Giovanni Zummo, and Alberto J L Macario. 2008. "Hsp60 Expression, New Locations, Functions and Perspectives for Cancer Diagnosis and Therapy." Cancer Biology and Therapy. doi:10.4161/cbt.7.6.6281.

Cargnello, Marie, and Philippe P Roux. 2011. "Activation and Function of the MAPKs and Their Substrates, the MAPK-Activated Protein Kinases." Microbiology and Molecular Biology Reviews : MMBR 75 (1): 50-83. doi:10.1128/MMBR.00031-10.

Carper, Stephen W., John J. Duffy, and Eugene W. Gerner. 1987. "Heat Shock Proteins in Thermotolerance and Other Cellular Processes." CANCER RESEARCH 47 (20): 5249-55.

Carrara, Marta, Filippo Prischi, and Maruf Ali. 2013. "UPR Signal Activation by Luminal Sensor Domains." International Journal of Molecular Sciences 14 (3). Multidisciplinary Digital Publishing Institute: 6454-66. doi:10.3390/ijms14036454.

Castro, Bruno M., Manuel Prieto, and Liana C. Silva. 2014. "Ceramide: A Simple Sphingolipid with Unique Biophysical Properties." Progress in Lipid Research 54 (1). Elsevier Ltd: 5367. doi:10.1016/j.plipres.2014.01.004.

Castro, Bruno M., Liana C. Silva, Alexander Fedorov, Rodrigo F M de Almeida, and Manuel Prieto. 2009. "Cholesterol-Rich Fluid Membranes Solubilize Ceramide Domains: Implications for the Structure and Dynamics of Mammalian Intracellular and Plasma Membranes." Journal of Biological Chemistry 284 (34): 22978-87. doi:10.1074/jbc.M109.026567.

Chen, Po-Wei, Luis L. Fonseca, Yusuf A. Hannun, Eberhard O. Voit, and DJ Montefusco. 2015. "Dynamics of the Heat Stress Response of Ceramides with Different Fatty-Acyl Chain Lengths in Baker's Yeast." Edited by Jorg Stelling. PLOS Computational Biology 11 (8). Cambridge University Press: e1004373. doi:10.1371/journal.pcbi.1004373.

Chiang, Wei Chung, Tsui Ting Ching, Hee Chul Lee, Carol Mousigian, and Ao Lin Hsu. 2012. "HSF-1 Regulators DDL-1/2 Link Insulin-like Signaling to Heat-Shock Responses and Modulation of Longevity." Cell 148 (1-2). Elsevier Inc.: 322-34. doi:10.1016/j.cell.2011.12.019.

Chou, Shiuh-Dih, Thomas Prince, Jianlin Gong, and Stuart K Calderwood. 2012. "mTOR Is Essential for the Proteotoxic Stress Response, HSF1 Activation and Heat Shock Protein Synthesis." PloS One 7 (6): e39679. doi:10.1371/journal.pone.0039679.

Chu, B, F Soncin, B D Price, M A Stevenson, and S K Calderwood. 1996. "Sequential Phosphorylation by Mitogen-Activated Protein Kinase and Glycogen Synthase Kinase 3 Represses Transcriptional Activation by Heat Shock Factor-1." The Journal of Biological Chemistry 271 (48). American Society for Biochemistry and Molecular Biology: 3084757. doi:10.1074/JBC.271.48.30847.

Clark, Andrew G, and Christopher D Fucito. 1998. "Stress Tolerance and Metabolic Response to Stress in Drosophila Melanogaster." Heredity 81 (5). Nature Publishing Group: 51427. doi:10.1046/j.1365-2540.1998.00414.x.

Conrad, Christian, and Daniel W. Gerlich. 2010. "Automated Microscopy for High-Content RNAi Screening." Journal of Cell Biology 188 (4): 453-61. doi:10.1083/jcb.200910105.

Crissman, Harry a, and John a Steinkamp. 1973. "Rapid, Simultaneous Measurement of Dna, Protein, and Cell Volume in Single Cells From Large Mammalian Cell Populations" I: 6.

Csont, Tamás, Gábor Balogh, Csaba Csonka, Imre Boros, Ibolya Horváth, László Vigh, and Péter Ferdinandy. 2002. "Hyperlipidemia Induced by High Cholesterol Diet Inhibits Heat Shock Response in Rat Hearts." Biochemical and Biophysical Research Communications 290 (5): 1535-38. doi:10.1006/bbrc.2002.6377. 
Czech, Michael P. 2000. "PIP2 and PIP3: Complex Roles at the Cell Surface." Cell 100 (6): 6036. doi:10.1016/S0092-8674(00)80696-0.

Darzynkiewicz, Z., H. Crissman, F. Traganos, and J. Steinkamp. 1982. "Cell Heterogeneity during the Cell Cycle." Journal of Cellular Physiology 113 (3). Wiley Subscription Services, Inc., A Wiley Company: 465-74. doi:10.1002/jcp.1041130316.

Dayalan Naidu, Sharadha, and Albena T. Dinkova-Kostova. 2017. "Regulation of the Mammalian Heat Shock Factor 1." The FEBS Journal, January. doi:10.1111/febs.13999.

Dayalan Naidu, Sharadha, Calum Sutherland, Ying Zhang, Ana Risco, Laureano de la Vega, Christopher J Caunt, C James Hastie, et al. 2016. "Heat Shock Factor 1 Is a Substrate for p38 Mitogen-Activated Protein Kinases." Molecular and Cellular Biology 36 (June). American Society for Microbiology (ASM): MCB.00292-16. doi:10.1128/MCB.00292-16.

Doil, Carsten, Niels Mailand, Simon Bekker-Jensen, Patrice Menard, Dorthe Helena Larsen, Rainer Pepperkok, Jan Ellenberg, et al. 2009. "RNF168 Binds and Amplifies Ubiquitin Conjugates on Damaged Chromosomes to Allow Accumulation of Repair Proteins." Cell 136 (3): 435-46. doi:10.1016/j.cell.2008.12.041.

Dolbeare, F, H Gratzner, M G Pallavicini, and J W Gray. 1983. "Flow Cytometric Measurement of Total DNA Content and Incorporated Bromodeoxyuridine." Proceedings of the National Academy of Sciences of the United States of America 80 (18): 5573-77. doi:10.1073/pnas.80.18.5573.

Donyo, Maya, Dror Hollander, Ziv Abramovitch, Shiran Naftelberg, and Gil Ast. 2016. "Phosphatidylserine Enhances IKBKAP Transcription by Activating the MAPK/ERK Signaling Pathway." Human Molecular Genetics 25 (7). Oxford University Press: 130717. doi:10.1093/hmg/ddw011.

Dorion, Sonia, Herman Lambert, and Jacques Landry. 2002. "Activation of the p38 Signaling Pathway by Heat Shock Involves the Dissociation of Glutathione S-Transferase Mu from Ask1." Journal of Biological Chemistry 277 (34): 30792-97. doi:10.1074/jbc.M203642200.

Dorion, Sonia, and Jacques Landry. 2002. "Activation of the Mitogen-Activated Protein Kinase Pathways by Heat Shock." Cell Stress \& Chaperones 7 (2): 200-206. doi:10.1379/14661268(2002)007<0200:AOTMAP>2.0.CO;2.

Durandau, Eric, Delphine Aymoz, and Serge Pelet. 2015. "Dynamic Single Cell Measurements of Kinase Activity by Synthetic Kinase Activity Relocation Sensors." BMC Biology 13 (1): 55. doi:10.1186/s12915-015-0163-z.

Fahy, E, S Subramaniam, R C Murphy, M Nishijima, C R Raetz, T Shimizu, F Spener, G van Meer, M J Wakelam, and E A Dennis. 2009. "Update of the LIPID MAPS Comprehensive Classification System for Lipids." J Lipid Res 50 Suppl: S9-14. doi:R800095-JLR200 [pii]\r10.1194/jlr.R800095-JLR200.

Falkenburger, Björn H., Eamonn J. Dickson, and Bertil Hille. 2013. "Quantitative Properties and Receptor Reserve of the DAG and PKC Branch of G $\mathrm{q}$-Coupled Receptor Signaling." The Journal of General Physiology 141 (5): 537-55. doi:10.1085/jgp.201210887.

Frechin, Mathieu, Thomas Stoeger, Stephan Daetwyler, Charlotte Gehin, Nico Battich, EvaMaria Damm, Lilli Stergiou, Howard Riezman, and Lucas Pelkmans. 2015. "Cell-Intrinsic Adaptation of Lipid Composition to Local Crowding Drives Social Behaviour." Nature 523 (7558): 88-91. doi:10.1038/nature14429.

Fulda, Simone, Adrienne M Gorman, Osamu Hori, and Afshin Samali. 2010. "Cellular Stress Responses: Cell Survival and Cell Death." International Journal of Cell Biology. Hindawi Publishing Corporation. doi:10.1155/2010/214074.

Gabai, Vladimir L, Anatoli B Meriin, D D Mosser, A W Caron, S Rits, Victor I Shifrin, Michael Y Sherman, et al. 1997. "Hsp70 Prevents Activation of Stress Kinases. A Novel Pathway of 
Cellular Thermotolerance." The Journal of Biological Chemistry 272 (29): 18033-37. http://www.jbc.org/content/272/29/18033.full.pdf.

Gault, Christopher R, Lina M Obeid, and Yusuf A Hannun. 2010. "An Overview of Sphingolipid Metabolism: From Synthesis to Breakdown." Advances in Experimental Medicine and Biology $688 . \quad \mathrm{NIH} \quad$ Public $1-23$. http://www.ncbi.nlm.nih.gov/pubmed/20919643.

Gehart, Helmuth, Susann Kumpf, Arne Ittner, and Romeo Ricci. 2010. "MAPK Signalling in Cellular Metabolism: Stress or Wellness?" EMBO Reports 11 (11): 834-40. doi:10.1038/embor.2010.160.

GERNER, EUGENE W., and MICHAEL J. SCHNEIDER. 1975. "Induced Thermal Resistance in HeLa Cells." Nature 256 (5517). Nature Publishing Group: 500-502. doi:10.1038/256500a0.

Gerthoffer, William T, and Susan J Gunst. 2001. "Signal Transduction in Smooth Muscle: Invited Review: Focal Adhesion and Small Heat Shock Proteins in the Regulation of Actin Remodeling and Contractility in Smooth Muscle." J Appl Physiol 91 (2): 963-72. http://jap.physiology.org/content/jap/91/2/963.full.pdf.

Geum, Dongho, Gi Hoon Son, and Kyungjin Kim. 2002. "Phosphorylation-Dependent Cellular Localization and Thermoprotective Role of Heat Shock Protein 25 in Hippocampal Progenitor Cells." Journal of Biological Chemistry 277 (22): 19913-21. doi:10.1074/jbc.M104396200.

Gidalevitz, Tali, Veena Prahlad, and Richard I. Morimoto. 2011. "The Stress of Protein Misfolding: From Single Cells to Multicellular Organisms." Cold Spring Harbor Perspectives in Biology 3 (6): 1-18. doi:10.1101/cshperspect.a009704.

Ginsberg, B H, J Jabour, and A A Spector. 1982. "Effect of Alterations in Membrane Lipid Unsaturation on the Properties of the Insulin Receptor of Ehrlich Ascites Cells." Biochimica et Biophysica Acta 690 (2): 157-64.

Gombos, Imre, Tim Crul, Stefano Piotto, Burcin Güngör, Zsolt Török, Gábor Balogh, Mária Péter, et al. 2011. "Membrane-Lipid Therapy in Operation: The HSP Co-Inducer BGP-15 Activates Stress Signal Transduction Pathways by Remodeling Plasma Membrane Rafts." Edited by Edathara Abraham. PLoS ONE 6 (12): e28818. doi:10.1371/journal.pone.0028818.

Gombos, Imre, and László Vígh. 2015. "Membrane Fluidity in the Center of Fever-Enhanced Immunity." Cell Cycle (Georgetown, Tex.) 14 (19). Taylor \& Francis: 3014-15. doi:10.1080/15384101.2015.1069506.

Görlach, Agnes, Katharina Bertram, Sona Hudecova, and Olga Krizanova. 2015. "Calcium and ROS: A Mutual Interplay." Redox Biology. doi:10.1016/j.redox.2015.08.010.

Graauw, Marjo De, Ine Tijdens, Rainer Cramer, Steve Corless, John F Timms, and Bob Van De Water. 2005. "Heat Shock Protein 27 Is the Major Differentially Phosphorylated Protein Involved in Renal Epithelial Cellular Stress Response and Controls Focal Adhesion Organization and Apoptosis." Journal of Biological Chemistry 280 (33). American Society for Biochemistry and Molecular Biology: 29885-98. doi:10.1074/jbc.M412708200.

Guettouche, Toumy, Frank Boellmann, William S Lane, and Richard Voellmy. 2005. "Analysis of Phosphorylation of Human Heat Shock Factor 1 in Cells Experiencing a Stress." BMC Biochemistry 6 (1): 4. doi:10.1186/1471-2091-6-4.

Gungor, Burcin, Imre Gombos, Tim Crul, Ferhan Ayaydin, László Szabó, Zsolt Török, Lajos Mátés, László Vígh, and Ibolya Horváth. 2014. "Rac1 Participates in Thermally Induced Alterations of the Cytoskeleton, Cell Morphology and Lipid Rafts, and Regulates the Expression of Heat Shock Proteins in B16F10 Melanoma Cells." PLoS ONE 9 (2): 89136111. doi:10.1371/journal.pone.0089136. 
Han, S I, S Y Oh, S H Woo, K H Kim, J H Kim, H D Kim, and H S Kang. 2001. "Implication of a Small GTPase Rac1 in the Activation of c-Jun N-Terminal Kinase and Heat Shock Factor in Response to Heat Shock." The Journal of Biological Chemistry 276 (3): 1889-95. doi:10.1074/jbc.M006042200.

Handayaningsih, Anastasia Evi, Genzo Iguchi, Hidenori Fukuoka, Hitoshi Nishizawa, Michiko Takahashi, Masaaki Yamamoto, Elizabeth Henny Herningtyas, et al. 2011. "Reactive Oxygen Species Play an Essential Role in IGF-I Signaling and IGF-I-Induced Myocyte Hypertrophy in C2C12 Myocytes." Endocrinology 152 (3): 912-21. doi:10.1210/en.2010-0981.

Hannun, Yusuf A., and Chiara Luberto. 2000. "Ceramide in the Eukaryotic Stress Response." Trends in Cell Biology 10 (2): 73-80. doi:10.1016/S0962-8924(99)01694-3.

Hannun, Yusuf A., and Lina M. Obeid. 2008. "Principles of Bioactive Lipid Signalling: Lessons from Sphingolipids." Nature Reviews. Molecular Cell Biology 9 (2). Nature Publishing Group: 139-50. doi:10.1038/nrm2329.

Hardie, D. Grahame, Fiona a. Ross, and Simon a. Hawley. 2012. "AMPK: A Nutrient and Energy Sensor That Maintains Energy Homeostasis." Nature Reviews Molecular Cell Biology 13 (4): 251-62. doi:10.1038/nrm3311.

Hardie, D Grahame. 2011. "Sensing of Energy and Nutrients by AMP-Activated Protein Kinase." In American Journal of Clinical Nutrition. Vol. 93. doi:10.3945/ajcn.110.001925.

HARWOOD, JOHN L., and LASZLO VIGH. 1998. "Membranes in Stress and Adaptation." Annals of the New York Academy of Sciences 851 (1 STRESS OF LIF). Blackwell Publishing Ltd: 162-68. doi:10.1111/j.1749-6632.1998.tb08990.x.

Hasday, Jeffrey D, and Ishwar S Singh. 2000. "Fever and the Heat Shock Response: Distinct, Partially Overlapping Processes." Cell Stress \& Chaperones 5 (5): 471-80. doi:10.1379/1466-1268(2000)005<0471:FATHSR>2.0.CO;2.

Hayes, David, Vanessa Napoli, Andrew Mazurkie, Walter F. Stafford, and Philip Graceffa. 2009. "Phosphorylation Dependence of Hsp27 Multimeric Size and Molecular Chaperone Function." Journal of Biological Chemistry 284 (28). American Society for Biochemistry and Molecular Biology: 18801-7. doi:10.1074/jbc.M109.011353.

Herzog, Ronny, Dominik Schwudke, Kai Schuhmann, Julio L Sampaio, Stefan R Bornstein, Michael Schroeder, and Andrej Shevchenko. 2011. "A Novel Informatics Concept for High-Throughput Shotgun Lipidomics Based on the Molecular Fragmentation Query Language." Genome Biology 12 (1): R8. doi:10.1186/gb-2011-12-1-r8.

Hetz, Claudio, Fabio Martinon, Diego Rodriguez, and Laurie H Glimcher. 2011. "The Unfolded Protein Response: Integrating Stress Signals Through the Stress Sensor IRE1." Physiological Reviews 91 (4): 1219-43. doi:10.1152/physrev.00001.2011.

Ho, Karen W, Nicholas J Ward, and David J Calkins. 2012. "TRPV1: A Stress Response Protein in the Central Nervous System." American Journal of Neurodegenerative Disease 1 (1). e-Century Publishing Corporation: 1-14. http://www.ncbi.nlm.nih.gov/pubmed/22737633.

Holmberg, Carina I, Ville Hietakangas, Andrey Mikhailov, Jouni O Rantanen, Marko Kallio, Annika Meinander, Jukka Hellman, et al. 2001. "Phosphorylation of Serine 230 Promotes Inducible Transcriptional Activity of Heat Shock Factor 1." EMBO Journal 20 (14). European Molecular Biology Organization: 3800-3810. doi:10.1093/emboj/20.14.3800.

Homolya, László, Zsolt Holló, Ursula A. Germann, Ira Pastan, Michael M. Gottesman, and Balázs Sarkadi. 1993. "Fluorescent Cellular Indicators Are Extruded by the Multidrug Resistance Protein." Journal of Biological Chemistry 268 (29): 21493-96. doi:VL - 268.

Hong, D, D Jaron, D G Buerk, and K a Barbee. 2006. "Heterogeneous Response of 
Microvascular Endothelial Cells to Shear Stress." American Journal of Physiology. Heart and Circulatory Physiology 290 (6): H2498-508. doi:10.1152/ajpheart.00828.2005.

Hooper, Philip L, and Joanna J Hooper. 2005. "Loss of Defense Against Stress: Diabetes and Heat Shock Proteins." DIABETES TECHNOLOGY \& THERAPEUTICS 7 (1).

Horváth, I, a Glatz, V Varvasovszki, Z Török, T Páli, G Balogh, E Kovács, et al. 1998. "Membrane Physical State Controls the Signaling Mechanism of the Heat Shock Response in Synechocystis PCC 6803: Identification of hsp17 as A 'fluidity Gene'." Proceedings of the National Academy of Sciences of the United States of America 95 (7): 3513-18. doi:10.1073/pnas.95.7.3513.

Hsu, Ao-Lin, Coleen T Murphy, and Cynthia Kenyon. 2003. "Regulation of Aging and AgeRelated Disease by DAF-16 and Heat-Shock Factor." Science 300 (5622): 1142-45. doi:10.1126/science.1083701.

Hung, Chien-Min, Luisa Garcia-Haro, Cynthia A Sparks, and David A Guertin. 2012. "mTORDependent Cell Survival Mechanisms." Cold Spring Harbor Perspectives in Biology 4 (12). Cold Spring Harbor Laboratory Press. doi:10.1101/cshperspect.a008771.

Hung, Mien-Chie, and Wolfgang Link. 2011. "Protein Localization in Disease and Therapy." Journal of Cell Science 124 (Pt 20): 3381-92. doi:10.1242/jcs.089110.

Jackson, Savannah, Dahlia M. Nielsen, and Nadia D. Singh. 2015. "Increased Exposure to Acute Thermal Stress is Associated with a Non-Linear Increase in Recombination Frequency and an Independent Linear Decrease in Fitness in Drosophila." BMC Evolutionary Biology 15 (1). BioMed Central: 175. doi:10.1186/s12862-015-0452-8.

Jansson, Erik T, Carolina L Trkulja, Aikeremu Ahemaiti, Maria Millingen, Gavin Dm Jeffries, Kent Jardemark, and Owe Orwar. 2013. "Effect of Cholesterol Depletion on the Pore Dilation of TRPV1." Molecular Pain 9 (1): 1. doi:10.1186/1744-8069-9-1.

Jenkins, G M, A Richards, T Wahl, C Mao, L Obeid, and Y Hannun. 1997. "Involvement of Yeast Sphingolipids in the Heat Stress Response of Saccharomyces Cerevisiae." The Journal of Biological Chemistry $272 \quad$ (51): 32566-72. http://www.ncbi.nlm.nih.gov/pubmed/9405471.

Jenkins, Gary M., L. Ashley Cowart, Paola Signorelli, Benjamin J Pettus, Charles E Chalfant, and Yusuf A Hannun. 2002. "Acute Activation of de Novo Sphingolipid Biosynthesis upon Heat Shock Causes an Accumulation of Ceramide and Subsequent Dephosphorylation of SR Proteins." Journal of Biological Chemistry 277 (45): 42572-78. doi:10.1074/jbc.M207346200.

Jóźwiak, Z, and W Leyko. 1992. "Role of Membrane Components in Thermal Injury of Cells and Development of Thermotolerance." International Journal of Radiation Biology 62 (6): 743-56. http://www.ncbi.nlm.nih.gov/pubmed/1362768.

Kabakov, Alexander E, Karina R Budagova, David S Latchman, and Harm H Kampinga. 2002. "Stressful Preconditioning and HSP70 Overexpression Attenuate Proteotoxicity of Cellular ATP Depletion." American Journal of Physiology. Cell Physiology 283 (2): C52134. doi:10.1152/ajpcell.00503.2001.

Kampinga, Harm H, and Elizabeth A Craig. 2010. "The HSP70 Chaperone Machinery: J Proteins as Drivers of Functional Specificity." Nature Reviews. Molecular Cell Biology 11 (8). Nature Publishing Group: 579-92. doi:10.1038/nrm2941.

Kasambalides, Efthimios J., and Karl W. Lanks. 1985. "Antagonistic Effects of Insulin and Dexamethasone on Glucose-Regulated and Heat Shock Protein Synthesis." Journal of Cellular Physiology 123 (2). Wiley Subscription Services, Inc., A Wiley Company: 28387. doi:10.1002/jcp.1041230220.

Katz, Menachem, Ido Amit, and Yosef Yarden. 2007. "Regulation of MAPKs by Growth Factors and Receptor Tyrosine Kinases." Biochimica et Biophysica Acta - Molecular Cell 
Research. NIH Public Access. doi:10.1016/j.bbamcr.2007.01.002.

Kaufman, Randal J., and Jyoti D. Malhotra. 2014. "Calcium Trafficking Integrates Endoplasmic Reticulum Function with Mitochondrial Bioenergetics." Biochimica et Biophysica Acta Molecular Cell Research. doi:10.1016/j.bbamcr.2014.03.022.

Kavran, Jennifer M, Jacqueline M McCabe, Patrick O Byrne, Mary Katherine Connacher, Zhihong Wang, Alexander Ramek, Sarvenaz Sarabipour, et al. 2014. "How IGF-1 Activates Its Receptor." eLife 3 (September). eLife Sciences Publications Limited: 113749. doi:10.7554/eLife.03772.

Kay, Jason G., and Sergio Grinstein. 2013. "Phosphatidylserine-Mediated Cellular Signaling." In , 177-93. Springer Netherlands. doi:10.1007/978-94-007-6331-9_10.

Kennedy, Donna, Richard Jäger, Dick D Mosser, and Afshin Samali. 2014. "Regulation of Apoptosis by Heat Shock Proteins." IUBMB Life 66 (5): 327-38. doi:10.1002/iub.1274.

Kirkegaard, Thomas, Anke G Roth, Nikolaj H T Petersen, Ajay K Mahalka, Ole Dines Olsen, Irina Moilanen, Alicja Zylicz, et al. 2010. "Hsp70 Stabilizes Lysosomes and Reverts Niemann-Pick Disease-Associated Lysosomal Pathology." Nature 463 (7280): 549-53. doi:10.1038/nature08710.

Klotzsch, Enrico, and Gerhard J Schütz. 2013. "A Critical Survey of Methods to Detect Plasma Membrane Rafts." Philosophical Transactions of the Royal Society of London. Series B, Biological Sciences 368 (1611): 20120033. doi:10.1098/rstb.2012.0033.

Konings, A W, and A C Ruifrok. 1985. "Role of Membrane Lipids and Membrane Fluidity in Thermosensitivity and Thermotolerance of Mammalian Cells." Radiation Research 102 (1): 86-98. doi:10.2307/3576432.

Konishi, Hiroaki, Hidenori Matsuzaki, Motonari Tanaka, Yukitoshi Takemura, Shun'ichi Kuroda, Yoshitaka Ono, and Ushio Kikkawa. 1997. "Activation of Protein Kinase B (Akt/RAC-Protein Kinase) by Cellular Stress and Its Association with Heat Shock Protein Hsp27." FEBS Letters 410 (2-3): 493-98. doi:10.1016/S0014-5793(97)00541-3.

Koren, John, Umesh K Jinwal, Ying Jin, John O'Leary, Jeff R Jones, Amelia G Johnson, Laura J Blair, et al. 2010. "Facilitating Akt Clearance via Manipulation of Hsp70 Activity and Levels." Journal of Biological Chemistry 285 (4). American Society for Biochemistry and Molecular Biology: 2498-2505. doi:10.1074/jbc.M109.057208.

Kose, Shingo, Maiko Furuta, and Naoko Imamoto. 2012. "Hikeshi, a Nuclear Import Carrier for Hsp70s, Protects Cells from Heat Shock-Induced Nuclear Damage." Cell 149 (3): 57889. doi:10.1016/j.cell.2012.02.058.

Kose, Shingo, and Naoko Imamoto. 2014. "Nucleocytoplasmic Transport under Stress Conditions and Its Role in HSP70 Chaperone Systems." Biochimica et Biophysica Acta General Subjects. doi:10.1016/j.bbagen.2014.04.022.

Kostenko, Sergiy, and Ugo Moens. 2009. "Heat Shock Protein 27 Phosphorylation: Kinases, Phosphatases, Functions and Pathology." Cellular and Molecular Life Sciences : CMLS 66 (20): 3289-3307. doi:10.1007/s00018-009-0086-3.

Kotoglou, Polychronis, Alexandras Kalaitzakis, Patra Vezyraki, Theodore Tzavaras, Lampros K Michalis, Francoise Dantzer, Jae U Jung, and Charalampos Angelidis. 2009. "Hsp70 Translocates to the Nuclei and Nucleoli, Binds to XRCC1 and PARP-1, and Protects HeLa Cells from Single-Strand DNA Breaks." Cell Stress and Chaperones 14 (4). Springer: 391406. doi:10.1007/s12192-008-0093-6.

Krebs, R A, and V Loeschcke. 1994. "Response to Environmental Change: Genetic Variation and Fitness in Drosophila Buzzatii Following Temperature Stress." EXS 68: 309-21. http://www.ncbi.nlm.nih.gov/pubmed/8032136.

Krumova, Katerina, and Gonzalo Cosa. 2016. "Overview of Reactive Oxygen Species." In , 1- 
21. doi:10.1039/9781782622208-00001.

Kültz, Dietmar. 2005. "MOLECULAR AND EVOLUTIONARY BASIS OF THE CELLULAR STRESS RESPONSE." Annual Review of Physiology 67 (1): 225-57. doi:10.1146/annurev.physiol.67.040403.103635.

Kusumi, Akihiro, Takahiro K Fujiwara, Rahul Chadda, Min Xie, Taka A Tsunoyama, Ziya Kalay, Rinshi S Kasai, and Kenichi G N Suzuki. 2012. "Dynamic Organizing Principles of the Plasma Membrane That Regulate Signal Transduction: Commemorating the Fortieth Anniversary of Singer and Nicolson's Fluid-Mosaic Model." Annual Review of Cell and Developmental Biology 28 (1): 215-50. doi:10.1146/annurev-cellbio-100809-151736.

Lee, Eung Ryoung, Jang Yong Kim, Yong Jin Kang, Jae Yeon Ahn, Jung Hyun Kim, Bong Woo Kim, Hye Yeon Choi, Mi Young Jeong, and Ssang Goo Cho. 2006. "Interplay between PI3K/Akt and MAPK Signaling Pathways in DNA-Damaging Drug-Induced Apoptosis." Biochimica et Biophysica Acta - Molecular Cell Research 1763 (9): 958-68. doi:10.1016/j.bbamcr.2006.06.006.

Lee, Kyoung Hee, Choon Taek Lee, Whan Kim Young, Koo Han Sung, Young Soo Shim, and Chul Gyu Yoo. 2005. "Preheating Accelerates Mitogen-Activated Protein (MAP) Kinase Inactivation Post-Heat Shock via a Heat Shock Protein 70-Mediated Increase in Phosphorylated MAP Kinase Phosphatase-1." Journal of Biological Chemistry 280 (13). American Society for Biochemistry and Molecular Biology: 13179-86. doi:10.1074/jbc.M410059200.

Levental, Ilya, Michal Grzybek, and Kai Simons. 2011. "Raft Domains of Variable Properties and Compositions in Plasma Membrane Vesicles." Proceedings of the National Academy of Sciences of the United States of America 108 (28): 11411-16. doi:10.1073/pnas.1105996108.

Li, Gloria C. 1985. "Elevated Levels of 70,000 Dalton Heat Shock Protein in Transiently Thermotolerant Chinese Hamster Fibroblasts and in Their Stable Heat Resistant Variants." International Journal of Radiation Oncology*Biology*Physics 11 (1): 165-77. doi:10.1016/0360-3016(85)90376-1.

Li, Song, Michael Kim, Y L Hu, Shila Jalali, David D Schlaepfer, Tony Hunter, Shu Chien, and John Y-J Shyy. 1997. "Fluid Shear Stress Activation of Focal Adhesion Kinase. Linking to Mitogen-Activated Protein Kinases." J Biol Chem 272: 30455-62. http://www.jbc.org/content/272/48/30455.full.pdf.

Li, Xiao-Xiao, Bun Tsoi, Yi-Fang Li, Hiroshi Kurihara, and Rong-Rong He. 2015. "Cardiolipin and Its Different Properties in Mitophagy and Apoptosis." The Journal of Histochemistry and Cytochemistry: Official Journal of the Histochemistry Society 63 (5): 301-11. doi:10.1369/0022155415574818.

Lim, Sung Chul, Hong Quan Duong, Jeong Eun Choi, Keshab Raj Parajuli, Ho Sung Kang, and Song ly Han. 2010. "Implication of PI3K-Dependent HSP27 and p53 Expression in Mild Heat Shock-Triggered Switch of Metabolic Stress-Induced Necrosis to Apoptosis in A549 Cells." International Journal of Oncology 36 (2): 387-93. doi:10.3892/ijo-00000511.

Lin, R. Z., Z.-W. Hu, J. H. Chin, and B. B. Hoffman. 1997. "Heat Shock Activates c-Src Tyrosine Kinases and Phosphatidylinositol 3-Kinase in NIH3T3 Fibroblasts." Journal of Biological Chemistry 272 (49). American Society for Biochemistry and Molecular Biology: 31196202. doi:10.1074/jbc.272.49.31196.

Lin, Richard Z., Zhuo Wei Hu, Jane H. Chin, and Brian B. Hoffman. 1997. "Heat Shock Activates c-Src Tyrosine Kinases and Phosphatidylinositol 3- Kinase in NIH3T3 Fibroblasts." Journal of Biological Chemistry 272 (49): 31196-202. doi:10.1074/jbc.272.49.31196.

Lindquist, Susan. 1986. "The Heat-Shock Response." Ann. Rev. Biochem. 55 (1). Annual Reviews 4139 El Camino Way, P.O. Box 10139, Palo Alto, CA 94303-0139, USA: 1151- 
91. doi:10.1146/annurev.bi.55.070186.005443.

Liu, Chien-Ting, and George A Brooks. 2012. "Mild Heat Stress Induces Mitochondrial Biogenesis in C2C12 Myotubes." Journal of Applied Physiology (Bethesda, Md. : 1985) 112 (3). American Physiological Society: 354-61. doi:10.1152/japplphysiol.00989.2011.

Liu, Yu, Yuan Su, and Xuemin Wang. 2013. "Phosphatidic Acid-Mediated Signaling." In , 15976. Springer Netherlands. doi:10.1007/978-94-007-6331-9_9.

Longo, V. D., and P. Fabrizio. 2002. "Regulation of Longevity and Stress Resistance: A Molecular Strategy Conserved from Yeast to Humans?" Cellular and Molecular Life Sciences 59 (6): 903-8. doi:10.1007/s00018-002-8477-8.

Luft, J C, I J Benjamin, R Mestril, and D J Dix. 2001. "Heat Shock Factor 1-Mediated Thermotolerance Prevents Cell Death and Results in G2/M Cell Cycle Arrest." Cell Stress $\begin{array}{lllll}\& & \text { Chaperones } & 6 & \text { (4). } & \text { Springer: }\end{array}$ http://www.ncbi.nlm.nih.gov/pubmed/11795469.

Lukacs, Viktor, Baskaran Thyagarajan, Peter Varnai, Andras Balla, Tamas Balla, and Tibor Rohács. 2007. "Dual Regulation of TRPV1 by Phosphoinositides." Journal of Neuroscience 27 (26): 7070-80. doi:10.1523/JNEUROSCI.1866-07.2007.

Maeda, T, K Balakrishnan, and S Q Mehdi. 1983. "A Simple and Rapid Method for the Preparation of Plasma Membranes." Biochim Biophys Acta 731 (1): 115-20. http://view.ncbi.nlm.nih.gov/pubmed/6405785.

Mahdi, M H Ben, ValÉrie Andrieu, and Catherine Pasquier. 2000. "Focal Adhesion Kinase Regulation by Oxidative Stress in Different Cell Types." IUBMB Life 50 (4). Informa Healthcare: 291-99. doi:10.1080/713803721.

Mao, Haiping, Fanghong Li, Kathleen Ruchalski, Dick D. Mosser, John H. Schwartz, Yihan Wang, and Steven C. Borkan. 2003. "hsp72 Inhibits Focal Adhesion Kinase Degradation in ATP-Depleted Renal Epithelial Cells." Journal of Biological Chemistry 278 (20): 1821420. doi:10.1074/jbc.M300126200.

Marshall, C.J. 1995. "Specificity of Receptor Tyrosine Kinase Signaling: Transient versus Sustained Extracellular Signal-Regulated Kinase Activation." Cell 80 (2): 179-85. doi:10.1016/0092-8674(95)90401-8.

Matsukawa, Jun, Atsushi Matsuzawa, Kohsuke Takeda, and Hidenori Ichijo. 2004. "The ASK1MAP Kinase Cascades in Mammalian Stress Response." Journal of Biochemistry. doi:10.1093/jb/mvh134.

Mayer, Matthias P. 2013. "Hsp70 Chaperone Dynamics and Molecular Mechanism." Trends in Biochemical Sciences 38 (10): 507-14. doi:10.1016/j.tibs.2013.08.001.

McMillan, D R, X Xiao, L Shao, K Graves, and I J Benjamin. 1998. "Targeted Disruption of Heat Shock Transcription Factor 1 Abolishes Thermotolerance and Protection against HeatInducible Apoptosis." The Journal of Biological Chemistry 273 (13): 7523-28.

Meier, K. D., Olivier Deloche, Kentaro Kajiwara, Kouichi Funato, and Howard Riezman. 2005. "Sphingoid Base Is Required for Translation Initiation during Heat Stress in Saccharomyces Cerevisiae." Molecular Biology of the Cell 17 (3). American Society for Cell Biology: 1164-75. doi:10.1091/mbc.E05-11-1039.

Michaud, Sébastien, Sébastien Lavoie, Marie Odile Guimond, and Robert M. Tanguay. 2008. "The Nuclear Localization of Drosophila Hsp27 Is Dependent on a Monopartite ArginineRich NLS and Is Uncoupled from Its Association to Nuclear Speckles." Biochimica et Biophysica Acta - Molecular Cell Research 1783 (6): 1200-1210. doi:10.1016/j.bbamcr.2008.01.031.

Mitra, Satyajit K., Daniel A. Hanson, and David D. Schlaepfer. 2005. "Focal Adhesion Kinase: In Command and Control of Cell Motility." Nature Reviews. Molecular Cell Biology 6 (1). 
Nature Publishing Group: 56-68. doi:10.1038/nrm1549.

Morimoto, Richard I. 1998. "Regulation of the Heat Shock Transcriptional Response: Cross Talk between a Family of Heat Shock Factors, Molecular Chaperones, and Negative Regulators." Genes and Development 12 (24): 3788-96. doi:10.1101/gad.12.24.3788.

Mymrikov, Evgeny V, Alim S Seit-Nebi, and Nikolai B Gusev. 2011. "Large Potentials of Small Heat Shock Proteins." Physiological Reviews 91 (4): 1123-59. doi:10.1152/physrev.00023.2010.

Nadeau, Sébastien lan, and Jacques Landry. 2007. "Mechanisms of Activation and Regulation of the Heat Shock-Sensitive Signaling Pathways." Adv Exp Med Biol 594. New York, NY: Springer New York: 100-113. doi:10.1007/978-0-387-39975-1_10.

Nagy, Eniko, Zsolt Balogi, Imre Gombos, Malin Akerfelt, A. Bjorkbom, Gábor Balogh, Z. Torok, et al. 2007. "Hyperfluidization-Coupled Membrane Microdomain Reorganization Is Linked to Activation of the Heat Shock Response in a Murine Melanoma Cell Line." Proceedings of the National Academy of Sciences 104 (19): 7945-50. doi:10.1073/pnas.0702557104.

Ng, Xue Wen, Nirmalya Bag, and Thorsten Wohland. 2015. "Characterization of Lipid and Cell Membrane Organization by the Fluorescence Correlation Spectroscopy Diffusion Law." CHIMIA International Journal for Chemistry 69 (3): 112-19. doi:10.2533/chimia.2015.112.

Nollen, E a, Florian A Salomons, Jeanette F Brunsting, J J van der Want, O C Sibon, and Harm H Kampinga. 2001. "Dynamic Changes in the Localization of Thermally Unfolded Nuclear Proteins Associated with Chaperone-Dependent Protection." Proceedings of the National Academy of Sciences of the United States of America 98 (21): 12038-43. doi:10.1073/pnas.201112398.

Noonan, Emily J., Robert F. Place, Reza J. Rasoulpour, Charles Giardina, and Lawrence E. Hightower. 2007. “Cell Number-Dependent Regulation of Hsp70B' Expression: Evidence of an Extracellular Regulator." Journal of Cellular Physiology 210 (1). Wiley Subscription Services, Inc., A Wiley Company: 201-11. doi:10.1002/jcp.20875.

Ouwens, D. Margriet, Daniel S. Gomes de Mesquita, Jeroen Dekker, and J Antonie Maassen. 2001. "Hyperosmotic Stress Activates the Insulin Receptor in CHO Cells." Biochimica et Biophysica Acta - Molecular Cell Research 1540 (2): 97-106. doi:10.1016/S01674889(01)00126-4.

Paepe, Rosine de, Stéphane D Lemaire, and Antoine Danon. 2014. "Cardiolipin at the Heart of Stress Response across Kingdoms." Plant Signaling \& Behavior 9 (9): e29228. doi:10.4161/psb.29228.

Palmer, Amy E, and Roger Y Tsien. 2006. "Measuring Calcium Signaling Using Genetically Targetable Fluorescent Indicators." Nature Protocols 1 (3): 1057-65. doi:10.1038/nprot.2006.172.

Paradies, Giuseppe, Valeria Paradies, Valentina De Benedictis, Francesca M. Ruggiero, and Giuseppe Petrosillo. 2014. "Functional Role of Cardiolipin in Mitochondrial Bioenergetics." Biochimica et Biophysica Acta - Bioenergetics. doi:10.1016/j.bbabio.2013.10.006.

Park, H. G., S. I. Han, S. Y. Oh, and H. S. Kang. 2005. "Cellular Responses to Mild Heat Stress." Cellular and Molecular Life Sciences 62 (1): 10-23. doi:10.1007/s00018-004-4208-7.

Parsell, D. A., J. Taulien, S. Lindquist, P. Viitanen, R. Jaenicke, A. Horwich, F.-U. Hartl, R. J. Ellis, and W. J. Welch. 1993. "The Role of Heat-Shock Proteins in Thermotolerance [and Discussion]." Philosophical Transactions of the Royal Society B: Biological Sciences 339 (1289): 279-86. doi:10.1098/rstb.1993.0026.

Pearl, Laurence $\mathrm{H}$, and Chrisostomos Prodromou. 2006. "Structure and Mechanism of the 
Hsp90 Molecular Chaperone Machinery." Annual Review of Biochemistry 75: 271-94. doi:10.1146/annurev.biochem.75.103004.142738.

Peng, Xuyang, Xinxin Guo, Steven C Borkan, Ajit Bharti, Yukio Kuramochi, Stuart Calderwood, and Douglas B Sawyer. 2005. "Heat Shock Protein 90 Stabilization of ErbB2 Expression Is Disrupted by ATP Depletion in Myocytes." Journal of Biological Chemistry 280 (13). American Society for Biochemistry and Molecular Biology: 13148-52. doi:10.1074/jbc.M410838200.

Péter, Mária, Gábor Balogh, Imre Gombos, Gerhard Liebisch, Ibolya Horváth, Zsolt Török, Enikő Nagy, et al. 2012. "Nutritional Lipid Supply Can Control the Heat Shock Response of B16 Melanoma Cells in Culture." Molecular Membrane Biology 29 (7): 274-89. doi:10.3109/09687688.2012.680203.

Péter, Mária, Attila Glatz, Péter Gudmann, Imre Gombos, Zsolt Török, Ibolya Horváth, László Vígh, and Gábor Balogh. 2017. "Metabolic Crosstalk between Membrane and Storage Lipids Facilitates Heat Stress Management in Schizosaccharomyces Pombe." Plos One 12 (3): e0173739. doi:10.1371/journal.pone.0173739.

Pinto, Sandra N., Liana C. Silva, Anthony H. Futerman, and Manuel Prieto. 2011. "Effect of Ceramide Structure on Membrane Biophysical Properties: The Role of Acyl Chain Length and Unsaturation." Biochimica et Biophysica Acta - Biomembranes 1808 (11): 2753-60. doi:10.1016/j.bbamem.2011.07.023.

Pratt, William B, and David O Toft. 2003. "Regulation of Signaling Protein Function and Trafficking by the hsp90/hsp70-Based Chaperone Machinery." Experimental Biology and Medicine (Maywood, NJ) 228 (2): 111-33. doi:10.1177/153537020322800201.

Rohacs, Tibor. 2015. "Phosphoinositide Regulation of TRPV1 Revisited." Pflugers Archiv European Journal of Physiology 467 (9): 1851-69. doi:10.1007/s00424-015-1695-3.

Rosette, C., and M. Karin. 1996. "Ultraviolet Light and Osmotic Stress: Activation of the JNK Cascade Through Multiple Growth Factor and Cytokine Receptors." Science 274 (5290): 1194-97. doi:10.1126/science.274.5290.1194.

Ruvolo, P P. 2001. "Ceramide Regulates Cellular Homeostasis via Diverse Stress Signaling Pathways." Leukemia : Official Journal of the Leukemia Society of America, Leukemia Research Fund, U.K 15 (8): 1153-60. doi:10.1038/sj.leu.2402197.

Sághy, Éva, Éva Szőke, Maja Payrits, Zsuzsanna Helyes, Rita Börzsei, János Erostyák, Tibor Zoltán Jánosi, György Sétáló, and János Szolcsányi. 2015. “Evidence for the Role of Lipid Rafts and Sphingomyelin in $\mathrm{Ca}(2+)$-Gating of Transient Receptor Potential Channels in Trigeminal Sensory Neurons and Peripheral Nerve Terminals." Pharmacological Research 100: 101-16. doi:10.1016/j.phrs.2015.07.028.

Saibil, Helen. 2013. "Chaperone Machines for Protein Folding, Unfolding and Disaggregation." Nature Reviews Molecular Cell Biology 14 (10): 630-42. doi:10.1038/nrm3658.

Saidi, Y., A. Finka, M. Muriset, Z. Bromberg, Y. G. Weiss, F. J.M. Maathuis, and P. Goloubinoff. 2009. "The Heat Shock Response in Moss Plants Is Regulated by Specific CalciumPermeable Channels in the Plasma Membrane." The Plant Cell Online 21 (9): 2829-43. doi:10.1105/tpc.108.065318.

Saidi, Y, M Peter, a Finka, C Cicekli, L Vigh, and P Goloubinoff. 2010. "Membrane Lipid Composition Affects Plant Heat Sensing and Modulates $\mathrm{Ca}(2+)$-Dependent Heat Shock Response." Plant Signal Behav 5 (12): 1530-33. doi:10.4161/psb.5.12.13163.

Sankaran, Jagadish, Xianke Shi, Liang Yoong Ho, Ernst H K Stelzer, and Thorsten Wohland. 2010. "ImFCS: A Software for Imaging FCS Data Analysis and Visualization." Optics Express 18 (25): 25468. doi:10.1364/OE.18.025468.

Sapra, Geeta, Yow Keat Tham, Nelly Cemerlang, Aya Matsumoto, Helen Kiriazis, Bianca C 
Bernardo, Darren C Henstridge, et al. 2014. "The Small-Molecule BGP-15 Protects against Heart Failure and Atrial Fibrillation in Mice." Nature Communications 5. Nature Publishing Group: 5705. doi:10.1038/ncomms6705.

Sarbassov, Dos D., David A. Guertin, Siraj M. Ali, and David M. Sabatini. 2005. "Phosphorylation and Regulation of Akt/PKB by the Rictor-mTOR Complex." Science 307 (5712). http://science.sciencemag.org/content/307/5712/1098.full.

Sato, S, N Fujita, and T Tsuruo. 2000. "Modulation of Akt Kinase Activity by Binding to Hsp90." Proc Natl Acad Sci U S A 97 (20). National Academy of Sciences: 10832-37. doi:10.1073/pnas.170276797.

Sato, Satoshi B., Kumiko Ishii, Asami Makino, Kazuhisa Iwabuchi, Akiko Yamaji-Hasegawa, Yukiko Senoh, Isao Nagaoka, Hitoshi Sakuraba, and Toshihide Kobayashi. 2004. "Distribution and Transport of Cholesterol-Rich Membrane Domains Monitored by a Membrane-Impermeant Fluorescent Polyethylene Glycol-Derivatizied Cholesterol." Journal of Biological Chemistry 279 (22): 23790-96. doi:10.1074/jbc.M313568200.

Schaller, M D, J D Hildebrand, and J T Parsons. 1999. "Complex Formation with Focal Adhesion Kinase: A Mechanism to Regulate Activity and Subcellular Localization of Src Kinases." Molecular Biology of the Cell 10 (10). American Society for Cell Biology: 3489-3505. doi:10.1091/MBC.10.10.3489.

Schröder, Martin, and Randal J Kaufman. 2005. "THE MAMMALIAN UNFOLDED PROTEIN RESPONSE." Annu. Rev. Biochem 74: 739-89. doi:10.1146/annurev.biochem.73.011303.074134.

Schubert, Charlotte. 2011. "Single-Cell Analysis: The Deepest Differences." Nature 480 (7375): 133-37. doi:10.1038/480133a.

Sengupta, Prabuddha, Tijana Jovanovic-Talisman, Dunja Skoko, Malte Renz, Sarah L Veatch, and Jennifer Lippincott-Schwartz. 2011. "Probing Protein Heterogeneity in the Plasma Membrane Using PALM and Pair Correlation Analysis." Nature Methods 8 (11): 969-75. doi:10.1038/nmeth.1704.

Sezgin, Erdinc, Theresia Gutmann, Tomasz Buhl, Ron Dirkx, Michal Grzybek, Ünal Coskun, Michele Solimena, Kai Simons, Ilya Levental, and Petra Schwille. 2015. "Adaptive Lipid Packing and Bioactivity in Membrane Domains." PLoS ONE 10 (4). doi:10.1371/journal.pone.0123930.

Sezgin, Erdinc, Ilya Levental, Michal Grzybek, Günter Schwarzmann, Veronika Mueller, Alf Honigmann, Vladimir N. Belov, et al. 2012. "Partitioning, Diffusion, and Ligand Binding of Raft Lipid Analogs in Model and Cellular Plasma Membranes." Biochimica et Biophysica Acta - Biomembranes 1818 (7). Elsevier B.V.: 1777-84. doi:10.1016/j.bbamem.2012.03.007.

Sezgin, Erdinc, Dominic Waithe, Jorge Bernardino De La Serna, and Christian Eggeling. 2015. "Spectral Imaging to Measure Heterogeneity in Membrane Lipid Packing." ChemPhysChem 16 (7): 1387-94. doi:10.1002/cphc.201402794.

Sharma, Pranav, Rajat Varma, R. C. Sarasij, Ira, Karine Gousset, G Krishnamoorthy, Madan Rao, and Satyajit Mayor. 2004. "Nanoscale Organization of Multiple GPI-Anchored Proteins in Living Cell Membranes." Cell 116 (4). Kluwer Academic/Plenum Publishers, New York: 577-89. doi:10.1016/S0092-8674(04)00167-9.

Shaw, M, P Cohen, and D R Alessi. 1998. "The Activation of Protein Kinase B by $\mathrm{H} 2 \mathrm{O} 2$ or Heat Shock Is Mediated by Phosphoinositide 3-Kinase and Not by Mitogen-Activated Protein Kinase-Activated Protein Kinase-2." The Biochemical Journal, no. Pt 1 (November). Portland Press Ltd: 241-46. http://www.ncbi.nlm.nih.gov/pubmed/9806907.

Shibata, Yoko, and Richard I. Morimoto. 2014. "How the Nucleus Copes with Proteotoxic Stress." Current Biology 24 (10). NIH Public Access: R463-74. 
doi:10.1016/j.cub.2014.03.033.

Shiizaki, Shigeru, Isao Naguro, and Hidenori Ichijo. 2013. "Activation Mechanisms of ASK1 in Response to Various Stresses and Its Significance in Intracellular Signaling." Advances in Biological Regulation. doi:10.1016/j.jbior.2012.09.006.

Shinohara, Tetsuji, Naohiko Takahashi, Tatsuhiko Ooie, Masahide Hara, Sakuji Shigematsu, Mikiko Nakagawa, Hidetoshi Yonemochi, Tetsunori Saikawa, and Hironobu Yoshimatsu. 2006. "Phosphatidylinositol 3-Kinase-Dependent Activation of Akt, an Essential Signal for Hyperthermia-Induced Heat-Shock Protein 72, Is Attenuated in StreptozotocinInduced Diabetic Heart." Diabetes 55 (5): 1307-15. http://www.ncbi.nlm.nih.gov/pubmed/16644687.

Siddle, Kenneth. 2011. "Signalling by Insulin and IGF Receptors: Supporting Acts and New Players." Journal of Molecular Endocrinology 47 (1). doi:10.1530/JME-11-0022.

Silva, Liana C L C, Rodrigo F M R F M de Almeida, Bruno M Bruno M Castro, Alexander Fedorov, and Manuel Prieto. 2007. "Ceramide-Domain Formation and Collapse in Lipid Rafts: Membrane Reorganization by an Apoptotic Lipid." Biophysical Journal 92 (2). Elsevier: 502-16. doi:10.1529/biophysj.106.091876.

Silver, Jordan Thomas, and Earl G Noble. 2012. "Regulation of Survival Gene hsp70." Cell Stress and Chaperones. doi:10.1007/s12192-011-0290-6.

Simons, Kai, and Julio L. Sampaio. 2011. "Membrane Organization and Lipid Rafts." Cold Spring Harbor Perspectives in Biology 3 (10): 1-17. doi:10.1101/cshperspect.a004697.

Snijder, Berend, Raphael Sacher, Pauli Rämö, Eva-Maria Damm, Prisca Liberali, and Lucas Pelkmans. 2009. "Population Context Determines Cell-to-Cell Variability in Endocytosis and Virus Infection." Nature 461 (7263): 520-23. doi:10.1038/nature08282.

Song, Jaewhan, Masahiro Takeda, and Richard I. Morimoto. 2001. "Bag1-Hsp70 Mediates a Physiological Stress Signalling Pathway That Regulates Raf-1/ERK and Cell Growth." Nature Cell Biology 3 (3): 276-82. doi:10.1038/35060068.

Szallasi, Arpad, Daniel N. Cortright, Charles A. Blum, and Samer R. Eid. 2007. "The Vanilloid Receptor TRPV1: 10 Years from Channel Cloning to Antagonist Proof-of-Concept." Nature Reviews Drug Discovery 6 (5). Nature Publishing Group: 357-72. doi:10.1038/nrd2280.

Szoke, Éva, Rita Börzsei, Dániel Márton Tóth, Orsolya Lengl, Zsuzsanna Helyes, Zoltán Sándor, and János Szolcsányi. 2010. "Effect of Lipid Raft Disruption on TRPV1 Receptor Activation of Trigeminal Sensory Neurons and Transfected Cell Line." European Journal of Pharmacology 628 (1-3): 67-74. doi:10.1016/j.ejphar.2009.11.052.

Taberner, Francisco J., Gregorio Fernández-Ballester, Asia Fernández-Carvajal, and Antonio Ferrer-Montiel. 2015. "TRP Channels Interaction with Lipids and Its Implications in Disease." Biochimica et Biophysica Acta (BBA) - Biomembranes 1848 (9): 1818-27. doi:10.1016/j.bbamem.2015.03.022.

Tahimic, Candice G T, Roger K. Long, Takuo Kubota, Maggie Yige Sun, Hashem Elalieh, Chak Fong, Alicia T. Menendez, Yongmei Wang, Jean Pierre Vilardaga, and Daniel D. Bikle. 2016. "Regulation of Ligand and Shear Stress-Induced Insulin-like Growth Factor 1 (IGF1) Signaling by the Integrin Pathway." Journal of Biological Chemistry 291 (15): 8140-49. doi:10.1074/jbc.M115.693598.

Taipale, Mikko, Daniel F Jarosz, and Susan Lindquist. 2010. "HSP90 at the Hub of Protein Homeostasis: Emerging Mechanistic Insights." Nature Reviews. Molecular Cell Biology 11 (7): 515-28. doi:10.1038/nrm2918.

Takahashi, Akihisa, Nobuhiro Yamakawa, Eiichiro Mori, Ken Ohnishi, Shin-ichi Yokota, Noriyuki Sugo, Yasuaki Aratani, Hideki Koyama, and Takeo Ohnishi. 2008. "Development of Thermotolerance Requires Interaction between Polymerase- $\beta$ and 
Heat Shock Proteins." Cancer Science 99 (5). Blackwell Publishing Asia: 973-78. doi:10.1111/j.1349-7006.2008.00759.x.

Takaki, Eiichi, and Akira Nakai. 2016. "Regulation of HSF Activation and Repression." In Heat Shock Factor, 51-72. Tokyo: Springer Japan. doi:10.1007/978-4-431-55852-1_3.

Tam, Christina, Vincent Idone, Cecilia Devlin, Maria Cecilia Fernandes, Andrew Flannery, Xingxuan He, Edward Schuchman, Ira Tabas, and Norma W. Andrews. 2010. "Exocytosis of Acid Sphingomyelinase by Wounded Cells Promotes Endocytosis and Plasma Membrane Repair." Journal of Cell Biology 189 (6): 1027-38. doi:10.1083/jcb.201003053.

Tang, Zijian, Siyuan Dai, Yishu He, Rosalinda A Doty, Leonard D Shultz, Stephen Byers Sampson, and Chengkai Dai. 2015. "MEK Guards Proteome Stability and Inhibits TumorSuppressive Amyloidogenesis via HSF1." Cell 160 (4). NIH Public Access: 729-44. doi:10.1016/j.cell.2015.01.028.

Tkáčová, Jana, and Mária Angelovičová. 2012. "Heat Shock Proteins (HSPs): A Review." Scientific Papers Animal Science and Biotechnologies 45 (1): 349-53. https://pdfs.semanticscholar.org/bf51/35c2f184715b4d9be5ee240231852269a05d.p df.

Török, Zsolt, Tim Crul, Bruno Maresca, Gerhard J. Schütz, Felix Viana, Laura Dindia, Stefano Piotto, et al. 2014. "Plasma Membranes as Heat Stress Sensors: From Lipid-Controlled Molecular Switches to Therapeutic Applications." Biochimica et Biophysical Acta 1838 (6). Elsevier: 1594-1618. doi:10.1016/j.bbamem.2013.12.015.

Trepel, Jane, Mehdi Mollapour, Giuseppe Giaccone, and Len Neckers. 2010. "Targeting the Dynamic HSP90 Complex in Cancer." Nature Reviews. Cancer 10 (8): 537-49. doi:10.1038/nrc2887.

Trinklein, Nathan D, Will C Chen, Robert E Kingston, and Richard M Myers. 2004. "Transcriptional Regulation and Binding of Heat Shock Factor 1 and Heat Shock Factor 2 to 32 Human Heat Shock Genes during Thermal Stress and Differentiation." Cell Stress \& Chaperones Cell Stress Society International 9 (1). https://www.ncbi.nlm.nih.gov/pmc/articles/PMC1065302/pdf/i1466-1268-9-1-21.pdf.

Velazquez, Jose M, and Susan Lindquist. 1984. "hsp70: Nuclear Concentration during Environmental Stress and Cytoplasmic Storage during Recovery." Cell 36 (3). Cold Spring Harbor Laboratory, Cold Spring Harbor, New York: 655-62. doi:10.1016/00928674(84)90345-3.

Velichko, Artem K., Elena N. Markova, Nadezhda V. Petrova, Sergey V. Razin, and Omar L. Kantidze. 2013. "Mechanisms of Heat Shock Response in Mammals." Cellular and Molecular Life Sciences. Springer Basel. doi:10.1007/s00018-013-1348-7.

Vertii, Anastassiia, Cosima Hakim, Alexey Kotlyarov, and Matthias Gaestel. 2006. "Analysis of Properties of Small Heat Shock Protein Hsp25 in MAPK-Activated Protein Kinase 2 (MK2)-Deficient Cells: MK2-Dependent Insolubilization of Hsp25 Oligomers Correlates with Susceptibility to Stress." Journal of Biological Chemistry 281 (37): 26966-75. doi:10.1074/jbc.M602134200.

Vihervaara, Anniina, and Lea Sistonen. 2014. "HSF1 at a Glance." Cell Science 127: 261-66. doi:10.1242/jcs.132605.

Vitale, A., A. Ceriotti, and J. Denecke. 1993. "The Role of the Endoplasmic Reticulum in Protein Synthesis, Modification and Intracellular Transport." Journal of Experimental Botany. Oxford University Press. doi:10.1093/jxb/44.9.1417.

Vos, Michel J., Marianne P. Zijlstra, Serena Carra, Ody C M Sibon, and Harm H. Kampinga. 2011. "Small Heat Shock Proteins, Protein Degradation and Protein Aggregation Diseases." Autophagy 7 (1): 101-3. doi:10.4161/auto.7.1.13935. 
Wang, Rongsheng E, Jeffrey L-F Kao, Carolyn A Hilliard, Raj K Pandita, Joseph L Roti Roti, Clayton R Hunt, and John-Stephen Taylor. 2009. "Inhibition of Heat Shock Induction of Heat Shock Protein 70 and Enhancement of Heat Shock Protein 27 Phosphorylation by Quercetin Derivatives." Journal of Medicinal Chemistry 52 (7). NIH Public Access: 191221. doi:10.1021/jm801445c.

Wang, XiaoZhe, Nicholas Grammatikakis, Aliki Siganou, and Stuart K Calderwood. 2003. "Regulation of Molecular Chaperone Gene Transcription Involves the Serine Phosphorylation, 14-3-3 Epsilon Binding, and Cytoplasmic Sequestration of Heat Shock Factor 1." Molecular and Cellular Biology 23 (17). American Society for Microbiology (ASM): 6013-26. doi:10.1128/mcb.23.17.6013-6026.2003.

Wells, Gerald B, Robert C Dickson, and Robert L Lester. 1998. "Heat-Induced Elevation of Ceramide in Saccharomyces Cerevisiae via de Novo Synthesis." Journal of Biological Chemistry 273 (13): 7235-43. doi:10.1074/jbc.273.13.7235.

Wersto, Robert P., Francis J. Chrest, James F. Leary, Christa Morris, Mary Alice StetlerStevenson, and Edward Gabrielson. 2001. "Doublet Discrimination in DNA Cell-Cycle Analysis." Communications in Clinical Cytometry 46 (5): 296-306. doi:10.1002/cyto.1171.

Woessmann, W, Y H Meng, and N F Mivechi. 1999. "An Essential Role for Mitogen-Activated Protein Kinases, ERKs, in Preventing Heat-Induced Cell Death." Journal of Cellular Biochemistry 74 (4): 648-62. http://www.ncbi.nlm.nih.gov/pubmed/10440934.

Xia, Jianguo, and David S Wishart. 2011. "Web-Based Inference of Biological Patterns, Functions and Pathways from Metabolomic Data Using MetaboAnalyst." Nature Protocols 6 (6): 743-60. doi:10.1038/nprot.2011.319.

Yaglom, Julia, Cornelia O'Callaghan-Sunol, Vladimir Gabai, and Michael Y Sherman. 2003. "Inactivation of Dual-Specificity Phosphatases Is Involved in the Regulation of Extracellular Signal-Regulated Kinases by Heat Shock and hsp72." Mol Cell Biol 23 (11). American Society for Microbiology (ASM): 3813-24. doi:10.1128/MCB.23.11.38133824.2003.

Yang, Lin, Gao-Yi Tan, Yu-Qiang Fu, Jin-Hai Feng, and Min-Hong Zhang. 2010. “Effects of Acute Heat Stress and Subsequent Stress Removal on Function of Hepatic Mitochondrial Respiration, ROS Production and Lipid Peroxidation in Broiler Chickens." Comparative Biochemistry and Physiology Part C: Toxicology \& Pharmacology 151 (2): 204-8. doi:10.1016/j.cbpc.2009.10.010.

Yokota, Shin Ichi, Noriko Yokosawa, Toru Kubota, Tamaki Okabayashi, Satoru Arata, and Nobuhiro Fujii. 2003. "Suppression of Thermotolerance in Mumps Virus-Infected Cells Is Caused by Lack of HSP27 Induction Contributed by STAT-1." Journal of Biological Chemistry 278 (43): 41654-60. doi:10.1074/jbc.M305701200.

Young, Jason C. 2010. "Mechanisms of the Hsp70 Chaperone System." Biochemistry and Cell Biology 88 (2): 291-300. doi:10.1139/009-175.

Young, Suzanne R L, Rita Gerard-O'Riley, Jae-Beom Kim, and Fredrick M Pavalko. 2009. “Focal Adhesion Kinase Is Important for Fluid Shear Stress-Induced Mechanotransduction in Osteoblasts." Journal of Bone and Mineral Research: The Official Journal of the American Society for Bone and Mineral Research 24 (3). American Society for Bone and Mineral Research: 411-24. doi:10.1359/jbmr.081102.

Yung, Hong Wa, D. Stephen Charnock-Jones, Graham J. Burton, KR McLeish, and D Hess. 2011. "Regulation of AKT Phosphorylation at Ser473 and Thr308 by Endoplasmic Reticulum Stress Modulates Substrate Specificity in a Severity Dependent Manner." Edited by Venugopalan Cheriyath. PLoS ONE 6 (3). Public Library of Science: e17894. doi:10.1371/journal.pone.0017894. 
Zhang, Rong, Dianhong Luo, Robert Miao, Lanfang Bai, Qingyuan Ge, William C Sessa, and Wang Min. 2005. "Hsp90-Akt Phosphorylates ASK1 and Inhibits ASK1-Mediated Apoptosis." Oncogene 24 (24): 3954-63. doi:10.1038/sj.onc.1208548.

Zhou, Yong, and John F Hancock. 2015. "Ras Nanoclusters: Versatile Lipid-Based Signaling Platforms." Biochimica et Biophysica Acta - Molecular Cell Research. doi:10.1016/j.bbamcr.2014.09.008.

Zhou, Yong, Hong Liang, Travis Rodkey, Nicholas Ariotti, Robert G Parton, and John F Hancock. 2014. "Signal Integration by Lipid-Mediated Spatial Cross Talk between Ras Nanoclusters." Molecular and Cellular Biology 34 (5): 862-76. doi:10.1128/MCB.0122713.

Zorzi, Elisa, and Paolo Bonvini. 2011. "Inducible Hsp70 in the Regulation of Cancer Cell Survival: Analysis of Chaperone Induction, Expression and Activity." Cancers 3: 392156. doi:10.3390/cancers3043921.

Zynda, Evan R., Melissa J. Grimm, Min Yuan, Lingwen Zhong, Thomas A. Mace, Maegan Capitano, Julie R. Ostberg, Kelvin P. Lee, Arnd Pralle, and Elizabeth A. Repasky. 2015. "A Role for the Thermal Environment in Defining Co-Stimulation Requirements for CD4+ T Cell Activation." Cell Cycle. doi:10.1080/15384101.2015.1049782. 


\section{SUMMARY}

Stress response $(S R)$ is a vitally important biological process that protects organisms against various environmental and pathophysiological conditions. Based on macromolecular damage, cells monitor stress irrespective of its type causing such damage. Therefore, many aspects of the cellular stress response are not stressor specific. One of the most studied stress is heat that results in deleterious damages, i.e. leakage of the plasma membrane or severe protein denaturation, only at relatively high temperatures. However, heat shock response could also be activated under mild pathophysiological conditions, such as in fever, that is unlikely to cause proteotoxicity. Fever appears to be an evolutionarily conserved response to bacterial or viral infection, which implies that it may have survival benefits. Recently, considerable evidence has been accumulated in favor of the "Membrane sensor hypothesis" which predicts that, the level of heat shock proteins (HSPs, also called stress proteins) changes as a result of alterations to the plasma membrane. Stressful conditions activate numerous membrane-related sensors at the top of the signaling pathways which are interconnected by the parameters of the membrane chemical and physical state. Phospholipids, sphingolipids and cholesterol are all involved in the generation of stress-induced second messengers.

The study of cellular stress response is of great importance to our understanding of how cells respond and adapt to various changes in their environments. The current research on cellular heat stress management focuses on the roles HSPs and the proteostasis network under severe stress conditions. The mild, fever-type stress and the maintenance of membrane homeostasis are less well understood. Herein, we characterized the acute effect of mild heat shock on membrane organization, and HSP synthesis and localization in mammalian cells, to delineate the role of membranes in the sensing and adaptation to heat.

In the first part of this work, the sequence of heat induced cellular events was investigated as a function of exposure time and temperature. HSP synthesis, HSP redistribution, re-modelling of plasma membrane structure and cellular lipidome and possible signal transduction pathways were analyzed. Multidisciplinary approach 
combining ultrasensitive fluorescence microscopy and lipidomics revealed the molecular details of distinct cellular stress profiles. Chinese hamster ovary (CHO) cells, at mild stress temperature $\left(40^{\circ} \mathrm{C}\right)$, adapt to environmental changes by activating lipid remodelling, maintaining membrane homeostasis and redistributing chaperone proteins whereas further increase in the temperature into moderate stress zone $\left(42.5^{\circ} \mathrm{C}\right)$ induces plasma membrane reorganization and HSP synthesis in addition to redistribution of chaperones. Under severe stress temperature $\left(44^{\circ} \mathrm{C}\right)$, additional defense mechanisms are activated, including elevated expression of molecular chaperones, contributing to an extended stress memory and acquired thermotolerance. Our results revealed the molecular details of a novel mild type of cellular eustress, when the mammalian cells adapt to fever-type mild heat and acquire thermotolerance in the complete absence of the induction of HSPs.

The current work addresses another fundamental question whether all cells in a culture (or in tissue) suffer the same consequence of an imposed stress and whether they respond in the same manner. Knowledge on gene expression and cellular responses in cells is derived from analyses of populations consisting of millions of cells. Although this approach provides useful insights into average population responses, they do not provide information on individual cells or subpopulations within cell cultures. The impact of heterogeneity is significant in many aspects: first, sample heterogeneity is critical for the functionality of cellular networks. Second, cell ensemble data can easily be misinterpreted when ignoring heterogeneity; a specific parameter - e.g. an expression profile, the molecular clustering or mobility - determined by measuring the average ensemble value need not to be preserved in the individual subclasses of cells. Third, correlation analysis at the single cell level allows for identifying molecular implications in a systemic approach; in this aspect, sample heterogeneity is utilized for obtaining mechanistic insights into cellular processes.

In the present project we demonstrated the individual variability in the stress response of genetically homogeneous mammalian cell population by combining state of the art lipidomics and ultrasensitive high content imaging. Cell cycle phase as a first cause of heterogeneity is linked to differential stress responses, however methods 
such as serum starvation and chemical treatments to block the cell cycle have collateral effects on the lipid composition of the cells. Therefore, results obtained with such methods can be misleading. The combination of microscopy and fluorescence activated cell sorting applied in this study bypasses the chemical treatments to analyze the cell cycle phases and allows the analysis of individuality of stress response. Our experiments revealed distinct, cell cycle dependent cellular lipidomes, however heat induced redistribution of chaperones was independent of the cell cycle phase. Therefore we extended our single cell approach to the individuality of the stress signaling. Calcium increase which is a hallmark of stress activates many kinases in the cells and hence coordinates the response. In single cells, heat treatment induced unsynchronized, distinct calcium peaks during the course of heat. Further efforts are needed to elucidate the importance of plasma membrane properties in the heterogeneity of calcium signalling and cellular stress response. 


\section{ÖSSZEFOGLALÓ}

A stresszválasz létfontosságú biológiai folyamat, amely megvédi az organizmusokat a különféle környezeti és patofiziológiás körülmények mellett. A sejtek minden stresszt (típustól függetlenül) nyomon követnek, amelyek makromolekuláris károsodást okoznak. Következésképpen a celluláris stresszválasz több szempontból sem stresszor specifikus. Az egyik leginkább tanulmányozott stressz-típus a hő, amely magas hőmérsékleteken komoly károkat eredményez (plazmamembrán integritásának csökkenése vagy súlyos fehérje denaturáció). A hősokk válasz azonban kiváltható enyhe patofiziológiás körülmények között is, pl. a láz esetén, amelynél proteotoxicitás nem valószínű. A láz a bakteriális és vírusos fertőzésekre adott evolúciósan konzervált válasz, amely feltételezhetően előnyt jelent a túlélés szempontjából. Az utóbbi időkben számottevő bizonyíték támasztotta alá az ún. „Membrán szenzor hipotézis"-t, amely azt feltételezi, hogy a plazmamembránban történt változások módosíthatják a hősokk fehérjék (a HSP-k vagy stressz fehérjék) szintjét. A stressz számos membránhoz kötött szenzoron keresztül indíthat el különböző jelátviteli útvonalakat. Ezek a membrán kémiai és fizikai állapotában bekövetkezett változásokkal hozhatók összefüggésbe. A stressz-indukált másodlagos hírvivő molekulák képződésében a koleszterin, a foszfolipidek és szfingolipidek játszhatnak elsődleges szerepet.

A sejtes stresszválasz vizsgálata rendkívül fontos ahhoz, hogy megértsük, hogyan reagálnak és adaptálódnak a sejtek, ha a környezetükben különféle változások következnek be. A celluláris hőstressz kezeléssel kapcsolatos jelenlegi kutatások a HSP-k szerepére és a proteosztázis hálózatra fokuszálnak súlyos stressz körülmények mellett. Az enyhe, láz-szerű stresszről és a membrán homeosztázis fenntartásáról azonban kevés ismerettel rendelkezünk. Jelen értekezésben az enyhe hősokk által a membrán szerveződésre valamint a HSP szintézisre és lokalizációra gyakorolt akut hatásokat jellemezzük különös tekintettel a membránok hőérzékelésben és az alkalmazkodásban betöltött szerepére.

Kísérleteinkben először a hő-indukálta celluláris események sorozatát vizsgáltuk meg az expozíciós idő és hőmérséklet függvényében. Tanulmányoztuk a HSP szintézist, a 
HSP redisztribúciót, a plazmamembrán szerkezet és a celluláris lipidom átrendeződését, valamint a lehetséges jelátviteli utakat. Multidiszciplináris megközelítéssel ultraszenzitív fluoreszcencia mikroszkópiát és lipidomikát kombinálva feltártuk a különböző sejtes stresszprofilok molekuláris részleteit.

Kínai hörcsög ovárium ( $\mathrm{CHO}$ ) sejtek a környezeti változásokhoz alkalmazkodva enyhe stressz-hőmérsékleten $\left(40^{\circ} \mathrm{C}\right)$ átrendezik a lipidjeiket, fenntartják a membrán homeosztázist és a sejten belül átszervezik a dajka fehérjék (chaperon HSPk) lokalizációját. Ha a hőmérséklet tovább emelkedik a mérsékelt tartományba $\left(42,5^{\circ} \mathrm{C}\right)$, a molekuláris dajka fehérjék sejten belüli újra elosztása mellett a sejtek elindítják a plazmamembrán újra szerveződését és a HSP szintézist. Súlyos stressz hőmérsékleten $\left(44^{\circ} \mathrm{C}\right)$ további védelmi mechanizmusok aktiválódnak, ide értve a molekuláris dajkafehérjék emelkedett expresszióját, ami hozzájárul a stresszmemória kiterjesztéséhez és a szerzett termotoleranciához. Eredményeink rámutattak egy sejtszintű eustressz tartomány molekuláris részleteire, amelyben az emlős sejtek adaptálódnak a láz-szerű enyhe hőmérséklethez, és kialakul a termotoleranciájuk a HSPk indukciójának teljes hiányában.

A jelen munka során egy másik alapvető kérdést is feltettünk arról, vajon a stressz hatása ugyanolyan következményekkel jár-e a sejtkultúra (vagy szövet) minden sejtjében, és azok azonos módon reagálnak-e a stresszorra. A génexpresszióval és a celluláris válaszokkal kapcsolatos ismereteinket több millió sejtet tartalmazó populációk vizsgálatával nyerjük. Ez a megközelítés hasznos információt nyújt a populáció átlagos válaszáról, a kultúrában lévő egyedi sejtek vagy szubpopulációk válaszáról azonban nem. E heterogenitás hatása több szempontól is jelentős: Egyrészt a sejtek individuális variabilitásának ismerete elengedhetetlen a celluláris hálózatok működésének megértéséhez.; Másrészt, a sejtekből együttesen nyert adatokat könnyen félreértelmezhetjük, ha figyelmen kívül hagyjuk a heterogenitást. A jellemző paraméterek (pl. expressziós profil, molekuláris klasztereződés vagy mobilitás) együttesen nyert átlagos értékei nem feltétlenül egyeznek meg az egyedi sejtek értékeivel. Harmadrészt, az egyedi sejtszintű korreláció analízis lehetővé teszi, hogy szisztematikus megközelítéssel molekuláris eseményeket azonosítsunk. Ebben a 
vonatkozásban a sejtek heterogenitását arra használjuk fel, hogy mechanisztikus betekintést nyerjünk a celluláris folyamatokba.

Jelen projekt során korszerü lipidomika és ultraszenzitív nagy információtartalmú képalkotó technikák kombinációjával bemutattuk, hogy a genetikailag homogén emlős sejtpopuláció egyedeinek stresszválasza nagy mértékben eltérő. A különböző stresszválaszokban megmutatkozó heterogenitás egyik fő oka lehet a sejtek eltérő sejtciklusa. Az olyan módszerek, mint pl. a széruméheztetés vagy a kémiai kezelések, amelyek célja a sejtciklus megállítása, egyúttal hatást gyakorolnak a sejtek lipidösszetételére is. Ebből adódóan az ilyen módszerekkel nyert adatok félrevezetők lehetnek. A vizsgálataink során alkalmazott mikroszkópia és fluoreszcencia-aktivált sejtválogatás (FACS) kombinációjával kémiai kezelések nélkül elemezhetjük a sejtciklust és az egyedi stresszválasz kapcsolatát. Kísérleteink alapján az eltérő sejtciklusokhoz különböző celluláris lipidomok tartoztak, a hő indukálta dajkafehérje lokalizáció a sejtciklus fázisától azonban nem függött. Ezért az egyedi sejt szintű megközelítésünket stressz-jelátvitel individualitásának vizsgálatával egészítettük ki. A stressz egyik fő jellemzője kalcium szint emelkedése, ami számos kináz aktiválásán keresztül szabályozhatja a választ. Kimutattuk, hogy a hőkezelés az egyes sejtekben eltérő, nem szinkronizált kalcium tranzienseket eredményez. További vizsgálatok szükségesek annak megértéséhez, hogy az egyes sejtek plazmamembránjának fizikaikémiai tulajdonságai milyen szereppel bírnak a kalcium jelátvitel ill. a stresszválasz heterogenitásában. 


\section{APPENDICES}

\subsection{Publication List}

MTMT number : 10052550

\section{Publications that are related to the PhD thesis :}

Peksel, Begüm, Imre Gombos, Mária Péter, László Vigh, Jr., Ádám Tiszlavicz, Mario Brameshuber, Gábor Balogh, Gerhard Schütz, Ibolya Horváth, László Vígh, Zsolt Török. "Mild heat induces a distinct "eustress" response in Chinese Hamster Ovary cells that does not require heat shock protein synthesis". (2017) Scientific Reports (in press)

\section{I.F.: 4.259}

Torok, Zsolt, Tim Crul, Bruno Maresca, Gerhard J Schutz, Felix Viana, Laura Dindia, Stefano Piotto, Mario Brameshuber, Gabor Balogh, Maria Peter, Amalia Porta, Alfonso Trapani, Imre Gombos, Attila Glatz, Burcin Gungor, Begum Peksel, Laszlo Vigh Jr, Balint Csoboz, Ibolya Horvath, Mathilakath M. Vijayan, Phillip L. Hooper, John L. Harwood, Laszlo Vigh. "Plasma Membranes as Heat Stress Sensors: From LipidControlled Molecular Switches to Therapeutic Applications." Biochimica et Biophysica Acta 1838, no. 6 (June 2014): 1594-1618. doi:10.1016/j.bbamem.2013.12.015.

I.F.: 3.498

Brameshuber, Mario, Eva Sevcsik, Benedikt K. Rossboth, Christina Manner, HansPeter Peter Deigner, Begüm Peksel, Mária Péter, Zsolt Török, Albin Hermetter, Gerhard J. Schütz. "Oxidized Phospholipids Inhibit the Formation of CholesterolDependent Plasma Membrane Nanoplatforms." Biophysical Journal 110, no. 1 (January 5, 2016): 205-13. doi:10.1016/j.bpj.2015.11.018.

\section{I.F.: 3.656}




\section{Publications that are not directly related to the PhD thesis:}

Cadenas, Cristina, Sonja Vosbeck, Eva Maria Hein, Birte Hellwig, Alice Langer, Heiko Hayen, Dennis Franckenstein Bettina Büttner, Seddik Hammad, Rosemarie Marchan, Matthias Hermes, Silvia Selinski, Jörg Rahnenführer, Begüm Peksel, Zsolt Török, László Vígh, Jan G. Hengstler. "Glycerophospholipid Profile in Oncogene-Induced Senescence." Biochimica et Biophysica Acta - Molecular and Cell Biology of Lipids 1821, no. 9 (September 2012): 1256-68. doi:10.1016/j.bbalip.2011.11.008.

\section{I.F.: 5.547}

Molnár, Eszter, Soujanya Kuntam, Pradeep Kumar Reddy Cingaram, Begüm Peksel, Bhavyashree Suresh, Gabriella Fábián, Liliána Z. Fehér, Attila Bokros, Agnes Medgyesi, Ferhan Ayaydin, Laszlo G. Puskas. "Combination of Small Molecule Microarray and Confocal Microscopy Techniques for Live Cell Staining Fluorescent Dye Discovery." Molecules 18, no. 8 (August 2013): 9999-10013.

\section{I.F.: 2.465}

Koos, Krisztian, Begüm Peksel, Lóránd Kelemen. "Phase Measurement Using DIC Microscopy" Acta Cybernetica 00 (0000) 1-15.

I.F.: 0.28

\section{Other publications:}

Kavas, Musa, Oya Ercan Akça, Ufuk Celikkol Akçay, Begüm Peksel, Seçkin Eroğlu, Hüseyin Avni Öktem, and Meral Yücel. "Antioxidant Responses of Peanut (Arachis Hypogaea L.) Seedlings to Prolonged Salt-Induced Stress." Archives of Biological Sciences 67, no. 4 (2015): 1303-12.

I.F.: 0.352

Özgür, Ebru, and Begüm Peksel. "Biohydrogen Production from Barley Straw Hydrolysate through Sequential Dark and Photofermentation." Journal of Cleaner Production 52 (2013): 14-20.

I.F.: 4.959 
Öztürk, Yavuz, Abdulmecit Gökçe, Begüm Peksel, Muazzez Gürgan, Ebru Özgür, Ufuk Gündüz, Nci Eroğlu, and Meral Yücel. "Hydrogen Production Properties of Rhodobacter Capsulatus with Genetically Modified Redox Balancing Pathways." International Journal of Hydrogen Energy 37, no. 2 (January 2012): 2014-20. doi:10.1016/j.ijhydene.2011.06.078.

\section{I.F.: 3.582}

Özgür, Ebru, Astrid E. Mars, Begüm Peksel, Annemarie Louwerse, Meral Yücel, Ufuk Gündüz, Pieternel A M Claassen, and Inci Eroğlu. "Biohydrogen Production from Beet Molasses by Sequential Dark and Photofermentation." International Journal of Hydrogen Energy 35, no. 2 (January 2010): 511-17. doi:10.1016/j.ijhydene.2009.10.094.

\section{I.F.: 3.582}

\section{Presentations in meetings and conferences:}

Begüm Peksel, Imre Gombos, László Vígh Jr, Péter Horváth, Mária Péter,Gábor Balogh, Ibolya Horváth, László Vígh, Zsolt Török. Cell-To-Cell Variation Of Stress Response Is Linked To Membrane Structure. EMBO Practical Course Single-cell Gene Expression Analysis. 17-22 April 2015, Heidelberg, Germany.

Begüm Peksel, Imre Gombos, László Vígh Jr, Péter Horváth, Mária Péter,Gábor Balogh, Ibolya Horváth, László Vígh, Zsolt Török. Cell-To-Cell Variation Of Stress Response Is Linked To Membrane Structure. EMBO/EMBL Symposium: Cellular Heterogeneity. 15-18 April 2015, Heidelberg,Germany.

Begüm Peksel, Imre Gombos, Peter Horvath, Akos Hunya, Anna-Maria Pilbat, Maria Peter, Gabor Balogh, Laszlo Vigh Jr., Kamilla Oglecka, Ibolya Horvath, Laszlo Vigh, Zsolt Torok. Individual variability in the stress response of genetically homogeneous mammalian cell population is linked to membrane rearrangement. FEBS workshop on Lipids. 25-30 August 2014, Spetses,Greece.

Begüm Peksel, Imre Gombos, László Vígh Jr, Péter Horváth, Mária Péter,Gábor Balogh, Ibolya Horváth, László Vígh, Zsolt Török. Single cell heat stress response: cell profiling and lipidomics. Straub Days - 28-29 May 2014 (oral presentation), Szeged, Hungary.

Begüm Peksel, Imre Gombos, László Vigh Jr., Ibolya Horváth, Mária Péter, Gábor Balogh, László Vígh, Zsolt Török. Individual variability in the stress response of 
genetically homogeneous mammalian cell population is linked to membrane rearrangement. Quantitative Single Cell Biology in Stem Cell Research, 10-11 October 2013, Münich, Germany.

Peksel B., Vígh L., Ayaydin F. Increased SUMOylation in response to membrane fluidization, ITC Alumni Meeting, (1-3 September 2011), (oral presentation) Szeged, Hungary. 


\section{DECLARATION}

Hereby, as corresponding author and supervisor I declare the role of Begüm Peksel Şahin in the following publications;

1. Peksel, Begüm, Imre Gombos, Mária Péter, László Vigh, Jr., Ádám Tiszlavicz, Mario Brameshuber, Gábor Balogh, Gerhard Schütz, Ibolya Horváth, László Vígh, Zsolt Török. "Mild heat induces a distinct "eustress" response in Chinese Hamster Ovary cells that does not require heat shock protein synthesis". (2017) Scientific Reports (in press)

The majority of the experiments were designed and carried out by Begüm Peksel Şahin in this article and it is the basis of the thesis. The results of Figure 1, Figure 2, Figure 4, Supplementary Figure S1, Supplementary Figure S2 and Supplementary Figure S3 were done by her. She was also involved in the treatments and sample preparations for the Figure 3, 5 and 6 and in writing the manuscript.

2. Török, Zsolt, Tim Crul, Bruno Maresca, Gerhard J Schütz, Felix Viana, Laura Dindia, Stefano Piotto, Mario Brameshuber, Gabor Balogh, Maria Peter, Amalia Porta, Alfonso Trapani, Imre Gombos, Attila Glatz, Burçin Güngör, Begüm Peksel, Laszlo Jr Vigh, Balint Csoboz, Ibolya Horvath, Mathilakath M. Vijayan, Phillip L. Hooper, John L. Harwood, Laszlo Vigh. "Plasma Membranes as Heat Stress Sensors: From Lipid-Controlled Molecular Switches to Therapeutic Applications." Biochimica et Biophysica Acta 1838, no. 6 (June 2014): 1594-1618. doi:10.1016/j.bbamem.2013.12.015.

This is a review article including several authors. Begüm Peksel Şahin was actively taken part in collecting literature and writing chapter 6 . : Cell profiling and lipidomics: novel tools to explore the primary membrane-associated events critical in the triggering of stress signals.

I also declare that those parts in the above mentioned articles were not or will not be used in the past or in the future, respectively for the purpose of acquiring an academic degree or title.

Dr. Zsolt TÖRÖK

Szeged, June 2, 2017. 
Hereby, as corresponding author I declare the role of Begüm Peksel Şahin in the following publication;

3. Brameshuber Mario, Eva Sevcsik, Benedikt K. Rossboth, Christina Manner, Hans-Peter Peter Deigner, Begüm Peksel, Mária Péter, Zsolt Török, Albin Hermetter, Gerhard J. Schütz. "Oxidized Phospholipids Inhibit the Formation of Cholesterol-Dependent Plasma Membrane Nanoplatforms." Biophysical Journal 110, no. 1 (January 5, 2016): 205-13. doi:10.1016/j.bpj.2015.11.018.

Begüm Peksel Şahin performed MS experiments and analyzed data for Figure 3.

I also declare that the part in the above mentioned article was not or will not be used in the past or in the future, respectively for the purpose of acquiring an academic degree or title.

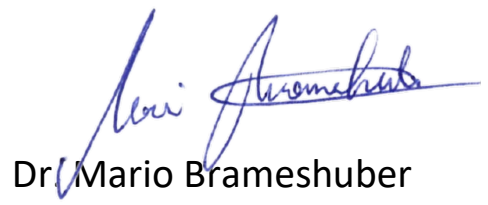

Szeged, June 2, 2017. 